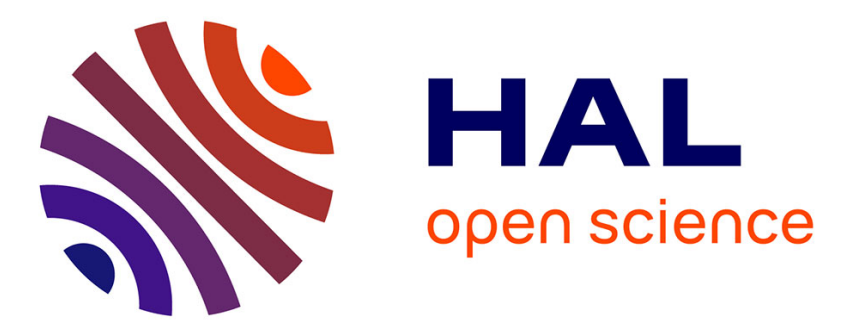

\title{
Sulfur isotope fractionation between aqueous and carbonate-associated sulfate in abiotic calcite and aragonite
}

Yigal Barkan, Guillaume Paris, Samuel M Webb, Jess F Adkins, Itay Halevy

\section{- To cite this version:}

Yigal Barkan, Guillaume Paris, Samuel M Webb, Jess F Adkins, Itay Halevy. Sulfur isotope fractionation between aqueous and carbonate-associated sulfate in abiotic calcite and aragonite. Geochimica et Cosmochimica Acta, 2020, 10.1016/j.gca.2020.03.022 . hal-02882260

\section{HAL Id: hal-02882260 \\ https://hal.science/hal-02882260}

Submitted on 26 Jun 2020

HAL is a multi-disciplinary open access archive for the deposit and dissemination of scientific research documents, whether they are published or not. The documents may come from teaching and research institutions in France or abroad, or from public or private research centers.
L'archive ouverte pluridisciplinaire HAL, est destinée au dépôt et à la diffusion de documents scientifiques de niveau recherche, publiés ou non, émanant des établissements d'enseignement et de recherche français ou étrangers, des laboratoires publics ou privés. 


\section{Journal Pre-proofs}

Sulfur isotope fractionation between aqueous and carbonate-associated sulfate in abiotic calcite and aragonite

Yigal Barkan, Guillaume Paris, Samuel M. Webb, Jess F. Adkins, Itay Halevy

PII:

S0016-7037(20)30193-9

DOI:

https://doi.org/10.1016/j.gca.2020.03.022

Reference:

GCA 11699

To appear in:

Geochimica et Cosmochimica Acta

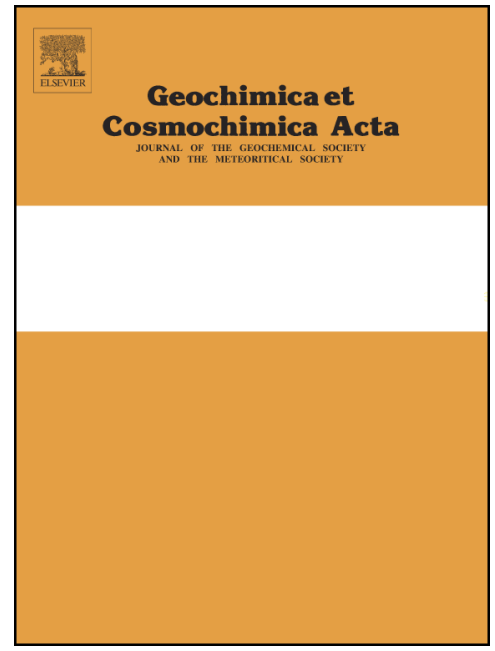

Received Date: $\quad 25$ July 2019

Accepted Date: $\quad 16$ March 2020

Please cite this article as: Barkan, Y., Paris, G., Webb, S.M., Adkins, J.F., Halevy, I., Sulfur isotope fractionation between aqueous and carbonate-associated sulfate in abiotic calcite and aragonite, Geochimica et Cosmochimica Acta (2020), doi: https://doi.org/10.1016/j.gca.2020.03.022

This is a PDF file of an article that has undergone enhancements after acceptance, such as the addition of a cover page and metadata, and formatting for readability, but it is not yet the definitive version of record. This version will undergo additional copyediting, typesetting and review before it is published in its final form, but we are providing this version to give early visibility of the article. Please note that, during the production process, errors may be discovered which could affect the content, and all legal disclaimers that apply to the journal pertain.

(C) 2020 Published by Elsevier Ltd. 
Sulfur isotope fractionation between aqueous and carbonate-associated sulfate in abiotic calcite and aragonite

Yigal Barkan ${ }^{\mathrm{a} *}$, Guillaume Paris ${ }^{\mathrm{b}, \mathrm{c}}$, Samuel M. Webb ${ }^{\mathrm{d}}$, Jess F. Adkins ${ }^{\mathrm{b}}$ \& Itay Halevy*

${ }^{a}$ Weizmann Institute of Science, Rehovot 76100, Israel

${ }^{\mathrm{b}}$ California Institute of Technology, 1200 E. California Blvd. Pasadena, CA 91125, USA

${ }^{\mathrm{c}}$ CRPG, UMR 7358 CNRS - Université de Lorraine, 15 rue Notre-Dame des Pauvres, Vandœuvre-lèsNancy 54500, France.

${ }^{\mathrm{d}}$ Stanford Synchrotron Radiation Lightsource, SLAC National Accelerator Laboratory, Menlo Park, California 94025, USA.

Correspondence:

Yigal Barkan,

Email: barkanyigal@gmail.com

Mobile: +972 (0)52 5757082

Itay Halevy,

Email: itay.halevy@weizmann.ac.il

\begin{abstract}
Sulfate $\left(\mathrm{SO}_{4}{ }^{2-}\right)$ incorporated into calcium carbonate minerals enables measurements of sulfur (S) isotope ratios in carbonate rocks. This Carbonate Associated Sulfate (CAS) in marine carbonate minerals is thought to faithfully represent the $\mathrm{S}$ isotope composition of the seawater sulfate incorporated into the mineral, with little or no $\mathrm{S}$ isotope fractionation in the process. However, comparison between different calcifying species reveals both positive and negative $\mathrm{S}$ isotope fractionation between CAS and seawater sulfate, and a large range of $\mathrm{S}$ isotope ratios can be found within a single rock sample, depending on the component measured. To better understand the isotopic effects associated with sulfate incorporation into carbonate minerals, we precipitated inorganic calcite and aragonite over a range covering more than two orders of magnitude of sulfate concentration and precipitation rate. Coupled measurements of CAS concentration, $\mathrm{S}$ isotope composition and X-ray absorption near-edge spectra (XANES) permit characterization and explanation of the observed dependence of $\mathrm{S}$ isotope fractionation between $\mathrm{CAS}$ and aqueous sulfate (CAS-SO ${ }_{4}{ }^{2-}$ isotope fractionation) on sulfate concentration and precipitation rate. In aragonite, the $\mathrm{CAS}_{-} \mathrm{SO}_{4}{ }^{2-}$ isotope fractionation is $1.0 \pm 0.3 \%$ and independent of the sulfate (and CAS) concentration. In contrast, the CAS-SO ${ }_{4}{ }^{2-}$ isotope fractionation in calcite covaries strongly with the sulfate concentration and weakly with the precipitation rate, between values of $1.3 \pm 0.1$ and $3.1 \pm 0.6 \%$. We suggest that the correlation between aqueous sulfate concentration and CAS-SO ${ }_{4}{ }^{2-}$ isotope fractionation in calcite reflects a dependence of the equilibrium $\mathrm{S}$ isotope fractionation on the concentration of CAS, through the effect of the sulfate impurity on the carbonate mineral's energetic state.
\end{abstract}

\title{
1. Introduction
}

Sulfate $\left(\mathrm{SO}_{4}{ }^{2-}\right)$ substitutes for carbonate $\left(\mathrm{CO}_{3}{ }^{2-}\right)$ in all calcium carbonate minerals, in the order of affinity aragonite < calcite < vaterite (Balan et al., 2014; Arroyo-de Dompablo et al., 2015). The concentration of this carbonate-associated sulfate (CAS) varies between tens parts-permillion ( $\mathrm{ppm}$ ) and a few percent, depending, in addition to mineralogy, on the dissolved $\mathrm{SO}_{4}{ }^{2-}$ to $\mathrm{CO}_{3}{ }^{2-}$ activity ratio $\left(a \mathrm{SO}_{4}{ }^{2-} / a \mathrm{CO}_{3}{ }^{2-}\right)$, the precipitation rate, and diagenetic processes (Busenberg and Plummer, 1985; Gellatly and Lyons, 2005; Gill et al., 2008; Fichtner et al., 2017). Concentrations of CAS as high as 24,000 and 47,000 ppm occur in natural and synthetic calcite, respectively (Busenberg and Plummer, 1985; Staudt and Schoonen, 1995), whereas natural and synthetic aragonite hosts up to 8,200 and 4,500 ppm, respectively (Busenberg and 
Plummer, 1985, this study). As the sulfate is sourced from the solutions that precipitated the carbonate minerals, the $\mathrm{S}$ isotope composition of CAS in marine carbonate rocks is commonly used as a proxy for the $\mathrm{S}$ isotope composition of seawater sulfate (e.g., Hurtgen et al., 2002; Kampschulte and Strauss, 2004; Lyons et al., 2004; Rennie et al., 2018). Although attempts to constrain the $\mathrm{S}$ isotope composition of seawater through time have resulted in an increasingly well-sampled geologic record of CAS, the $\mathrm{S}$ isotope fractionation associated with sulfate incorporation into $\mathrm{CaCO}_{3}$ has not been systematically constrained in experiments. In this study we perform $\mathrm{CaCO}_{3}$ precipitation experiments to constrain the $\mathrm{CAS}_{-} \mathrm{SO}_{4}{ }^{2-} \mathrm{S}$ isotope fractionation and its dependence on the precipitation rate and the concentration of aqueous sulfate, in both calcite and aragonite.

\subsection{Aqueous speciation of $\mathrm{S}(\mathrm{VI})$}

In a solution containing $\mathrm{S}(\mathrm{VI})$ and metal ions, $\mathrm{S}(\mathrm{VI})$ exists in a variety of species, including free ions, such as $\mathrm{SO}_{4}{ }^{2-}$ and $\mathrm{HSO}_{4}{ }^{-}$, and ion pairs, such as $\mathrm{CaSO}_{4}{ }^{0}$ and $\mathrm{MgSO}_{4}{ }^{0}$. We refer to the sum of all S(VI) species as dissolved inorganic sulfate, or DIS. In contrast with other isotopic systems (e.g., oxygen and carbon), which may include gaseous, liquid, and dissolved species, $\mathrm{S}(\mathrm{VI})$ is practically all DIS.

In most natural solutions with neutral to alkaline $\mathrm{pH}$, free DIS consists almost exclusively of aqueous $\mathrm{SO}_{4}{ }^{2-}$, and in the presence of metal cations a substantial proportion of the DIS is made up of metal ion pairs, depending on the concentration of the cations. For example, in seawater free $\mathrm{SO}_{4}{ }^{2-}$ represents more than half of the DIS, and the rest is distributed evenly between $\mathrm{Mg}^{2+}$ and $\mathrm{Na}^{+}$ion pairs with more minor contribution from $\mathrm{Ca}^{2+}$ ions pairs (Garrels and Thompson, 1962). The DIS chemistry remains relatively invariant over a large range of $\mathrm{pH}$ (3-10), unless metal ion concentrations vary with $\mathrm{pH}$ due to precipitation/dissolution of other minerals or formation of additional complexes (Figure 1).

\subsection{Incorporation of sulfate into carbonate minerals}

Studies of the mode of sulfate incorporation into $\mathrm{CaCO}_{3}$ minerals suggest that the vast majority of $\mathrm{S}$ measured in these minerals is tetrahedral sulfate, which substitutes for the trigonal, planar carbonate ion, despite sulfate's three-dimensional structure and O-O distances that are 8\% larger than the carbonate ion (Staudt et al., 1994; Reeder et al., 1994; Pingitore et al., 1995; Perrin et al., 2017). Fluid inclusions (Takano et al., 1980), adsorbed sulfate (Takano et al., 1980; Staudt et al., 1994) and separate sulfate phases (Takano et al., 1980; Staudt et al., 1994; Reeder et al., 1994; Pingitore et al., 1995) are apparently negligible contributors to the total S in most carbonate rocks. Organic $\mathrm{S}$ may coexist in biogenic $\mathrm{CaCO}_{3}$ alongside inorganic $\mathrm{CAS}$, but it is usually minor (Takano, 1985; Vielzeuf et al., 2013; Trong Nguyen et al., 2014; Tamenori et al., 2014; Perrin et al., 2017), and can be removed during sample preparation (e.g., Wotte et al., 2012).

Sulfate incorporation into aragonite and calcite expands the mineral lattice in the direction perpendicular to the planar carbonate groups, as shown by density functional theory (DFT) calculations (Balan et al., 2014; Arroyo-de Dompablo et al., 2015), and X-ray diffraction analyses (Busenberg and Plummer, 1985; Kontrec et al., 2004). CAS-bearing calcite is less stable than pure calcite, proportionally to its CAS content, as indicated by higher solubility (Busenberg and Plummer, 1985), lower decomposition temperature in differential thermal analysis (Kontrec et al., 2004), and more sluggish kinetics of the transformation from vaterite to calcite when vaterite is a precursor phase (Fernández-Díaz et al., 2010). At low concentrations of aqueous $\mathrm{SO}_{4}{ }^{2-}$, calcite is the stable $\mathrm{CaCO}_{3}$ polymorph in dilute solutions. At $\mathrm{SO}_{4}{ }^{2-}$ concentrations greater than approximately $8 \mathrm{mM}$ calcite nucleation and precipitation is inhibited, and aragonite precipitates from saturated solutions (Kitano, 1962; Kitano et al., 1975). A similar stabilization of aragonite relative to calcite is observed at $\mathrm{Mg}^{2+}$ to $\mathrm{Ca}^{2+}$ ratios 
$\left(\mathrm{Mg}^{2+} / \mathrm{Ca}^{2+}\right)$ greater than about 2, as in the present "aragonite seas" with $\mathrm{Mg}^{2+} / \mathrm{Ca}^{2+}=5.2(\mathrm{Fyfe}$ and Bischoff, 1965; Bots et al., 2011; Sun et al., 2015).

In addition to increasing the incorporation of CAS and destabilizing calcite, high aqueous $\mathrm{SO}_{4}{ }^{2-}$ activity in the precipitating solution alters the precipitation and dissolution kinetics. At a given saturation state, the precipitation rate is reduced by a factor of a few by an increase of the aqueous $\mathrm{SO}_{4}{ }^{2-}$ concentration from 3 to $50 \mathrm{mmol} / \mathrm{kg}$ (Busenberg and Plummer, 1985). Calcite also dissolves more rapidly in solutions with $\mathrm{NaCl}$ or with $\mathrm{MgSO}_{4}$ at high concentrations $(>10 \mathrm{mM})$, where the latter strongly promotes etch-pit nucleation. $\mathrm{Na}_{2} \mathrm{SO}_{4}$ alone does not promote etch-pit nucleation, but slightly promotes pit spreading rates (Ruiz-Agudo et al., 2009; Ruiz-Agudo et al., 2010).

\subsection{Existing constraints on CAS- $\mathrm{SO}_{4}{ }^{2-} \mathrm{S}$ isotope fractionation}

The suggestion that CAS should faithfully record the $\delta^{34} \mathrm{~S}^{\mathrm{a}}$ of the seawater from which the carbonate minerals precipitated was originally based on $\delta^{34} \mathrm{~S}$ measured in modern foraminifera and mollusca, each collected from two locations (mean $20.6 \pm 0.4 \%$ ), which were found to fall within analytical uncertainty of the $\delta^{34} \mathrm{~S}(20.8 \pm 0.4 \%)$ of modern seawater collected at three locations (Burdett et al., 1989). Subsequent analyses showed that CAS in the skeletons of modern calcifying organisms (collected from natural environments or cultured) exhibits $\delta^{34} \mathrm{~S}$ values both higher and lower than the seawater in which the organisms grew, spanning a range of more than 3.5\% (Figure 2). In addition to this isotopic variation among biogenic carbonates, variation of up to $20 \%$ in the $\delta^{34} \mathrm{~S}$ values of different carbonate rock constituents has been reported (Present et al., 2015), which does not reflect variation in seawater sulfate $\delta^{34} S$ values. Deviations towards more negative values are mostly due to oxidation and incorporation of ${ }^{34} \mathrm{~S}$ depleted sulfide, whereas deviations towards more positive values probably reflect incorporation of ${ }^{34} \mathrm{~S}$-enriched sulfate that is residual to microbial sulfate reduction (MSR).

Analytical progress (Paris et al., 2013), which allows reliable $\delta^{34} \mathrm{~S}$ measurements in carbonate mineral samples as small as a few tens of milligrams, make it possible to avoid this secondary variability by selection of well-preserved shells (e.g., brachiopods as in Kampschulte et al., 2001; Present et al., 2015). Nevertheless, better understanding of the fractionating processes during precipitation of primary and secondary carbonate minerals, including vital effects and abiotic $\mathrm{S}$ isotope fractionation, is necessary for robust use of CAS as a proxy for seawater sulfate $\delta^{34} \mathrm{~S}$ values.

Most carbonate mineral precipitation in the modern ocean is skeletal, and this has been the case over the entire Phanerozoic. In this work we studied the effects of CAS incorporation into abiotic calcium carbonate minerals, a choice driven by the recognition that abiotic calibrations, in which the underlying physico-chemical mechanisms may be understood, must serve as a basis and a comparison to any biogenic calibrations. Furthermore, carbonate minerals precipitate abiotically in some marine environments, most notably as cements formed during diagenesis (Moore and Wade, 2013). In addition, in microbially mediated $\mathrm{CaCO}_{3}$ formation, the precipitation itself is abiotic, and the metabolic activity of the microbes serves to alter environmental conditions in favor of carbonate mineral saturation and precipitation (Castanier et al., 1999). Finally, the carbonate minerals in the Precambrian geologic record, before the appearance of calcifying organisms, are exclusively abiotic or microbially mediated (Sumner and Grotzinger, 2000; Grotzinger and James, 2000; Schrag et al., 2013).

\footnotetext{
${ }^{a} \delta^{34} S=\left({ }^{34} R_{S}{ }^{34} R_{r}-1\right) \times 1000$, in permil units (\%o), where ${ }^{34} R_{s}$ and ${ }^{34} R_{r}$ are ${ }^{34} S /{ }^{32} S$ ratios in a sample and
} a reference material, respectively. 
Despite the important contribution of abiotic carbonate rocks to the sedimentary record, experimental constraints on $\mathrm{S}$ isotope fractionation between aqueous sulfate and CAS in abiotic $\mathrm{CaCO}_{3}$ minerals do not exist. Theoretical constraints do exist, and reduced partition function ratios ( $\beta$ values) of aqueous sulfate (Otake et al., 2008; Eldridge et al., 2016) and of CAS in calcite, aragonite and vaterite (Balan et al., 2014) have been calculated by DFT. Calculations using $\beta$ values from Otake et al. (2008) and Balan et al. (2014) yield $1000 \ln \alpha_{\mathrm{CAS}_{-} \mathrm{SO}_{4}^{2-}}^{\mathrm{eq}}$ at $25^{\circ} \mathrm{C}$ of 3.6, 4.5 and $4.0 \%$, in calcite, aragonite and vaterite, respectively. Fractionations are $0.4 \%$ larger when using $\mathrm{SO}_{4}{ }^{2-}$ (aq) $\beta$ values from Eldridge et al. (2016). Considerations of computational expense do not allow calculations over the range of naturally occurring CAS concentrations. Consequently, the CAS concentrations in the calculations of Balan et al. (2014) are equivalent to 59,000,30,000 and 52,000 ppm, in calcite, aragonite and vaterite, respectively, higher than the most CAS-rich samples documented (Figure 2). Furthermore, the calculated $S$ isotope fractionations are at least 2\% larger than those measured in natural (albeit biogenic) samples (Figure 2).

To better understand the factors determining CAS $\delta^{34} \mathrm{~S}$ values in marine carbonate rocks, we performed $\mathrm{CaCO}_{3}$ precipitation experiments from solutions with variable $\mathrm{SO}_{4}{ }^{2-}$ concentrations, and at variable precipitation rate, and measured the $\mathrm{S}$ isotope fractionation between CAS and the $\mathrm{SO}_{4}{ }^{2-}$ in solution. We found that the CAS- $\mathrm{SO}_{4}{ }^{2-} \mathrm{S}$ isotope fractionation in aragonite is independent of the concentration of aqueous $\mathrm{SO}_{4}{ }^{2-}$. On the other hand, in calcite the CAS- $\mathrm{SO}_{4}{ }^{2-}$ $\mathrm{S}$ isotope fractionation covaries strongly with the concentration of aqueous $\mathrm{SO}_{4}{ }^{2-}$, and weakly with precipitation rate. We explored possible explanations for these dependences, and suggest that the appreciable sulfate impurity in calcite affects the carbonate mineral's energetic state and modulates the equilibrium $\mathrm{CAS}-\mathrm{SO}_{4}{ }^{2} \mathrm{~S}$ isotope fractionation, with possible implications for other isotopic systems.

\section{Methods}

\subsection{Precipitation methods}

We employed two $\mathrm{CaCO}_{3}$ precipitation methods, " $\mathrm{CO}_{2}$ degassing" and "constant addition". In the $\mathrm{CO}_{2}$ degassing experiments, we tested the impact of aqueous sulfate concentration on the CAS concentration and $\mathrm{S}$ isotope composition in both calcite and aragonite. In the constant addition experiments, we tested the effect of precipitation rate on the concentration and $\mathrm{S}$ isotope composition of CAS in calcite. We briefly describe the precipitation methods below, and provide a detailed description of the methods, $\mathrm{pH}$ measurements, calculation of precipitation rates, and geochemical parameters in Appendix I.

In the constant addition method, a mixture of 1:1 $\mathrm{NaHCO}_{3}-\mathrm{Na}_{2} \mathrm{SO}_{4}-\mathrm{NaCl}$ and $\mathrm{CaCl}_{2}-\mathrm{Na}_{2} \mathrm{SO}_{4}-$ $\mathrm{NaCl}$ stock solutions, referred to hereafter as DIC and $\mathrm{Ca}^{2+}$ solutions, respectively, was injected at various rates into a reactor maintained at a temperature of $25.0 \pm 0.1^{\circ} \mathrm{C}$. Solution injection rates and the mass of the nucleation seeds added were varied to facilitate a range of precipitation rates, spanning over more than 2 orders of magnitude.

In the $\mathrm{CO}_{2}$ degassing method, we varied $\mathrm{pCO}_{2}$ in a $0.3 \mathrm{~m}^{3}$ Plexiglas glove box (GB) containing multiple 2-liter solutions in glass bottles, to allow for dissolution of $\mathrm{a} \mathrm{CaO}_{3}$ reagent and its reprecipitation as calcite in solutions with no added $\mathrm{Mg}^{2+}$, or as aragonite in solutions where $\mathrm{Mg}^{2+}$ was added. The $\mathrm{Na}_{2} \mathrm{SO}_{4}$ concentration was varied to facilitate a range of sulfate concentrations spanning more than 3 orders of magnitude. During the precipitation, the temperature was $30.1 \pm 0.4$ and $30.7 \pm 0.4^{\circ} \mathrm{C}$ in the aragonite- and calcite-precipitating sets, respectively.

\subsection{Measurements of sulfate concentrations and $\delta^{34} \mathrm{~S}$}

Powder samples of $\sim 10 \mathrm{mg}$ were dissolved in triplicate and split into aliquots for sulfate concentration and $\delta^{34} \mathrm{~S}$ analysis. Sulfate concentrations were measured by ion chromatography 
on a Dionex ICS-2000 with an AS-19 column and $20 \mathrm{mM}$ KOH eluent at the Caltech Environmental Analysis Center. Sulfur isotope ratios were measured by MC-ICP-MS on a Thermo Fischer Scientific Neptune Plus, coupled to a Cetac Aridus heated spray chamber in the Division of Geological and Planetary Sciences at Caltech. Prior to S isotope measurement, $\mathrm{Ca}^{2+}$ was removed from the remaining dissolved carbonate by ion exchange chromatography, and the isotopic measurements were made on aqueous sodium sulfate solutions (Paris et al., 2013; Paris et al., 2014). Specimens were prepared in a clean room with high-purity acids (Seastar) and deionized water, and analyzed in sets of up to 20 samples, along with 2-4 procedural blanks, 2 replicates of an in-house dissolved deep-sea coral consistency standard, and 2 replicates of seawater. The powder pretreatment process for natural samples described in Paris et al. (2013) was applied to some samples, and the results yielded no difference from untreated samples. The results were corrected for insoluble residues and for the CAS concentration and $\delta^{34} \mathrm{~S}$ of the nucleation seeds, whenever seeds were added. The $\mathrm{S}$ isotope fractionation factor $(\alpha)$ was calculated between the samples and the $\mathrm{Na}_{2} \mathrm{SO}_{4}$ reagent used and is reported against the Vienna Canyon Diablo Troilite (VCDT) standard:

$$
\text { 1) } \quad \alpha_{\mathrm{CAS}-\mathrm{Na}_{2} \mathrm{SO}_{4}}=\frac{1000+\delta^{34} \mathrm{~S}_{\mathrm{CAS}}}{1000+\delta^{34} \mathrm{~S}_{\mathrm{Na}_{2} \mathrm{SO}_{4}}} \text {. }
$$

The intermediate analytical error (for definition see Paris et al., 2013) on the isotopic measurements was $0.14 \%$ o $(1 \sigma)$ but sample variability was often larger. Average concentrations and isotopic fractionations are reported below with an error calculated as the larger of the standard deviation $(1 \sigma)$ on the average, and a root mean square (RMS) of the associated errors, as reported in the tables. The number of samples averaged (n) is presented in parentheses.

\subsection{Mineral identification}

The mineralogy of the precipitates was determined by powder X-ray diffraction (XRD) on a Bruker D2 PHASER equipped with $\mathrm{Cu} \mathrm{K}_{\alpha}$ tube $(30 \mathrm{kV}, 10 \mathrm{~mA})$ and a 1D Lynxeye detector, in a Bragg-Brentano configuration. Acquisition was in $2 \theta$ steps of $0.025^{\circ}$, for 1.5 seconds per step at $\phi=40 \mathrm{rpm}$. The diffractogram background was removed using the BEADS method (Duval, 2015), and the abundances of calcite, aragonite and vaterite were then quantified following Kontoyannis and Vagenas (2000) and factors described therein. Most samples consisted of pure phases (>98\% pure).

\subsection{X-ray absorption spectroscopy}

X-ray absorption near edge spectra (XANES) were collected at the Stanford Synchrotron Radiation Lightsource (SSRL), using beam line 14-3 on the Stanford Positron Electron Accelerating Ring (SPEAR), run with $500 \mathrm{~mA}$ and $3.0 \mathrm{GeV}$. The energy of incident X-rays was set using a Si (111) double crystal monochromator and calibrated to the thiol peak of a sodium thiosulfate powder at $2472.02 \mathrm{eV}$. Intensities of incident X-rays were measured with a heliumfilled ion chamber, and the sulfur fluorescence measured with 4-element Si drift detector (Hitachi) using Xspress3 pulse processing electronics (Quantum Detectors). The sulfur K-edge was measured at a variable energy resolution of $0.2 \mathrm{eV}$ at $2460-2480 \mathrm{eV}, 0.05 \mathrm{eV}$ at $2480-2484$ $\mathrm{eV}, 0.2 \mathrm{eV}$ at $2484-2500 \mathrm{eV}$, and $2 \mathrm{eV}$ at $2500-2536 \mathrm{eV}$. Spectra were averaged using SIXPack (Webb, 2005) and then detrended and fit using a MATLAB program of our own development. The fit was composed of a combination of one step-function for the post-edge plateau, and four Voight line shapes for the main features of the sulfur K-edge spectra (Figure 3). The line shapes were chosen solely to fit the spectra and not with any known S-species in mind. We calculated Voigt line shapes using a publicly available program (Abrarov, 2016; Ruzi, 2016). Poor fits to the spectra $\left(\mathrm{r}^{2}<0.9\right)$, due to low $[\mathrm{CAS}]$ and consequently low signal-to-noise ratios (Appendix I), are not discussed further. 


\section{Results}

The experiments produced the expected $\mathrm{CaCO}_{3}$ polymorphs with two exceptions. At the highest injection rates in the constant addition experiments (CCL samples, $\log (J)=-4.3 \mathrm{~mol} / \mathrm{m}^{2} / \mathrm{s}$ ) 31 $48 \%$ vaterite precipitated along with calcite (Table A1), and in the $\mathrm{CO}_{2}$ degassing experiments at $8 \mathrm{mM} \mathrm{Na}_{2} \mathrm{SO}_{4}$ (no added $\mathrm{MgCl}_{2}$ ), 52\% aragonite precipitated along with calcite (Table A2). Only pure (>98\%) samples will be described and discussed in the following sections. As discussed in Section 1.1, in solutions where ion pairs are abundant, the activity of free sulfate, rather than the total DIS concentration, is a more meaningful quantity. Additionally, during the precipitation of $\mathrm{CaCO}_{3}$ minerals and incorporation of $\mathrm{CAS}$, aqueous sulfate competes with the carbonate ion for available kink sites for anion attachment (Vavouraki et al., 2008). We therefore adopt the activity ratio of sulfate to carbonate $\left(a \mathrm{SO}_{4}{ }^{2-} / a \mathrm{CO}_{3}{ }^{2-}\right)$ as the relevant measure of the abundance of DIS.

\subsection{CAS concentrations}

The concentrations of CAS ([CAS]) from the two experimental methods are in agreement for corresponding values of $\log (J)$ and $a \mathrm{SO}_{4}{ }^{2-} / a \mathrm{CO}_{3}{ }^{2-}$ (Figure 4). The concentration of CAS in both aragonite and calcite from the $\mathrm{CO}_{2}$ degassing experiments increases linearly with sulfate concentration. Calcite and aragonite show a $\sim 160$-fold and $\sim 170$-fold increase in [CAS] over a $\sim 170$-fold and $\sim 220$-fold increase in $a \mathrm{SO}_{4}{ }^{2-} / a \mathrm{CO}_{3}{ }^{2-}$, respectively.

The dependence of [CAS] in calcite on precipitation rate (Figure 4b), as determined in the constant addition experiments, is much weaker than on $a \mathrm{SO}_{4}{ }^{2-} / a \mathrm{CO}_{3}{ }^{2-}$. An increase of a factor of $\sim 170$ in precipitation rate only leads to approximately a doubling of [CAS] in calcite, whereas $\mathrm{a} \sim 170$-fold increase in $a \mathrm{SO}_{4}{ }^{2-} / a \mathrm{CO}_{3}{ }^{2-}$ leads to a $\sim 160$-fold increase in [CAS].

3.2 $\mathrm{CAS}-\mathrm{SO}_{4}{ }^{2-} \mathrm{S}$ isotope fractionation in aragonite and calcite

The CAS-SO ${ }_{4}{ }^{2-} \mathrm{S}$ isotope fractionation $\left(1000 \ln \alpha_{\mathrm{CAS}_{-} \mathrm{Na}_{2} \mathrm{SO}_{4}}\right)$ of the aragonitic samples over the entire range of $a \mathrm{SO}_{4}{ }^{2-} / a \mathrm{CO}_{3}{ }^{2-}$ (Table 1, Figure 5a) falls within error of an average value of $1.0 \pm 0.3 \%$ (RMS, $\mathrm{n}=12$ ). This value of $1000 \ln \alpha_{\mathrm{CAS}-\mathrm{Na}_{2} \mathrm{SO}_{4}}$ is smaller than all of the values measured in the calcite samples (see below). The samples precipitated at low $a \mathrm{SO}_{4}{ }^{2-} / a \mathrm{CO}_{3}{ }^{2-}$ (which have low CAS concentrations) display the largest error on $1000 \ln \alpha_{\mathrm{CAS}_{-} \mathrm{Na}_{2} \mathrm{SO}_{4}}$. Repeated analysis suggests that this error is the result of sample heterogeneity rather than an analytical artifact.

The $1000 \ln \alpha_{\mathrm{CAS}-\mathrm{Na}_{2} \mathrm{SO}_{4}}$ values for calcite are all positive over the entire range of $a \mathrm{SO}_{4}{ }^{2-} / a \mathrm{CO}_{3}{ }^{2-}$ , and decrease with increasing $a \mathrm{SO}_{4}{ }^{2-} / a \mathrm{CO}_{3}{ }^{2-}$, from $2.9 \pm 0.5 \%$ (RMS, n=2) at $a \mathrm{SO}_{4}{ }^{2-} / a \mathrm{CO}_{3}{ }^{2-}$ of $\sim 7$ to $1.9 \pm 0.1 \%$ o (RMS, n=3) at $a \mathrm{SO}_{4}{ }^{2-} / a \mathrm{CO}_{3}{ }^{2-}$ of $\sim 1,200$ (Table 1, Figure 5a). It is unclear whether $1000 \ln \alpha_{\mathrm{CAS}_{-} \mathrm{Na}_{2} \mathrm{SO}_{4}}$ values continue to decrease in calcite at higher $a \mathrm{SO}_{4}{ }^{2-} / a \mathrm{CO}_{3}{ }^{2-}$, though pure calcite is unlikely to precipitate under these conditions. As in the case of aragonite, the calcite samples precipitated at low $a \mathrm{SO}_{4}{ }^{2-} / a \mathrm{CO}_{3}{ }^{2-}$ show the largest error on $1000 \ln \alpha_{\mathrm{CAS}-\mathrm{Na}_{2} \mathrm{SO}_{4}}$, which is the result of heterogeneity among the samples.

The $1000 \ln \alpha_{\mathrm{CAS}-\mathrm{Na}_{2} \mathrm{SO}_{4}}$ values for calcite decrease with increasing precipitation rate, from $1.7 \pm 0.2 \%_{0}(\mathrm{n}=2)$ at $\log (J)$ of $\sim-7.5$ to $1.3 \pm 0.1 \%$ o $(\mathrm{n}=3)$ at $\log (J)$ of $\sim-5.3$ (Table 1, Figure $\left.5 \mathrm{~b}\right)$. The $1000 \ln \alpha_{\mathrm{CAS}-\mathrm{Na}_{2} \mathrm{SO}_{4}}$ values from the two experimental methods at the corresponding $\log (J)$ and $a \mathrm{SO}_{4}{ }^{2-} / a \mathrm{CO}_{3}{ }^{2-}$ do not fall within error like the CAS concentration values, but are offset by $\sim 0.3 \%$. 
Table 1 - CAS concentrations and $\mathrm{S}$ isotope fractionation in all samples.

\begin{tabular}{|c|c|c|}
\hline Name & $\begin{array}{c}\text { CAS conc. } \\
\text { (ppm) }\end{array}$ & $\begin{array}{c}1000 \ln \alpha_{\mathrm{CAS}-\mathrm{Na}_{2} \mathrm{SO}_{4}}{ }^{*} \\
(\% \mathrm{o})\end{array}$ \\
\hline 30CL1 & $87( \pm 7)$ & $2.7 \pm 0.4$ \\
\hline 30CL2 & $11( \pm 2) \times 10^{1}$ & $3.1 \pm 0.6$ \\
\hline 100CL1 & $25( \pm 6) \times 10^{1}$ & $2.8 \pm 0.2$ \\
\hline 100CL2 & $32( \pm 3) \times 10^{1}$ & $2.9 \pm 0.3$ \\
\hline 300CL1 & $82( \pm 3) \times 10^{1}$ & $2.5 \pm 0.2$ \\
\hline 300CL2 & $11( \pm 1) \times 10^{2}$ & $2.6 \pm 0.1$ \\
\hline 1KCL1 & $34( \pm 2) \times 10^{2}$ & $2.2 \pm 0.1$ \\
\hline $1 \mathrm{KCL} 2$ & $35( \pm 2) \times 10^{2}$ & $2.2 \pm 0.1$ \\
\hline 3KCL1 & $7( \pm 1) \times 10^{3}$ & $2.0 \pm 0.1$ \\
\hline $3 \mathrm{KCL} 2$ & $95( \pm 8) \times 10^{2}$ & $1.9 \pm 0.1$ \\
\hline 8KCL2 & $16( \pm 3) \times 10^{3}$ & $1.8 \pm 0.1$ \\
\hline 100AR1 & $33( \pm 8)$ & $1.0 \pm 0.4$ \\
\hline 100AR2 & $18( \pm 2)$ & $1.0 \pm 0.7$ \\
\hline 300AR1 & $9( \pm 2) \times 10^{1}$ & $1.1 \pm 0.3$ \\
\hline 300AR2 & $9( \pm 3) \times 10^{1}$ & $0.9 \pm 0.2$ \\
\hline 1KAR1 & $22( \pm 2) \times 10^{1}$ & $1.1 \pm 0.3$ \\
\hline 1KAR2 & $38( \pm 1) \times 10^{1}$ & $1.0 \pm 0.2$ \\
\hline 3KAR1 & $72( \pm 5) \times 10^{1}$ & $1.0 \pm 0.1$ \\
\hline 3KAR2 & $5( \pm 1) \times 10^{2}$ & $1.2 \pm 0.2$ \\
\hline 10KAR1 & $14( \pm 1) \times 10^{2}$ & $1.1 \pm 0.1$ \\
\hline 10KAR2 & $141( \pm 7) \times 10^{1}$ & $1.0 \pm 0.1$ \\
\hline 30KAR1 & $44( \pm 2) \times 10^{2}$ & $1.0 \pm 0.4$ \\
\hline 30KAR2 & $43( \pm 3) \times 10^{2}$ & $1.0 \pm 0.1$ \\
\hline ССНА & $71( \pm 1) \times 10^{2}$ & $1.7 \pm 0.2$ \\
\hline ССНB & $71( \pm 1) \times 10^{2}$ & $1.7 \pm 0.3$ \\
\hline CCIA & $82( \pm 2) \times 10^{2}$ & $1.8 \pm 0.1$ \\
\hline CCIB & $75( \pm 1) \times 10^{2}$ & $1.6 \pm 0.1$ \\
\hline CCIC & $107( \pm 2) \times 10^{2}$ & $1.5 \pm 0.1$ \\
\hline CCJA & $101( \pm 2) \times 10^{2}$ & $1.5 \pm 0.1$ \\
\hline ССJB & $96( \pm 2) \times 10^{2}$ & $1.5 \pm 0.1$ \\
\hline CCJC & $105( \pm 2) \times 10^{2}$ & $1.6 \pm 0.1$ \\
\hline CCKC & $146( \pm 6) \times 10^{2}$ & $1.4 \pm 0.1$ \\
\hline CCKD & $138( \pm 5) \times 10^{2}$ & $1.3 \pm 0.1$ \\
\hline CCKE & $134( \pm 2) \times 10^{2}$ & $1.3 \pm 0.1$ \\
\hline $\mathrm{CCLB}^{* *}$ & $90( \pm 1) \times 10^{2}$ & $1.4 \pm 0.1$ \\
\hline $\operatorname{CCLC}^{* *}$ & $131( \pm 2) \times 10^{2}$ & $1.5 \pm 0.2$ \\
\hline CCLD** & $122( \pm 2) \times 10^{2}$ & $1.7 \pm 0.2$ \\
\hline
\end{tabular}

* Uncertainty is given by the larger of the root mean square error and 1 standard deviation of external replicates.

** Samples with 31-48\% vaterite precipitated along with calcite (Table A2). 


\subsection{Sulfur K-edge XANES}

Spectra of CAS in calcite and aragonite differ subtly from each other (Figure 6; see discussion), but the spectra of CAS within each individual $\mathrm{CaCO}_{3}$ polymorph differ from each other mostly in fluorescence intensity and in the signal-to-noise ratios, which depend on [CAS] (Appendix I). The fit to the spectra included four Voigt lines (V1...4), each with a peak location ( $E_{\mathrm{Vi}}$ in $\mathrm{eV}$ ), an intensity ( $\mathrm{I}_{\mathrm{Vi}}$ in arbitrary units) and a full width at half maximum height (FWHM $\mathrm{Vi}_{\mathrm{i}}$ in $\mathrm{eV}$ ). The I $\mathrm{V}_{\mathrm{V} 1-4}$ strongly correlate with [CAS] (Figure 6c, Appendix III), and the FWHM $\mathrm{v}_{\mathrm{V} 1}$ also show a correlation with [CAS], albeit more scattered (Figure 6d).

We find no correlation between the $\mathrm{E}_{\mathrm{V} 1-4}$ and [CAS] (Figure 6b). All $\mathrm{E}_{\mathrm{V} 1}$ correspond to a typical sulfate pre-edge energy, as previously reported (Pingitore et al., 1995; Fleet, 2005). Furthermore, except for the two aragonite samples with the highest [CAS], $\mathrm{E}_{\mathrm{V} 1}$ is shifted by 0.1 $\mathrm{eV}$ to lower energy in aragonite $(2482.6 \pm 0.0 \mathrm{eV}, 1 \sigma, \mathrm{n}=7)$, relative to calcite $(2482.7 \pm 0.0 \mathrm{eV}$, $1 \sigma, \mathrm{n}=11$ ) (Figure 6a-b).

The $\mathrm{E}_{\mathrm{V} 1}$ of 2,482.6 and 2,482.7 eV found in this study for aragonite and calcite, respectively, are within the range found in previous studies, but the observed shift of $0.1 \mathrm{eV}$ in $\mathrm{E}_{\mathrm{V} 1}$ between these $\mathrm{CaCO}_{3}$ polymorphs has not been previously described.

\section{Discussion}

4.1 CAS concentrations in aragonite and calcite

Higher [CAS] in calcite than in aragonite has been reported in both natural and synthetic samples (e.g., Kitano et al., 1975; Busenberg and Plummer, 1985) and is supported by molecular modeling (Section 1). Concentrations of CAS as high as 4,500 ppm in synthetic aragonite have not been reported previously to this study. Concentrations of CAS as high as $8,200 \mathrm{ppm}$ were previously measured in modern aragonitic corals, and if the corals display a [CAS] $-a \mathrm{SO}_{4}{ }^{2-} / a \mathrm{CO}_{3}{ }^{2-}$ relationship similar to the synthetic aragonite, this implies $a \mathrm{SO}_{4}{ }^{2-}$ $/ a \mathrm{CO}_{3}{ }^{2-}$ of 2,500 in the precipitating fluid. This $a \mathrm{SO}_{4}{ }^{2-} / a \mathrm{CO}_{3}{ }^{2-}$ is much higher than in modern seawater ( 315), which is thought to be the source of the calcifying fluid (McConnaughey, 1989a; 1989b; Adkins et al., 2003; Erez and Braun, 2007; Gagnon et al., 2007; 2012; Tambutté et al., 2011). Without pumping protons out of, or $\mathrm{Ca}^{2+}$ into the calcifying fluid, quantitative precipitation of aragonite from seawater may only lead to $a \mathrm{SO}_{4}{ }^{2-} / a \mathrm{CO}_{3}{ }^{2-}$ of $\sim 1,300$. In other words, the mineral will precipitate from a solution with an average $a \mathrm{SO}_{4}{ }^{2-} / a \mathrm{CO}_{3}{ }^{2-}$ between $\sim 315$, as in seawater, and $\sim 1,300$. The high $a \mathrm{SO}_{4}{ }^{2-} / a \mathrm{CO}_{3}{ }^{2-}$ of 2,500 suggested by coralline aragonite [CAS] may, therefore, imply either the existence of such proton or $\mathrm{Ca}^{2+}$ pumps or that coralline aragonite displays a different $[\mathrm{CAS}]-a \mathrm{SO}_{4}{ }^{2-} / a \mathrm{CO}_{3}{ }^{2-}$ relationship than abiotic aragonite.

A positive correlation between [CAS] and $a \mathrm{SO}_{4}{ }^{2-} / a \mathrm{CO}_{3}{ }^{2-}$ has been previously shown for synthetic calcite (Busenberg and Plummer, 1985; Fernández-Díaz et al., 2010). The ratio of the mole fractions $(X, \mathrm{~mol})$ of sulfate and carbonate ions in $\mathrm{CaCO}_{3}$, are related to the molar concertation $(M, \mathrm{~mol} / \mathrm{L})$ in solution by $\mathrm{K}_{\mathrm{d}}$, the partition coefficient:

$$
\frac{X \mathrm{SO}_{4}^{2-}}{X \mathrm{CO}_{3}^{2-}}=\mathrm{K}_{\mathrm{d}}\left(\frac{M \mathrm{SO}_{4}^{2-}}{M \mathrm{CO}_{3}^{2-}}\right) \text {. }
$$

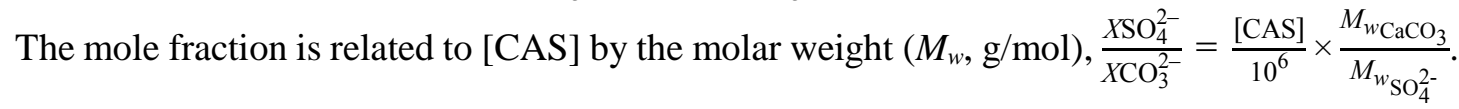

Using the measured [CAS] (in ppm) in the calcite and aragonite precipitated in the $\mathrm{CO}_{2}$ degassing experiments and a few constant addition samples with similar $\log (J)$ (CCJA-CCJC), the corresponding values of $\mathrm{K}_{\mathrm{d}}$ for calcite and aragonite are $16 \pm 6 \times 10^{-6}$ and $8 \pm 4 \times 10^{-6}$, respectively. 
Taking the logarithm of equation 2 and expressing aqueous concentrations in terms of activities and activity coefficients yields

$$
\log \left(\frac{X \mathrm{SO}_{4}^{2-}}{X \mathrm{CO}_{3}^{2-}}\right)=C \times \log \left(\frac{a \mathrm{SO}_{4}^{2-}}{a \mathrm{CO}_{3}^{2-}}\right)+\log \left(\mathrm{K}_{\mathrm{d}} \times \frac{\gamma \mathrm{CO}_{3}^{2-}}{\gamma \mathrm{SO}_{4}^{2-}}\right) .
$$

a linear regression through the logarithm of the data yields the relations:

4) $\quad \log \left(\frac{X \mathrm{SO}_{4}^{2-}}{X \mathrm{CO}_{3}^{2-}}\right)_{\text {calcite }}=1.03( \pm 0.05) \times \log \left(\frac{a \mathrm{SO}_{4}^{2-}}{a \mathrm{CO}_{3}^{2-}}\right)-4.87( \pm 0.10) \quad \mathrm{R}^{2}=0.995$,
5) $\quad \log \left(\frac{X \mathrm{SO}_{4}^{2-}}{X \mathrm{CO}_{3}^{2-}}\right)_{\text {aragonite }}=0.91( \pm 0.09) \times \log \left(\frac{a \mathrm{SO}_{4}^{2-}}{a \mathrm{CO}_{3}^{2-}}\right)-5.20( \pm 0.19) \quad \mathrm{R}^{2}=0.981$.

According to the Berthelot-Nernst distribution law, the slope of the regression line $(C)$ should be equal to unity at equilibrium when $\mathrm{K}_{\mathrm{d}}$ and $\frac{\gamma \mathrm{CO}_{3}^{2-}}{\gamma \mathrm{SO}_{4}^{2-}}$ are constant (McIntire, 1963; Busenberg and Plummer, 1985). In the experiments of Busenberg and Plummer (1985), hereafter B\&P, $\log ([\mathrm{CAS}])$ was linearly proportional to $\log \left(a \mathrm{SO}_{4}{ }^{2-} / a \mathrm{CO}_{3}{ }^{2-}\right)$, with slopes between 0.6 and 0.8 , which were interpreted to reflect a kinetic control of sulfate incorporation, while in our experiments slopes of the regression lines are within error of unity. In B\&P, the calculated value of $K_{d}$ was linearly proportional to the precipitation rate, which was itself proportional to $\Omega$. Based on the $\mathrm{pH}$ measurements and thermodynamic calculations (Section 6.4), the weighted average precipitation rate in all of our $\mathrm{CO}_{2}$ degassing experiments was lower than the rates in $\mathrm{B} \& \mathrm{P}$, and the near-unity slopes of $\log ([\mathrm{CAS}])$ versus $\log \left(a \mathrm{SO}_{4}{ }^{2-} / a \mathrm{CO}_{3}{ }^{2-}\right)$ in our experiments suggests near-equilibrium sulfate incorporation. The calcite $K_{d}$ value derived from the experiments in this study $\left(16 \pm 6 \times 10^{-6}\right)$ is slightly smaller than, but within error of the value from the least supersaturated $(\Omega=2.5)$, slowest to precipitate $\left(J \leq 3 \mathrm{mg} \mathrm{g}^{-1} \mathrm{~min}^{-1}\right)$ experiments of $\mathrm{B} \& \mathrm{P}\left(\mathrm{K}_{\mathrm{d}}=19 \pm 8 \times 10^{-6}\right)$.

\subsection{Sulfur K-edge XANES}

In XANES spectroscopy the energy at which the absorption edge is located is sensitive to the valence of the element and to the electronic influence of bonds with neighboring atoms. In sulfate compounds, the distinct white line pre-edge feature results from a transition from the $1 \mathrm{~s}$ orbital to the unoccupied $t_{2}{ }^{*}$ anti-bonding orbital (Pin et al., 2013). This feature typically peaks at 2482-2483 eV (Cuif et al., 2003; Fleet, 2005; Frisia et al., 2005; Yoshimura et al., 2013; Perrin et al., 2017). Post-edge features are distinctive for different sulfate minerals (e.g., anhydrite, thenardite) and for CAS in the different carbonate minerals (Pingitore et al., 1995; Fleet, 2005; Yoshimura et al., 2013).

The energy of $E_{\mathrm{V} 1}$ suggests that sulfur occurs as sulfate in all samples. The $E_{\mathrm{V} 1}$ of 2,482.6 and $2,482.7 \mathrm{eV}$ found in this study for aragonite and calcite, respectively, is within the range found in previous studies. However, the observed shift of $0.1 \mathrm{eV}$ in $\mathrm{E}_{\mathrm{V} 1}$ between calcite and aragonite has not been previously described. The observed increase in $\mathrm{FWHM}_{\mathrm{V} 1}$ with increasing [CAS] is not associated with a change in the peak center energy, $\mathrm{E}_{\mathrm{V} 1}$. A narrow $\mathrm{FWHM}_{\mathrm{V} 1}$ is expected when the geometry of sulfate is close to tetrahedral and the S-O bonds are nearly identical for $\mathrm{O} 1$ through $\mathrm{O} 4$ (e.g., as in dissolved sulfate). An increase in $\mathrm{FWHM}_{\mathrm{V} 1}$ suggests a larger variety of S-O bonding configurations, each with a slightly different X-ray absorption energy (Pin et al., 2013). More specifically, distorting the $T_{d}$ tetrahedral geometry of the sulfate ion, as in CAS, causes the degeneracy of the unoccupied anti-bonding orbitals to collapse, providing a distribution of unoccupied states for the pre-edge transition to occupy. This suggests a slightly different coordination environment of the sulfate in CAS between the carbonate polymorphs.

\section{3 $\mathrm{CAS}-\mathrm{SO}_{4}{ }^{2-} \mathrm{S}$ isotope fractionation in calcite}

The experimental conditions of the constant addition and the $\mathrm{CO}_{2}$ degassing experiments differed in the $\mathrm{pH}$ range, the overlying $\mathrm{pCO}_{2}$, the introduction method of dissolved $\mathrm{Ca}$ and 
inorganic $\mathrm{C}$, the salt concentration and corresponding ionic activity and ionic strength, the presence of carbonic anhydrase, the presence of nucleation seeds, and temperature. The

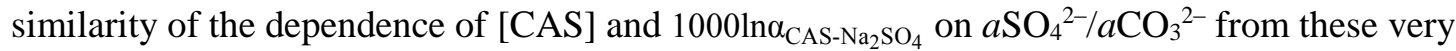
different experimental conditions highlights the dominant influence of $a \mathrm{SO}_{4}{ }^{2-} / a \mathrm{CO}_{3}{ }^{2-}$ on sulfate incorporation as CAS and on the associated $\mathrm{S}$ isotope fractionation. It is difficult to confidently ascribe the $\sim 0.3 \%$ difference in $1000 \ln \alpha_{\mathrm{CAS}^{-\mathrm{Na}_{2}} \mathrm{SO}_{4}}$ values at $a \mathrm{SO}_{4}{ }^{2-} / a \mathrm{CO}_{3}{ }^{2-}$ of $\sim 500$ and $\log (J)$ of $\sim-6$ in the two experimental sets to one of the many differences between them. Temperature differences can be precluded, however, as theoretical calculations suggest decreasing isotope fractionation with increasing temperature (Balan et al., 2014; Eldridge et al., 2016). The higher temperature of the $\mathrm{CO}_{2}$ degassing experiments (by $5.7 \pm 0.4^{\circ} \mathrm{C}$ ) would thus lead to smaller $\mathrm{S}$ isotope fractionation (by $\sim 0.1 \%$ ), which is opposite to what we observe.

\subsubsection{The dependence of CAS-SO ${ }_{4}{ }^{2-} \mathrm{S}$ isotope fractionation on calcite precipitation rate}

The fractionation of $\mathrm{S}$ isotopes between CAS in calcite and aqueous sulfate decreases with increasing precipitation rate (Figure 5b). Isotopic effects associated with diffusion (e.g., Lemarchand et al., 2004) may be ruled out, as the stirring rate in our experiments implies a diffusional boundary layer about 30 times thinner than the critical boundary layer. Under such conditions, surface reactions, not diffusion from the bulk solution, are expected to control the fractionation of isotopes (DePaolo, 2011). Next, we discuss possible explanations for the precipitation rate-dependent CAS-SO ${ }_{4}^{2-} \mathrm{S}$ isotope fractionation.

The net isotope fractionation $\left(\alpha_{\text {net }}\right)$ expressed in a reaction depends on the ratio between the rate of formation of reactant from product (dissolution or backward flux, $J_{b}$ ) and the rate of product formation from reactant (precipitation or forward flux, $J_{f}$ ). The incorporation of sulfate into a carbonate mineral is analogous to precipitation and the release back into solution is analogous to dissolution. This ratio of sulfate release to incorporation is the reversibility $(f)$ and is related to the Gibbs free energy of the reaction, $\Delta G_{\mathrm{r}}$,

$$
f=\frac{J_{b}}{J_{f}}=e^{\frac{\Delta G_{\mathrm{r}}}{R T}}
$$

(Beard and Qian, 2007),

where $R$ is the gas constant and $T$ the absolute temperature. The equilibrium isotope fractionation $\left(\alpha_{\mathrm{eq}}\right)$ will be expressed during nearly fully reversible precipitation $(f \rightarrow 1)$, while the forward kinetic isotope fractionation $\left(\alpha_{\mathrm{f}}\right)$ will be expressed during far-from-equilibrium precipitation $(f \rightarrow 0)$. The net isotope fractionation is then:

$$
\alpha_{\text {net }}=\frac{\alpha_{\mathrm{f}}}{1+f\left(\frac{\alpha_{\mathrm{f}}}{\alpha_{\mathrm{eq}}}-1\right)},
$$

(DePaolo, 2011).

Equation 7 has been shown to apply to atomic ratios (e.g., $\mathrm{Sr} / \mathrm{Ca}$ ) as well as to isotopic ratios (e.g., $\left.{ }^{44} \mathrm{Ca} /{ }^{40} \mathrm{Ca}\right)$. The net precipitation $\left(J_{p}=J_{f}-J_{b}\right)$, in units of moles per surface area per time, is related to $f$ by

8)

$$
\frac{J_{p}}{J_{b}}=\frac{1}{f}-1
$$

The inflection point in the transition of $\alpha_{\text {net }}$ between the equilibrium and kinetic end members will be observable when $J_{p} \approx J_{b}$ or $f \approx 0.5$, if no fractionating processes other than precipitation are expressed, if the equilibrium and kinetic end members are distinguishable analytically $\left(\alpha_{\mathrm{eq}}-\alpha_{\mathrm{f}}>\sigma\right)$, and if the experimental range of precipitation rate covers this transition.

Modeling of elemental ( $\mathrm{Sr} / \mathrm{Ca}$ ) and isotopic compositions ( $\mathrm{Ca}$ and $\mathrm{O}$ at $\mathrm{pH}$ values of 7-8) of experimentally precipitated calcite suggests that the inflection point $\left(J_{p} \approx J_{b}\right)$ lies at $J_{p}$ between $10^{-7.5}$ and $10^{-5.5}$ mole $\mathrm{m}^{-2} \mathrm{~s}^{-1}$ (DePaolo, 2011; Watkins et al., 2013), similar to our experimental range of precipitation rates. In the $\mathrm{Sr} / \mathrm{Ca}$ and $\mathrm{Ca}$ isotope systems equilibration among aqueous 
species is rapid, as is equilibration of $\mathrm{O}$ isotopes in the $\mathrm{CaCO}_{3}-\mathrm{H}_{2} \mathrm{O}$ system in the presence of carbonic anhydrase. Hence, in the absence of diffusive effects, the main isotope fractionation expressed in such cases is expected to be due to precipitation. We expect similar behavior (i.e., rapid DIS equilibration and isotope fractionation predominantly associated with precipitation) during CAS incorporation in our experiments. Assuming that attachment and detachment rates, among other essential surface reaction parameters, are not dramatically different between $\mathrm{CO}_{3}{ }^{2-}$ , $\mathrm{HCO}_{3}{ }^{-}$and $\mathrm{SO}_{4}{ }^{2-}$, we may also expect the transition between the equilibrium and kinetic endmember isotope fractionations in the case of CAS incorporation into calcite to occur over a similar range of $J_{p}$. If this is true, then our experimental range of precipitation rates $\left(10^{-7.5}\right.$ to $10^{-5.3} \mathrm{~mole} \mathrm{~m}^{-2} \mathrm{~s}^{-1}$ ) should include the inflection point (scenario 1, Figure 7a). In this case, the difference between $\alpha_{\mathrm{eq}}$ and $\alpha_{\mathrm{f}}$ is on the order of tenths of a permil; 1000ln $\alpha_{\mathrm{eq}}$ is $\sim 1.7 \%$, and $1000 \ln \alpha_{\mathrm{f}}$ is $\sim 1.3 \%$, and we should expect natural calcites to exhibit CAS-SO ${ }_{4}{ }^{2-} \mathrm{S}$ isotope fractionation of $1.5 \pm 0.2 \%$ o $(1 \sigma, \mathrm{n}=11$, Table 1$)$, which is only weakly dependent on their precipitation rate.

The near-unity slope of $\log ([\mathrm{CAS}])$ versus $\log \left(a \mathrm{SO}_{4}{ }^{2-} / a \mathrm{CO}_{3}{ }^{2-}\right)$ in our $\mathrm{CO}_{2}$ degassing experiments suggests sulfate incorporation close to chemical equilibrium at precipitation rates of about $10^{-6}$ mole $\mathrm{m}^{-2} \mathrm{~s}^{-1}$. This, in combination with rapid DIS equilibration, may result in near-equilibrium CAS-SO ${ }_{4}^{2-} \mathrm{S}$ isotope fractionation in most of our constant addition samples $\left(J<10^{-6}\right.$ mole $\left.\mathrm{m}^{-2} \mathrm{~s}^{-1}\right)$, rather than a transition from $\alpha_{\mathrm{eq}}$ to $\alpha_{\mathrm{f}}$. In this case, the range of experimental $J_{p}$ does not cover the entire transition (scenario 2, Figure $7 \mathrm{~b}$ ), $\alpha_{\mathrm{eq}}$ is constrained to be approximately $1.7 \pm 0.2 \%$ o $(1 \sigma, \mathrm{n}=2)$ at $a \mathrm{SO}_{4}{ }^{2-} / a \mathrm{CO}_{3}{ }^{2-}$ of $\sim 500$ (left of Figure $5 \mathrm{~b}$ ), and $\alpha_{\mathrm{f}}$ cannot be constrained.

We note that the values for the equilibrium end-member $\mathrm{S}$ isotope fractionation were obtained at $a \mathrm{SO}_{4}{ }^{2-} / a \mathrm{CO}_{3}{ }^{2-}$ of $\sim 500$, and that the measured CAS- $\mathrm{SO}_{4}{ }^{2-} \mathrm{S}$ isotope fractionation in calcite depends strongly on $a \mathrm{SO}_{4}{ }^{2-} / a \mathrm{CO}_{3}{ }^{2-}$ (discussed in Section 4.3.2). In modern seawater, where $a \mathrm{SO}_{4}{ }^{2-} / a \mathrm{CO}_{3}{ }^{2-}$ is $\sim 315$, the inferred isotope fractionations would be higher by a few tenths of a permil.

We cannot conclusively distinguish between the two scenarios suggested above, though inferences may be made about CAS- $\mathrm{SO}_{4}{ }^{2-} \mathrm{S}$ isotope fractionation in natural calcite. Abiotic rates of natural $\mathrm{CaCO}_{3}$ precipitation are, on average, orders of magnitude slower than experimental precipitation rates (e.g., Coplen, 2007; Fantle and DePaolo, 2007). Therefore, CAS-SO ${ }_{4}{ }^{2-} \mathrm{S}$ isotope fractionation in most natural abiotic calcite is expected to be $\geq 1.7 \pm 0.2 \%$ o $(1 \sigma, \mathrm{n}=2)$ at $a \mathrm{SO}_{4}{ }^{2-} / a \mathrm{CO}_{3}{ }^{2-}$ of $\sim 500$, the value measured at our lowest precipitation rates. For biogenic $\mathrm{CaCO}_{3}$, we cannot rule out the possibility that average precipitation rates reflect brief pulses of rapid growth separated by periods of no growth. In such cases, the majority of mineral mass may be precipitated under kinetic control, and if scenario 2 is correct, $\mathrm{CAS}-\mathrm{SO}_{4}{ }^{2-} \mathrm{S}$ isotope fractionation lower than the lowest values measured in our experiments is expected. It is interesting to note that almost all CAS-SO ${ }_{4}{ }^{2-} \mathrm{S}$ isotope fractionations measured in biogenic $\mathrm{CaCO}_{3}$ are lower than the lowest $\mathrm{S}$ isotope fractionations measured in this study (Figure 8). For $\mathrm{S}$ isotopes in CAS, might relatively rapid biotic rates of precipitation be an explanation for these "vital effects" (discussed in Section 4.5)?

\subsubsection{The dependence of CAS-SO ${ }_{4}^{2-} \mathrm{S}$ isotope fractionation on $a \mathrm{SO}_{4}{ }^{2-} / a \mathrm{CO}_{3}{ }^{2-}$ in calcite}

Next, we discuss possible mechanisms for the decreasing $\mathrm{S}$ isotope fractionation with increasing $a \mathrm{SO}_{4}{ }^{2-} / a \mathrm{CO}_{3}{ }^{2-}$ in the calcite samples. In both experimental methods, sulfate was removed from the system only by incorporation into the growing $\mathrm{CaCO}_{3}$ from a single reservoir, the dissolved $\mathrm{Na}_{2} \mathrm{SO}_{4}$. Thus, any isotopic fractionation between the sulfate in solution and CAS is due to the processes involved in the transport of sulfate to the precipitation surface or due to 
the incorporation itself. In both the $\mathrm{CO}_{2}$ degassing and constant addition methods, solutions were well stirred suggesting that diffusion-driven isotope fractionation should be insignificant, as discussed above. Differing degrees of Rayleigh distillation as a function of the initial sulfate concentration (and, therefore, $a \mathrm{SO}_{4}{ }^{2-} / a \mathrm{CO}_{3}{ }^{2-}$ ) may also be ruled out due to the small fraction of aqueous sulfate that was incorporated from all experimental solutions into the minerals $(<0.5 \%)$. The absence of measurable deviation in the $\delta^{34} \mathrm{~S}$ values of sulfate remaining in the solutions after $\mathrm{CaCO}_{3}$ precipitation in preliminary experiments supports the inference that Rayleigh distillation cannot explain the dependence on $a \mathrm{SO}_{4}{ }^{2-} / a \mathrm{CO}_{3}{ }^{2-}$. We note that the $a \mathrm{SO}_{4}{ }^{2-}$ $/ a \mathrm{CO}_{3}{ }^{2-}$ did not affect the $\mathrm{S}$ isotope fractionation in the aragonite samples, suggesting a mechanism for the dependence of isotope fractionation on $a \mathrm{SO}_{4}{ }^{2-} / a \mathrm{CO}_{3}{ }^{2-}$ that is specific to calcite. In the next sections we discuss other mechanisms that may lead to a relationship between CAS-SO ${ }_{4}{ }^{2-} \mathrm{S}$ isotope fractionation and $a \mathrm{SO}_{4}{ }^{2-} / a \mathrm{CO}_{3}{ }^{2-}$, which required a more elaborate treatment.

\section{Competition between entrapment and exchange of CAS cannot explain the trend}

It is possible that at the precipitation rates of the $\mathrm{CO}_{2}$ degassing experiments, the growing mineral entrapped sulfate ions that had not isotopically equilibrated with aqueous sulfate in the solution. We discuss this possibility in detail in Appendix II, and only briefly summarize the resulting insight below. In this mechanism, the decrease in bulk precipitation rate with increasing $a \mathrm{SO}_{4}{ }^{2-}$, which has been demonstrated experimentally (Busenberg and Plummer, 1985; Vavouraki et al., 2008; Nielsen et al., 2016), would manifest as a dependence on $a \mathrm{SO}_{4}{ }^{2-}$ $/ a \mathrm{CO}_{3}{ }^{2-}$ of the competition between $\mathrm{S}$ isotope exchange and entrapment by the growing crystal. A high $a \mathrm{SO}_{4}{ }^{2-} / a \mathrm{CO}_{3}{ }^{2-}$ would result in a lower precipitation rate, allowing for longer $\mathrm{S}$ isotope exchange times between surface-attached and aqueous sulfate, and promoting $\mathrm{S}$ isotope fractionations closer to isotopic equilibrium. If this were correct, the small CAS-SO ${ }_{4}^{2-} \mathrm{S}$ isotope fractionation exhibited at high $a \mathrm{SO}_{4}{ }^{2-} / a \mathrm{CO}_{3}{ }^{2-}$ should represent a value closer to the equilibrium $\mathrm{S}$ isotope fractionation. In other words, the equilibrium $\mathrm{S}$ isotope fractionation associated with sulfate incorporation into calcite is expected to be smaller than the kinetic $\mathrm{S}$ isotope fractionation (i.e., $\alpha_{\mathrm{eq}}<\alpha_{\mathrm{f}}$ ) in this scenario. However, the results of our constant addition experiments clearly demonstrate that the equilibrium $S$ isotope fractionation associated with sulfate incorporation into calcite is larger than the forward kinetic $\mathrm{S}$ isotope fractionation. This makes competition between entrapment and exchange of sulfate at the carbonate mineral's surface an unlikely explanation for the dependence of the CAS-SO ${ }_{4}{ }^{2-} \mathrm{S}$ isotope fractionation on $a \mathrm{SO}_{4}{ }^{2-} / a \mathrm{CO}_{3}{ }^{2-}$.

\section{Internal isotopic distribution among $S(V I)$ species requires implausibly large $S$ isotope fractionations to explain the trend}

In a solution with $\mathrm{Ca}^{2+}, \mathrm{Mg}^{2+}$ and $\mathrm{Na}^{+}$, such as our $\mathrm{CO}_{2}$ degassing solutions, $\mathrm{S}(\mathrm{VI})$ rapidly forms a variety of aqueous species (e.g., $\mathrm{SO}_{4}{ }^{2-}, \mathrm{HSO}_{4}{ }^{-}, \mathrm{CaSO}^{0}, \mathrm{CaHSO}^{+}, \mathrm{MgSO}^{0}, \mathrm{MgHSO}^{+}$, $\mathrm{NaSO}^{-}$). These aqueous species of DIS may be fractionated from each other in $\mathrm{S}$ isotopes as in other isotopic systems (Zeebe and Wolf-Gladrow, 2001; Beck et al., 2005). If the pool from which CAS forms (e.g., $\mathrm{SO}_{4}{ }^{2-}$ or $\mathrm{CaSO}_{4}{ }^{0}$ ) is fractionated relative to the DIS, and the proportion of the different species changes with the total DIS concentration, then the CAS- $\mathrm{SO}_{4}{ }^{2-} \mathrm{S}$ isotope fractionation may vary with $a \mathrm{SO}_{4}{ }^{2-} / a \mathrm{CO}_{3}{ }^{2-}$. Although we found no work constraining sulfur isotopic fractionation among the different DIS species, it is possible to determine the speciation in thermodynamic calculations (here using PHREEQC, see Section 6.4), and evaluate the isotope fractionation among DIS species that would explain our data. As the speciation changes slightly during the $\mathrm{CO}_{2}$ degassing experiments, the mole percentages given below represent $\mathrm{CaCO}_{3}$ precipitated mass-weighted averages (as, e.g., our calculations of the precipitation rate, see Section 6.4). 
We find that free sulfate $\left(\mathrm{SO}_{4}{ }^{2-}\right)$ constitutes about $87 \%$ of the total DIS in all the $\mathrm{CO}_{2}$ degassing calcite precipitation experiments. The rest of the pool is composed of ion pairs, so that $\mathrm{CaSO}_{4}{ }^{0}$ makes up 13.3 and $8.7 \%$ of the total DIS in the low- and high- $a \mathrm{SO}_{4}{ }^{2-} / a \mathrm{CO}_{3}{ }^{2-}$ experiments, respectively, and $\mathrm{NaSO}_{4}{ }^{-}$makes up 0.02 and $3.7 \%$ in the low- and high- $a \mathrm{SO}_{4}{ }^{2-} / a \mathrm{CO}_{3}{ }^{2-}$ experiments, respectively. $\mathrm{HSO}_{4}{ }^{-}$and $\mathrm{CaHSO}_{4}{ }^{+}$together make up less than $0.0005 \%$. To first order, we may approximate the DIS pool in the calcite-precipitating experiments as being composed of $\mathrm{SO}_{4}{ }^{2-}$ and $\mathrm{CaSO}_{4}{ }^{0}$. We were able to reproduce the $\mathrm{CAS}_{-} \mathrm{SO}_{4}{ }^{2-} \mathrm{S}$ isotope fractionation trend observed in calcite (Figure 9) if $\mathrm{SO}_{4}{ }^{2-}$ is the source of CAS, and $\mathrm{CaSO}_{4}{ }^{0}$ is ${ }^{34} \mathrm{~S}$-depleted relative to $\mathrm{SO}_{4}{ }^{2-}$ by $\sim 20 \%$. We could not reproduce the data with other combinations of $\mathrm{S}$ isotope distributions among DIS species. In the aragonite-precipitating $\mathrm{CO}_{2}$ degassing experiments, $\mathrm{MgSO}_{4}{ }^{0}$ comprises 42 and $31 \%$ of the DIS in the low- and high-a $\mathrm{SO}_{4}{ }^{2-}$ $/ a \mathrm{CO}_{3}{ }^{2-}$ experiments, and $\mathrm{CaSO}_{4}{ }^{0}$ comprises only a minor fraction. Consequently, assuming the same $\mathrm{SO}_{4}{ }^{2-}-\mathrm{CaSO}_{4}{ }^{0}$ isotope fractionation of $\sim 20 \%$ as for the calcite experiments, and $\mathrm{MgSO}_{4}{ }^{0}$ isotopically unfractionated from $\mathrm{SO}_{4}{ }^{2-}$, it is possible to reproduce the relatively invariant CAS$\mathrm{SO}_{4}{ }^{2-}$ isotope fractionation in aragonite (Figure 9).

Despite the ability to explain the CAS-SO ${ }_{4}{ }^{2-} \mathrm{S}$ isotope fractionation trends with $a \mathrm{SO}_{4}{ }^{2-} / a \mathrm{CO}_{3}{ }^{2-}$ in calcite and aragonite, we find an explanation by aqueous DIS speciation implausible for two reasons. First, this explanation requires that: (1) $\mathrm{CaSO}_{4}{ }^{0}$ be ${ }^{34} \mathrm{~S}$-depleted relative to $\mathrm{SO}_{4}{ }^{2-}$ by $\sim 20 \%$, and (2) that $\mathrm{MgSO}_{4}{ }^{0}$ be essentially unfractionated from $\mathrm{SO}_{4}{ }^{2-}$. Because $\mathrm{MgSO}_{4}{ }^{0}$ constitutes a major fraction of the DIS in the aragonite-precipitating experiments, the solution is extremely sensitive to the $\mathrm{MgSO}_{4}{ }^{0}-\mathrm{SO}_{4}{ }^{2-} \mathrm{S}$ isotope fractionation, and the second requirement is quite strict. Considering that $\mathrm{MgCl}_{2}$ was found to be the only one out of a few common chloride salts to have an influence on carbon isotope fractionation among dissolved inorganic carbon species (Thode et al., 1965), a $\mathrm{SO}_{4}{ }^{2-}{ }_{-} \mathrm{CaSO}_{4}{ }^{0}$ isotope fractionation of $\sim 20 \%$ alongside a negligible $\mathrm{SO}_{4}{ }^{2-}-\mathrm{MgSO}_{4}{ }^{0}$ isotope fractionation seems unlikely. In addition, the gypsum- $\mathrm{SO}_{4}{ }^{2-}$ $\mathrm{S}$ isotope fractionation is thought to be small and positive (Thode and Monster, 1965; Raab and Spiro, 1991; Van Driessche et al., 2016) and it seems unlikely that an aqueous complex of $\mathrm{Ca}^{2+}$ and $\mathrm{SO}_{4}{ }^{2-}$ (with less stiff bonds than gypsum) discriminate against ${ }^{34} \mathrm{~S}$ (at isotopic equilibrium) so much more strongly than the mineral.

\section{The identity of the calcite or aragonite precursor is unlikely to affect the CAS-SO ${ }_{4}^{2-} \mathrm{S}$ isotope fractionation}

The common $\mathrm{CaCO}_{3}$ polymorphs, calcite and aragonite, often form via amorphous calcium carbonate (ACC) or vaterite precursors, which have been previously observed in biological precipitation as well as in abiotic experiments (Politi et al., 2006; Bots et al., 2012; Nielsen et al., 2014). Under most conditions, vaterite and ACC transform to the stable polymorphs, calcite and aragonite, within minutes to hours (Fernández-Díaz et al., 2010; Bots et al., 2012; Nielsen et al., 2014). Several organic and inorganic compounds are known to stabilize vaterite or ACC, slowing down or altogether preventing its transformation to calcite or aragonite (Kato et al., 1998; Kai et al., 2002; Raz et al., 2003; Halevy and Schrag, 2009; Bentov et al., 2010; Fernández-Díaz et al., 2010; Bots et al., 2012). The transformation between the precursors and the stable minerals is suggested to occur through dissolution-recrystallization (e.g., Nielsen et al., 2014) or through solid-state transformation (e.g., Nakahara et al., 1976; Walker et al., 2017). The latter involves dehydration of the precursor phase, and is likely to capture some of the impurities in the precursor. In the case of CAS, for example, solid-state transformation is expected to conserve the initial isotopic fractionation, whereas dissolution-recrystallization involves incorporation of sulfate from solution, with a $\mathrm{S}$ isotope fractionation that should reflect the ultimate stable polymorph rather than the precursor.

We considered the possibility that the relative abundance of metastable precursors and/or the mechanism of transformation to the stable $\mathrm{CaCO}_{3}$ polymorphs change with increasing $a \mathrm{SO}_{4}{ }^{2-}$ 
$/ a \mathrm{CO}_{3}{ }^{2-}$, and that this may explain the dependence of calcite $\mathrm{CAS}-\mathrm{SO}_{4}{ }^{2-} \mathrm{S}$ isotope fractionation on $a \mathrm{SO}_{4}{ }^{2-} / a \mathrm{CO}_{3}{ }^{2-}$. The XRD results do not support an increase in the relative abundance of vaterite with increasing $a \mathrm{SO}_{4}{ }^{2-} / a \mathrm{CO}_{3}{ }^{2-}$. Nevertheless, it is possible that more vaterite formed and then transformed into calcite, and that this influenced the final $\mathrm{CAS}-\mathrm{SO}_{4}{ }^{2-} \mathrm{S}$ isotope fractionation. However, the only experiments in which vaterite inadvertently formed and was detected by XRD (CCLB, CCLC, CCLD) suggest that the CAS-SO ${ }_{4}{ }^{2-} \mathrm{S}$ isotope fractionation in vaterite is larger than in calcite, not smaller (Table 1). Therefore, an increasing abundance of vaterite with increasing $a \mathrm{SO}_{4}{ }^{2-} / a \mathrm{CO}_{3}{ }^{2-}$, as would be expected given existing knowledge on the effects of $\mathrm{Na}_{2} \mathrm{SO}_{4}$ on $\mathrm{CaCO}_{3}$ polymorph stability (Fernández-Díaz et al., 2010), would lead to increasing calcite CAS-SO ${ }_{4}{ }^{2-} \mathrm{S}$ isotope fractionation with increasing $a \mathrm{SO}_{4}{ }^{2-} / a \mathrm{CO}_{3}{ }^{2-}$, which is opposite to the trend observed in our experiments.

The carbonate minerals precipitated in our experiments were not sampled and analyzed shortly after precipitation, and we cannot rule out the formation of an ACC precursor. However, both in-situ TEM observations (Nielsen et al., 2014) and the evolving $\mathrm{Ca}$ and $\mathrm{Mg}$ isotope composition during transformation of ACC to calcite (Giuffre et al., 2015) suggest that the transformation occurs by dissolution-reprecipitation, rather than in the solid state. In an experimental system such as ours, which was well mixed and in which the abundance of sulfate in solution was much greater than in the precipitated solid, dissolution of ACC and reprecipitation of calcite would lead to incorporation of sulfate from solution rather than an inheritance of the isotopic composition of CAS in the precursor ACC. Thus, it appears that neither inheritance from vaterite nor from $\mathrm{ACC}$ can explain the observed decreasing CAS-SO ${ }_{4}^{2-}$ $\mathrm{S}$ isotope fractionation with increasing $a \mathrm{SO}_{4}{ }^{2-} / a \mathrm{CO}_{3}{ }^{2-}$.

Does the sulfate "impurity" affect lattice energy and the equilibrium S isotope fractionation? Although CAS is not one of the main building blocks of $\mathrm{CaCO}_{3}$, it occurs at much higher concentrations than most impurities, and may thus have a non-negligible effect on the lattice energy. Distortion of the mineral structure, and changes to cell parameters, solubility, and stability of calcite correlate with [CAS] and $a \mathrm{SO}_{4}{ }^{2-} / a \mathrm{CO}_{3}{ }^{2-}$ in solution (Section 1.2). These effects of CAS on the properties of calcite support an effect of [CAS] on the lattice energy. Indeed, Fernández-Díaz et al. (2010) calculated an increase in lattice energy of 1.6 and 4.2 $\mathrm{kJ} / \mathrm{mol}$ for every $10,000 \mathrm{ppm}$ CAS added to calcite and aragonite, respectively.

Equilibrium isotope fractionation associated with mineral precipitation is related to the energetic difference between isotopic species of a solvated ion relative to the energetic difference between isotopic species of the ion in the solid. In the schematic isotope exchange reaction:

9)

$$
{ }^{*} \mathrm{Ca}^{32} \mathrm{SO}_{4}+{ }^{34} \mathrm{SO}_{4}^{2-} \rightleftharpoons{ }^{*} \mathrm{Ca}^{34} \mathrm{SO}_{4}+{ }^{32} \mathrm{SO}_{4}^{2-},
$$

${ }^{*} \mathrm{Ca}^{32} \mathrm{SO}_{4}$ and ${ }^{*} \mathrm{Ca}^{34} \mathrm{SO}_{4}$ are a calcite or aragonite unit containing exactly one sulfate molecule (with ${ }^{32} \mathrm{~S}$ and ${ }^{34} \mathrm{~S}$, respectively) and many carbonate molecules, with the exact number of carbonate molecules depending on the overall [CAS]. According to solid-solution thermodynamics (e.g., Matschei et al., 2007), the Gibbs free energy of these solids may be expressed as follows:

$$
\begin{aligned}
& \Delta \mathrm{G}^{\mathrm{o}}{ }_{\mathrm{Ca}^{32} \mathrm{SO}_{4}}=(N-1) \Delta \mathrm{G}_{\mathrm{CaCO}_{3}}^{\mathrm{o}}+\Delta \mathrm{G}_{\mathrm{Ca}^{32} \mathrm{SO}_{4}}^{\mathrm{o}}+\Delta \mathrm{G}_{\mathrm{M}, 32}, \\
& \Delta \mathrm{G}^{\mathrm{o}}{ }_{\mathrm{Ca}^{34} \mathrm{SO}_{4}}=(N-1) \Delta \mathrm{G}_{\mathrm{CaCO}_{3}}^{\mathrm{o}}+\Delta \mathrm{G}_{\mathrm{Ca}^{34} \mathrm{SO}_{4}}^{\mathrm{o}}+\Delta \mathrm{G}_{\mathrm{M}, 34} \text {, }
\end{aligned}
$$

where $N$ is the sum of $\mathrm{CaCO}_{3}$ and $\mathrm{CaSO}_{4}$ subunits within the calcite or aragonite unit. $\Delta \mathrm{G}_{\mathrm{CaCO}_{3}}^{\mathrm{o}}$, $\Delta \mathrm{G}_{\mathrm{Ca}^{32} \mathrm{SO}_{4}}^{\mathrm{O}}$ and $\Delta \mathrm{G}_{\mathrm{Ca}^{34} \mathrm{SO}_{4}}^{\mathrm{O}}$ are the Gibbs free energies of formation of a single $\mathrm{CaCO}_{3}, \mathrm{Ca}^{32} \mathrm{SO}_{4}$ 
and $\mathrm{Ca}^{34} \mathrm{SO}_{4}$ subunit, respectively, and $\Delta \mathrm{G}_{\mathrm{M}, 32}$ and $\Delta \mathrm{G}_{\mathrm{M}, 34}$ are the Gibbs free energies of mixing a single subunit of $\mathrm{Ca}^{32} \mathrm{SO}_{4}$ and $\mathrm{Ca}^{34} \mathrm{SO}_{4}$, respectively, together with $(N-1)$ subunits of $\mathrm{CaCO}_{3}$. The Gibbs free energy of reaction 16 , which is related to the equilibrium $\mathrm{S}$ isotope fractionation between the CAS and the sulfate, is:

$$
\Delta \mathrm{G}_{\mathrm{r}}=\Delta \mathrm{G}^{\mathrm{O}}{ }^{\mathrm{O}} \mathrm{Ca}^{34} \mathrm{SO}_{4}+\Delta \mathrm{G}^{\mathrm{O} 2} \mathrm{SO}_{4}^{2-}-\Delta \mathrm{G}^{\mathrm{O}} \mathrm{Ca}^{32} \mathrm{SO}_{4}-\Delta \mathrm{G}^{\mathrm{O}}{ }^{\mathrm{O}} \mathrm{SO}_{4}^{2-} .
$$

Substituting equations 10 and 11 into equation 12:

$$
\Delta \mathrm{G}_{\mathrm{r}}=\left(\Delta \mathrm{G}_{\mathrm{Ca}^{34} \mathrm{SO}_{4}}^{\mathrm{o}}-\Delta \mathrm{G}_{\mathrm{Ca}^{32} \mathrm{SO}_{4}}^{\mathrm{o}}\right)-\left(\Delta \mathrm{G}_{34}^{\mathrm{o}} \mathrm{SO}_{4}^{2-}-\Delta \mathrm{G}_{32}^{\mathrm{o}} \mathrm{SO}_{4}^{2-}\right)+\left(\Delta \mathrm{G}_{\mathrm{M}, 34}-\Delta \mathrm{G}_{\mathrm{M}, 32}\right) .
$$

The third term on the right-hand side of the resulting expression for $\Delta \mathrm{G}_{\mathrm{r}}$ depends on [CAS], and so the equilibrium CAS-SO ${ }_{4}{ }^{2-} \mathrm{S}$ isotope fractionation is also expected to depend on [CAS], as we observe. Equation 13 illustrates how a sulfate impurity may affect the equilibrium CAS$\mathrm{SO}_{4}{ }^{2-} \mathrm{S}$ isotope fractionation.

An influence of a minor component on the isotopic composition of carbonate minerals is observed in the effect of $\mathrm{Mg}$ on the calcite-water $\mathrm{O}$ isotope fractionation. The $\mathrm{O}$ isotope fractionation between synthetic magnesian calcites and water at $25^{\circ} \mathrm{C}$ changes by 0.06 to 0.17 \%o for every 1 mole \% of $\mathrm{MgCO}_{3}$ (Tarutani et al., 1969; Jiménez-López et al., 2004). Additionally, DFT calculations suggest a change in the $\mathrm{Mg}$ and $\mathrm{Ca}$ isotopic compositions of calcite-type minerals, which arises from a change in bond lengths with changes in the proportion of $\mathrm{MgCO}_{3}$ and $\mathrm{CaCO}_{3}$ in the solid (Wang et al., 2017). It is not unexpected, therefore, that a change in [CAS] may be associated with a change in $\mathrm{S}$ isotope fractionation, as well as the fractionation of isotopes of the other elements in the mineral lattice, namely $\mathrm{O}, \mathrm{C}$ and $\mathrm{Ca}$.

Support for the hypothesis of a change in the energetics of the $\mathrm{CaCO}_{3}$ lattice (and the sulfate in it), and an associated change in the equilibrium CAS- $\mathrm{SO}_{4}{ }^{2-} \mathrm{S}$ isotope fractionation, may come from the XANES results. The correlation observed between the FWHM $\mathrm{v}_{1}$ and [CAS] (Figure 6d) may arise from an increase in the available electronic states due to the breaking of the symmetry (and the anti-bonding degeneracy) of the $\mathrm{SO}_{4}{ }^{2-}$ tetrahedron. The resulting heterogeneity in the S-O bonding environment should manifest as a change in vibrational frequencies and the associated chemical and isotopic equilibrium constants. Interestingly, other than the two aragonite samples with the highest [CAS], which appear to display anomalous behavior relative to the other aragonite samples (Figure 6), the $\mathrm{FWHM}_{\mathrm{V} 1}$ of the aragonite precipitated in this study do not show a clear correlation with [CAS] (Figure 6d). In contrast, all calcite samples with high signal-to-noise ratios display $\mathrm{FWHM}_{\mathrm{V} 1}$ values that clearly correlate with [CAS]. This observation is consistent with the dependence of the CAS-SO ${ }_{4}{ }^{2-} \mathrm{S}$ isotope fractionation on $a \mathrm{SO}_{4}{ }^{2-} / a \mathrm{CO}_{3}{ }^{2-}$ in calcite, but not in aragonite (Figure 5).

If the change in equilibrium CAS-SO ${ }_{4}^{2-} \mathrm{S}$ isotope fractionation arises from distortion of the lattice due to sulfate incorporation, a physical-chemical model of sulfate in a calcium carbonate mineral lattice, such as the one developed by Balan et al. (2014), should capture this phenomenon. However, the results from that study suggest a $\mathrm{S}$ isotope fractionation of approximately $4 \%$ between CAS in calcite and aqueous sulfate, at a very high [CAS] (set by practical computational cost), where our data suggest $\mathrm{CAS}-\mathrm{SO}_{4}{ }^{2-} \mathrm{S}$ isotope fractionation should be small at comparable CAS concentrations.

\subsection{CAS- $\mathrm{SO}_{4}{ }^{2-} \mathrm{S}$ isotope fractionation in aragonite}

The fractionation of $\mathrm{S}$ isotopes between sulfate in aragonite and aqueous sulfate does not show a dependence on [CAS] over the range of $a \mathrm{SO}_{4}{ }^{2-} / a \mathrm{CO}_{3}{ }^{2-}$ explored in this study (6 to $\sim 1300$; Figure 5a). This is unexpected if the explanation for [CAS]-dependent CAS- $\mathrm{SO}_{4}{ }^{2-} \mathrm{S}$ isotope 
fractionation is an effect of the sulfate impurity on lattice energy and the equilibrium fractionation, as the lattice energy change calculated for aragonite is almost 3 times that calculated for calcite (Fernandez-Diez et al., 2010). First, it is possible that CAS-SO ${ }_{4}{ }^{2-} \mathrm{S}$ isotope fractionation in aragonite is as sensitive to [CAS] as the $\mathrm{S}$ isotope fractionation in calcite, but due to the smaller partition coefficients of sulfate into aragonite (and the lower [CAS]), the trend is not resolved. Alternatively, it is possible that the molecular model does not capture all of the relevant processes involved in incorporation of sulfate into aragonite at an appropriate accuracy. In this case, aragonite would be less sensitive to substitution of sulfate for the carbonate ion, an inference that is supported also by the XANES data. Similar insensitivity has been observed for $\mathrm{O}$ isotope fractionation between aragonite and water in past studies. For example, experimental aragonite-water $\mathrm{O}$ isotope fractionation shows little or no response to variation in the $\mathrm{Mg}^{2+}$ concentration, precipitation method and rate (Kim et al., 2007).

Finally, "coupled" incorporation of $\mathrm{SO}_{4}{ }^{2-}$ and $\mathrm{Mg}^{2+}$ into the aragonite precipitated in our experiments may have resulted in [CAS]-independent $\mathrm{CAS}_{-} \mathrm{SO}_{4}{ }^{2-} \mathrm{S}$ isotope fractionation. A possible reason is the compensating effect of incorporation of the oversized (relative to $\mathrm{CO}_{3}{ }^{2-}$ ) $\mathrm{SO}_{4}{ }^{2-}$ ion, and the undersized (relative to $\mathrm{Ca}^{2+}$ ) $\mathrm{Mg}^{2+}$ ion. Sulfate incorporation expands the $\mathrm{d}$ spacing and cell size (Section 1.2), while $\mathrm{Mg}^{2+}$ decreases d-spacing leading to shorter bond lengths (Goldsmith et al., 1961; Finch and Allison, 2007). To the best of our knowledge, similar effects in aragonite have not been studied systematically, but may exist. In this case, aragonite formation in the $\mathrm{CO}_{2}$ degassing experiments, which was promoted by $\mathrm{Mg}^{2+} / \mathrm{Ca}^{2+}$ of 5 , is expected to be accompanied by a [CAS]-insensitive CAS-SO ${ }_{4}^{2-} \mathrm{S}$ isotope fractionation.

We expect $\mathrm{S}$ isotope fractionation similar to our experiments in the majority of marine environments in either case. The concentration of $\mathrm{Mg}^{2+}$ in seawater is thought to have been at least $\sim 30 \mathrm{mmol} \mathrm{kg}^{-1}$ through Phanerozoic time (Horita et al., 2002), and was unlikely much lower than $\sim 10 \mathrm{mmol} \mathrm{kg}{ }^{-1}$ over the majority of Earth history (Halevy and Bachan, 2017). Thus, if co-substitution of $\mathrm{Mg}^{2+}$ and $\mathrm{SO}_{4}{ }^{2-}$ is responsible for the insensitivity of CAS-SO ${ }_{4}^{2-} \mathrm{S}$ isotope fractionation to [CAS], this is expected in natural abiotic aragonite as well. Alternatively, if the low [CAS] is responsible for the insensitivity, then this is also expected in most abiotic inorganic aragonites, which would incorporate low [CAS], especially in the Precambrian ocean, in which aqueous sulfate concentrations are thought to have been much lower than today.

Support for the values of the aragonite $\mathrm{CAS}-\mathrm{SO}_{4}{ }^{2-} \mathrm{S}$ isotope fractionation determined in our experiments comes from natural aragonite ooids precipitated abiotically in the Bahamas. These ooids contain CAS, which is fractionated from the aqueous sulfate in seawater by $0.7 \pm 0.3 \%$ o (Trower et al., 2018), in agreement with the $1.0 \pm 0.3 \%$ we find experimentally, both at $\sim 30^{\circ} \mathrm{C}$. Note that both the experiments and natural samples suggest that the $\mathrm{S}$ isotope fractionation is much closer to the 1-2\%o gypsum- $\mathrm{SO}_{4}{ }^{2-} \mathrm{S}$ isotope fractionation (Thode et al., 1961; Raab and Spiro, 1991; Van Driessche et al., 2016), than the DFT calculations, which suggested 4.5\%o for the CAS-SO ${ }_{4}^{2-} \mathrm{S}$ isotope fractionation in aragonite at $30^{\circ} \mathrm{C}$. The agreement between CAS-SO ${ }_{4}^{2-}$ $\mathrm{S}$ isotope fractionations observed in experimental and natural abiotic aragonite provides confidence in the use of CAS in abiogenic aragonite to reconstruct paleo- $\delta^{34} S$ values in ancient seawater.

\subsection{Implications for natural samples}

\subsubsection{Effects on CAS-SO ${ }_{4}^{2-} \mathrm{S}$ isotope fractionation in abiotic and biogenic primary} carbonate minerals

The experimental results in this study apply to the primary carbonate minerals precipitated from Precambrian seawater (if well preserved, see discussion below), all of which were abiotic or microbially-mediated (Sumner and Grotzinger, 2000; Grotzinger and James, 2000; Schrag et al., 2013). The experimental results also apply to abundant abiotic precipitates, such as ooids 
(Trower et al., 2018). Phanerozoic carbonate minerals, however, are mostly biogenic. All but one of the CAS-SO ${ }_{4}{ }^{2-} \mathrm{S}$ isotope fractionations observed in modern calcifying organisms (Figure 2,8 ) are smaller positive values (or even small negative values) than the experimental CAS$\mathrm{SO}_{4}{ }^{2-} \mathrm{S}$ isotope fractionation in aragonite, and all are smaller than $\mathrm{CAS}-\mathrm{SO}_{4}{ }^{2-}$ isotope fractionation in calcite. As mentioned in section 4.3.1, variation in precipitation rate $\left(0.4 \pm 0.2 \%\right.$ ) cannot explain the large variation in $\mathrm{CAS}-\mathrm{SO}_{4}{ }^{2-} \mathrm{S}$ isotope fractionation observed in the skeletons of calcifying organisms, and especially not negative fractionation. It is possible that a variety of yet uncharacterized biological processes shift the isotopic fractionation down from the experimental values. The existence of such "vital effects" suggests that the use of CAS in biogenic carbonate minerals to constrain paleo- $\delta^{34} \mathrm{~S}$ values in Phanerozoic seawater requires calibration of species-specific CAS- $\mathrm{SO}_{4}{ }^{2-} \mathrm{S}$ isotope fractionations in controlled experiments. Such calibrations of CAS-SO ${ }_{4}^{2-} \mathrm{S}$ isotope fractionation have been performed for a few species (Paris et al., 2014; Rennie et al., 2018), and are performed routinely for other isotopic systems, such as $\mathrm{O}$ isotopes in carbonate minerals (e.g., Wefer and Berger, 1991). Future focus on testing the dependence of CAS-SO ${ }_{4}{ }^{2-} \mathrm{S}$ isotope fractionation in biogenic calcite on $a \mathrm{SO}_{4}{ }^{2-} / a \mathrm{CO}_{3}{ }^{2-}$ would provide confidence in the use of CAS in biogenic carbonate minerals to reconstruct seawater sulfate $\mathrm{S}$ isotopes.

With the caveats to the interpretation of CAS $\delta^{34} \mathrm{~S}$ values discussed below in mind, it is important to note that according to several proxies (sulfate evaporites, barite and CAS), seawater sulfate $\delta^{34} \mathrm{~S}$ values have varied between $0 \%$ and 50\% VCDT throughout Earth history (Kampschulte and Strauss, 2004; Paytan et al., 2004; Fike et al., 2015). Perhaps with the exception of diagenetic carbonate formation in MSR-influenced sediments, the proposed mechanisms below alter (mostly increase) CAS $\delta^{34} S$ values by only a few permil relative to the original CAS. Therefore, CAS $\delta^{34} \mathrm{~S}$ values in primary, well preserved carbonate samples should capture the major changes in seawater $\delta^{34} \mathrm{~S}$ values.

\subsubsection{Post-depositional processes}

Post-depositional recrystallization of the original carbonate minerals and precipitation of diagenetic carbonate minerals may affect the $\delta^{34} \mathrm{~S}$ values preserved in CAS in several ways. Recrystallization rates in some marine sediments are tens of percent per million years (Walter et al., 1993; Fantle and DePaolo, 2007), and diagenetic carbonate minerals, both recrystallized and new void-filling cements, may contribute a substantial fraction of the total carbonate rock mass preserved in some environments (Schrag et al., 2013; Sun and Turchyn, 2014). If these processes occur in good communication with seawater sulfate (i.e., the sulfate incorporated into the diagenetic or recrystallized carbonate minerals is similar in isotopic composition to seawater sulfate), they will shift bulk $\delta^{34} \mathrm{~S}_{\mathrm{CAS}}$ values upwards as abiotic carbonate minerals are added to or replace the original biogenic minerals. For example, in the Phanerozoic, when $a \mathrm{SO}_{4}{ }^{2-} / a \mathrm{CO}_{3}{ }^{2-}$ in the oceans mostly stayed within the range of 220 to 2530 , abiotic calcite CAS concentrations are expected to be between 3,100 and 38,400 ppm (Equation 4; gray rectangle, Figure 8). At such CAS concentrations the minimal fractionation we measured will be expressed, which averages to $1.7 \pm 0.3 \%$ o $(1 \sigma, \mathrm{n}=20)$. Thus, recrystallization or diagenetic carbonate mineral formation in good communication with aqueous sulfate in the overlying seawater is expected to shift CAS-SO ${ }_{4}{ }^{2-}$ isotope fractionation from a biogenic value of approximately $-1 \%$ to an abiotic value of $+1-2 \%$ (Figure 8 ). In a study of diagenesis of Key Largo carbonates, Gill et al. (2008) interpreted a $1 \%$ enrichment in $\delta^{34} \mathrm{~S}$ of secondary calcite relative to the primary aragonite to reflect local microbial sulfate reduction, which enriched pore-water sulfate in ${ }^{34} \mathrm{~S}$ (see discussion below). Because the difference in CAS- $\mathrm{SO}_{4}{ }^{2-} \mathrm{S}$ isotope fractionation between calcite and aragonite is $0.5-2 \%$, a ${ }^{34} \mathrm{~S}$ enrichment of $1 \%$ in calcite is also consistent with aragonite dissolution and calcite precipitation in contact with seawater-like solutions. In Precambrian sediments, all carbonate minerals are abiotic, and less of an isotopic difference is 
expected between CAS in primary and diagenetic or recrystallized carbonate minerals. Nevertheless, mineralogical transformations, for example, from primary aragonite to calcite or dolomite, may shift the preserved $\mathrm{S}$ isotope composition.

In the case of poor communication with the overlying seawater (i.e., near-closed-system conditions), the original isotopic composition of the CAS may be retained in the recrystallized or diagenetic carbonate minerals. However, such near-closed-system conditions are often associated with the drawdown of sulfate within the sediments by MSR. Anaerobic respiration of organic matter (e.g., MSR) often involves an increase in porewater alkalinity and in carbonate mineral saturation state (Higgins et al., 2009), and promotes diagenetic carbonate mineral formation. The $\mathrm{S}$ isotope composition of CAS in MSR-influenced minerals may be altered from the original values in several ways. First, the drawdown of sulfate and the production of alkalinity depresses $a \mathrm{SO}_{4}{ }^{2-} / a \mathrm{CO}_{3}{ }^{2-}$, and consequently, the CAS concentration in the diagenetic minerals. Our experiments suggest that the CAS- $\mathrm{SO}_{4}{ }^{2-}$ isotope fractionation under such conditions should be larger in calcite, approaching $+3 \%$ (compared to between +1 and $+2 \%$ for abiotic calcite and between -1 and $+1 \%$ in biogenic carbonate minerals formed in seawater), and $\sim 1 \%$ in aragonite. The sulfate preserved in the diagenetic or recrystallized carbonate minerals may thus be between 1 and $4 \%$ enriched in ${ }^{34} \mathrm{~S}$ relative to the original carbonate. Perhaps more importantly, isotopic fractionation during MSR leads to production of ${ }^{34} \mathrm{~S}$-depeleted sulfide and gradual ${ }^{34} \mathrm{~S}$ enrichment of the residual sulfate (e.g., Harrison and Thode, 1958; Canfield, 2004). Thus, carbonate minerals formed due to MSR-driven production of alkalinity in sediment porewater are expected to incorporate ${ }^{34} \mathrm{~S}$-enriched sulfate, sometimes by several percent relative to seawater (Rennie and Turchyn, 2014; Present et al., 2015). In combination with larger CAS-SO${ }_{4}^{2-}$ isotope fractionation expected as sulfate is utilized by MSR, CAS in diagenetic or recrystallized carbonate minerals is expected to be enriched in ${ }^{34} \mathrm{~S}$ relative to primary marine carbonates. Seawater sulfate $\delta^{34} \mathrm{~S}$ values inferred from measured $\delta^{34} \mathrm{~S}_{\mathrm{CAS}}$ values may, therefore, be erroneously high if care is not taken in avoiding recrystallized or diagenetic carbonate minerals.

\section{Conclusions}

The fractionation of S isotopes between CAS and aqueous sulfate was observed experimentally to be positive and significant both in calcite and aragonite, in contrast with the common assumption of negligible CAS-SO ${ }_{4}{ }^{2-} \mathrm{S}$ isotope fractionation. The magnitude of the CAS- $\mathrm{SO}_{4}{ }^{2-}$ $\mathrm{S}$ isotope fractionation at high CAS concentrations ( $\sim 1 \%$ in aragonite, $\sim 2 \%$ in calcite) is also inconsistent with the large isotope fractionations $(>4 \%$ o) suggested by DFT modeling. Our results reveal a different response of aragonite and calcite to the $a \mathrm{SO}_{4}{ }^{2-} / a \mathrm{CO}_{3}{ }^{2-}$ in aqueous solutions. The CAS-SO ${ }_{4}^{2-} \mathrm{S}$ isotope fractionation in synthetic aragonite is in agreement with the isotope fractionation observed in natural abiotic aragonite ooids, and we suggest a constant value of $1.0 \pm 0.3 \%$ (at $\sim 30^{\circ} \mathrm{C}$ ) for this isotope fractionation, which is independent of $a \mathrm{SO}_{4}{ }^{2-}$ $/ a \mathrm{CO}_{3}{ }^{2-}$. The CAS-SO ${ }_{4}{ }^{2-} \mathrm{S}$ isotope fractionation in calcite, on the other hand, varies between $3.1 \pm 0.6$ and $1.7 \pm 0.4 \%$ o (at $\sim 30^{\circ} \mathrm{C}$ ) at low and high $a \mathrm{SO}_{4}{ }^{2-} / a \mathrm{CO}_{3}{ }^{2-}$, respectively. While precipitation rate inversely correlates with the CAS-SO ${ }_{4}{ }^{2-} \mathrm{S}$ isotope fractionation, its effect is too small and cannot explain the stronger inverse correlation of $\mathrm{S}$ isotope fractionation with $a \mathrm{SO}_{4}{ }^{2-} / a \mathrm{CO}_{3}{ }^{2-}$. This correlation is probably due to a change in the equilibrium $\mathrm{S}$ isotope fractionation caused by the effect of CAS incorporation on the lattice energy of calcite, but not of aragonite. Such an effect is consistent with the change in the S K-edge X-ray absorption spectra, which we observe in calcite but not in aragonite, and which is presumably caused by a change in the distorted tetrahedral symmetry of sulfate.

The majority of CAS-SO ${ }_{4}^{2-} \mathrm{S}$ isotope fractionations observed in our aragonite and calcite samples are larger, sometimes by several permil, than those displayed by modern calcifying organisms. These differences cannot be explained by the effects of $a \mathrm{SO}_{4}{ }^{2-} / a \mathrm{CO}_{3}{ }^{2-}$ on the CAS- 
$\mathrm{SO}_{4}{ }^{2-} \mathrm{S}$ isotope fractionation observed in our abiotic samples. As our experiments cannot constrain the kinetic fractionation of $\mathrm{S}$ isotopes upon incorporation of sulfate into carbonate minerals, we cannot rule out much higher, "pulsed" rates of biogenic precipitation as the cause for the smaller positive and even small negative CAS-SO ${ }_{4}{ }^{2-} \mathrm{S}$ isotope fractionation in biogenic carbonate minerals. Alternatively, other isotope fractionation mechanisms upon sulfate incorporation into biogenic carbonate minerals may exist, and calibrations of CAS- $\mathrm{SO}_{4}{ }^{2-}$ isotope fractionation in specific skeletal carbonates may be inevitable.

The dependence of CAS-SO ${ }_{4}{ }^{2-} \mathrm{S}$ isotope fractionation on $a \mathrm{SO}_{4}{ }^{2-} / a \mathrm{CO}_{3}{ }^{2-}$ described here, and the effects of other aqueous species on carbonate mineral thermodynamics and kinetics documented in previous studies, suggest that the chemistry of carbonate mineral-forming solutions may affect CAS-SO ${ }_{4}^{2-} \mathrm{S}$ isotope fractionation in other ways as well. This highlights not only the importance of experimental constraints on the effects of solution chemistry on CAS-SO ${ }_{4}^{2-} \mathrm{S}$ isotope fractionation, but also of constraints on the chemical composition of geologic carbonate mineral-forming solutions, which are often difficult to obtain. Furthermore, the perspective on isotope-fractionating processes in the presence of impurities that emerges from this study calls for an investigation of such effects on other isotopic systems (e.g., C and $\mathrm{O}$ isotopes in carbonate minerals) and for impurities other than sulfate.

\section{Acknowledgments}

We thank Ziv Sade and Nir Galili for discussions. I.H. acknowledges support from a European Research Council Starting Grant (No. 337183). This work was supported by the Tellus program from CNRS/INSU. Use of the Stanford Synchrotron Radiation Lightsource, SLAC National Accelerator Laboratory, is supported by U.S. Department of Energy, Office of Science, Office of Basic Energy Sciences under Contract No. DE-AC02-76SF00515. 


\section{References}

Abrarov S. (2016) The Voigt/complex error function. MATLAB Cent. File Exch.

Adkins J. F., Boyle E. A., Curry W. B. and Lutringer A. (2003) Stable isotopes in deep-sea corals and a new mechanism for "vital effects." Geochim. Cosmochim. Acta 67, 1129-1143.

Arroyo-de Dompablo M. E., Fernández-González M. A. and Fernández-Díaz L. (2015) Computational investigation of the influence of tetrahedral oxoanions (sulphate, selenate and chromate) on the stability of calcium carbonate polymorphs. RSC Adv. 5, 59845-59852.

Balan E., Blanchard M., Pinilla C. and Lazzeri M. (2014) First-principles modeling of sulfate incorporation and ${ }^{34} \mathrm{~S} /{ }^{32} \mathrm{~S}$ isotopic fractionation in different calcium carbonates. Chem. Geol. 374-375, 84-91.

Beard D. A. and Qian H. (2007) Relationship between Thermodynamic Driving Force and One-Way Fluxes in Reversible Processes ed. T. Secomb. PLoS One 2, e144.

Beck W. C., Grossman E. L. and Morse J. W. (2005) Experimental studies of oxygen isotope fractionation in the carbonic acid system at $15^{\circ}, 25^{\circ}$, and $40^{\circ} \mathrm{C}$. Geochim. Cosmochim. Acta 69 , 3493-3503.

Bentov S., Weil S., Glazer L., Sagi A. and Berman A. (2010) Stabilization of amorphous calcium carbonate by phosphate rich organic matrix proteins and by single phosphoamino acids. J. Struct. Biol. 171, 207-215.

Bots P., Benning L. G., Rickaby R. E. M. and Shaw S. (2011) The role of $\mathrm{SO}_{4}$ in the switch from calcite to aragonite seas. Geology 39, 331-334.

Bots P., Benning L. G., Rodriguez-Blanco J.-D., Roncal-Herrero T. and Shaw S. (2012) Mechanistic Insights into the Crystallization of Amorphous Calcium Carbonate (ACC). Cryst. Growth Des. 12, 3806-3814.

Burdett J. W., Arthur M. A. and Richardson M. (1989) A Neogene seawater sulfur isotope age curve from calcareous pelagic microfossils. Earth Planet. Sci. Lett. 94, 189-198.

Busenberg E. and Plummer L. N. (1985) Kinetic and thermodynamic factors controlling the distribution of $\mathrm{SO}_{4}{ }^{2-}$ and $\mathrm{Na}^{+}$in calcites and selected aragonites. Geochim. Cosmochim. Acta 49 , $713-725$.

Canfield D. E. (2004) The evolution of the Earth surface sulfur reservoir. Am. J. Sci. 304, 839-861.

Castanier S., Le Métayer-Levrel G. and Perthuisot J.-P. (1999) Ca-carbonates precipitation and limestone genesis — the microbiogeologist point of view. Sediment. Geol. 126, 9-23.

Coplen T. B. (2007) Calibration of the calcite-water oxygen-isotope geothermometer at Devils Hole, Nevada, a natural laboratory. Geochim. Cosmochim. Acta 71, 3948-3957.

Cuif J.-P., Dauphin Y., Doucet J., Salome M. and Susini J. (2003) XANES mapping of organic sulfate in three scleractinian coral skeletons. Geochim. Cosmochim. Acta 67, 75-83.

Davis K. J., Dove P. M. and Yoreo J. J. De (2000) The Role of $\mathrm{Mg}^{2+}$ as an Impurity in Calcite Growth. Science 290, 1134-1137.

DePaolo D. J. (2011) Surface kinetic model for isotopic and trace element fractionation during precipitation of calcite from aqueous solutions. Geochim. Cosmochim. Acta 75, 1039-1056.

Van Driessche A. E. S., Canals A., Ossorio M., Reyes R. C. and García-Ruiz J. M. (2016) Unraveling the Sulfate Sources of (Giant) Gypsum Crystals Using Gypsum Isotope Fractionation Factors. $J$. Geol. 124, 235-245.

Duval L. (2015) BEADS: Baseline Estimation And Denoising w/ Sparsity (chromatogram signals). MathWorks File Exch.

Eldridge D. L., Guo W. and Farquhar J. (2016) Theoretical estimates of equilibrium sulfur isotope effects in aqueous sulfur systems: Highlighting the role of isomers in the sulfite and sulfoxylate systems. Geochim. Cosmochim. Acta 195, 171-200.

Erez J. and Braun A. (2007) Calcification in hermatypic corals is based on direct seawater supply to the biomineralization site. Geochim. Cosmochim. Acta 71, A260.

Fantle M. S. and DePaolo D. J. (2007) Ca isotopes in carbonate sediment and pore fluid from ODP Site 807A: The $\mathrm{Ca}^{2+}(\mathrm{aq})$-calcite equilibrium fractionation factor and calcite recrystallization rates in 
Pleistocene sediments. Geochim. Cosmochim. Acta 71, 2524-2546.

Fernández-Díaz L., Fernández-González Á. and Prieto M. (2010) The role of sulfate groups in controlling $\mathrm{CaCO}_{3}$ polymorphism. Geochim. Cosmochim. Acta 74, 6064-6076.

Fichtner V., Strauss H., Immenhauser A., Buhl D., Neuser R. D. and Niedermayr A. (2017) Diagenesis of carbonate associated sulfate. Chem. Geol. 463, 61-75.

Fike D. A., Bradley A. S. and Rose C. V. (2015) Rethinking the Ancient Sulfur Cycle. Annu. Rev. Earth Planet. Sci. 43, 593-622.

Finch A. A. and Allison N. (2007) Coordination of Sr and Mg in calcite and aragonite. Mineral. Mag. 71, 539-552.

Fleet M. E. (2005) XANES spectroscopy of sulfur in earth materials. Can. Mineral. 43, 1811-1838.

Frisia S., Borsato A., Fairchild I. J. and Susini J. (2005) Variations in atmospheric sulphate recorded in stalagmites by synchrotron micro-XRF and XANES analyses. Earth Planet. Sci. Lett. 235, 729 740 .

Fyfe W. S. and Bischoff J. L. (1965) The Calcite Aragonite Problem. Spec. Publ. Soc. Econ. Paleontol. Mineral. 13.

Gagnon A. C., Adkins J. F. and Erez J. (2012) Seawater transport during coral biomineralization. Earth Planet. Sci. Lett. 329-330, 150-161.

Gagnon A. C., Adkins J. F., Fernandez D. P. and Robinson L. F. (2007) Sr/Ca and Mg/Ca vital effects correlated with skeletal architecture in a scleractinian deep-sea coral and the role of Rayleigh fractionation. Earth Planet. Sci. Lett. 261, 280-295.

Garrels R. M. and Thompson M. E. (1962) A chemical model for sea water at 25 degrees C and one atmosphere total pressure. Am. J. Sci. 260, 57-66.

Gellatly A. M. and Lyons T. W. (2005) Trace sulfate in mid-Proterozoic carbonates and the sulfur isotope record of biospheric evolution. Geochim. Cosmochim. Acta 69, 3813-3829.

Gill B. C., Lyons T. W. and Frank T. D. (2008) Behavior of carbonate-associated sulfate during meteoric diagenesis and implications for the sulfur isotope paleoproxy. Geochim. Cosmochim. Acta 72, 4699-4711.

Giuffre A. J., Gagnon A. C., De Yoreo J. J. and Dove P. M. (2015) Isotopic tracer evidence for the amorphous calcium carbonate to calcite transformation by dissolution-reprecipitation. Geochim. Cosmochim. Acta 165, 407-417.

Goldsmith J. R., Graf D. L. and Heard H. C. (1961) Lattice constants of the calcium-magnesium carbonates. Am. Mineral. 46, 453-457.

Grotzinger J. P. and James N. P. (2000) Precambrian Carbonates: Evolution of Understanding. In Carbonate Sedimentation and Diagenesis in the Evolving Precambrian World (eds. J. P. Grotzinger and N. P. James). SEPM Society for Sedimentary Geology.

Halevy I. and Bachan A. (2017) The geologic history of seawater pH. Science 355, 1069-1071.

Halevy I. and Schrag D. P. (2009) Sulfur dioxide inhibits calcium carbonate precipitation: Implications for early Mars and Earth. Geophys. Res. Lett. 36, L23201.

Harrison A. G. and Thode H. G. (1958) Mechanism of the bacterial reduction of sulphate from isotope fractionation studies. Trans. Faraday Soc. 54, 84.

Higgins J. A., Fischer W. W. and Schrag D. P. (2009) Oxygenation of the ocean and sediments: Consequences for the seafloor carbonate factory. Earth Planet. Sci. Lett. 284, 25-33.

Horita J., Zimmermann H. and Holland H. D. (2002) Chemical evolution of seawater during the Phanerozoic. Geochim. Cosmochim. Acta 66, 3733-3756.

Hurtgen M. T., Arthur M. A., Suits N. S. and Kaufman A. J. (2002) The sulfur isotopic composition of Neoproterozoic seawater sulfate: implications for a snowball Earth? Earth Planet. Sci. Lett. 203, 413-429.

Jiménez-López C., Romanek C. S., Huertas F. J., Ohmoto H. and Caballero E. (2004) Oxygen isotope fractionation in synthetic magnesian calcite. Geochim. Cosmochim. Acta 68, 3367-3377.

Kai A., Fujikawa K. and Miki T. (2002) Vaterite Stabilization in $\mathrm{CaCO}_{3}$ Crystal Growth by Amino 
Acid. Jpn. J. Appl. Phys. 41, 439-444.

Kampschulte A., Bruckschen P. and Strauss H. (2001) The sulphur isotopic composition of trace sulphates in Carboniferous brachiopods: implications for coeval seawater, correlation with other geochemical cycles and isotope stratigraphy. Chem. Geol. 175, 149-173.

Kampschulte A. and Strauss H. (2004) The sulfur isotopic evolution of Phanerozoic seawater based on the analysis of structurally substituted sulfate in carbonates. Chem. Geol. 204, 255-286.

Kato T., Suzuki T., Amamiya T., Irie T., Komiyama M. and Yui H. (1998) Effects of macromolecules on the crystallization of $\mathrm{CaCO}_{3}$ the Formation of Organic/Inorganic Composites. Supramol. Sci. 5, 411-415.

Kim S.-T., O’Neil J. R., Hillaire-Marcel C. and Mucci A. (2007) Oxygen isotope fractionation between synthetic aragonite and water: Influence of temperature and $\mathrm{Mg}^{2+}$ concentration. Geochim. Cosmochim. Acta 71, 4704-4715.

Kitano Y. (1962) The Behavior of Various Inorganic Ions in the Separation of Calcium Carbonate from a Bicarbonate Solution. Bull. Chem. Soc. Jpn. 35, 1973-1980.

Kitano Y., Okumura M. and Idogaki M. (1975) Incorporation of sodium, chloride and sulfate with calcium carbonate. Geochem. J 9, 75-84.

Kontoyannis C. G. and Vagenas N. V. (2000) Calcium carbonate phase analysis using XRD and FTRaman spectroscopy. Analyst 125, 251-255.

Kontrec J., Kralj D., Brečević L., Falini G., Fermani S., Noethig-Laslo V. and Mirosavljević K. (2004) Incorporation of Inorganic Anions in Calcite. Eur. J. Inorg. Chem. 2004, 4579-4585.

Lemarchand D., Wasserburg G. J. and Papanastassiou D. A. (2004) Rate-controlled calcium isotope fractionation in synthetic calcite. Geochim. Cosmochim. Acta 68, 4665-4678.

Lyons T. W., Walter L. M., Gellatly A. M., Martini A. M. and Blake R. E. (2004) Sites of anomalous organic remineralization in the carbonate sediments of South Florida, USA: The sulfur cycle and carbonate-associated sulfate. In Geological Society of America Special Papers Geological Society of America. pp. 161-176.

Matschei T., Lothenbach B. and Glasser F. P. (2007) Thermodynamic properties of Portland cement hydrates in the system $\mathrm{CaO}-\mathrm{Al}_{2} \mathrm{O}_{3}-\mathrm{SiO}_{2}-\mathrm{CaSO}_{4}-\mathrm{CaCO}_{3}-\mathrm{H}_{2} \mathrm{O}$. Cem. Concr. Res. 37, 1379-1410.

McConnaughey T. (1989a) ${ }^{13} \mathrm{C}$ and ${ }^{18} \mathrm{O}$ isotopic disequilibrium in biological carbonates: I. Patterns. Geochim. Cosmochim. Acta 53, 151-162.

McConnaughey T. (1989b) ${ }^{13} \mathrm{C}$ and ${ }^{18} \mathrm{O}$ isotopic disequilibrium in biological carbonates: II. In vitro simulation of kinetic isotope effects. Geochim. Cosmochim. Acta 53, 151-162.

McIntire W. L. (1963) Trace element partition coefficients-a review of theory and applications to geology. Geochim. Cosmochim. Acta 27, 1209-1264.

Moore C. H. and Wade W. J. (2013) Carbonate reservoirs : porosity and diagenesis in a sequence stratigraphic framework., Elsevier Science.

Nakahara Y., Tazawa T. and Miyata K. (1976) Properties of Calcium Carbonate Prepared by Interfacial Reaction Method. Nippon Kagaku Kaishi 1976, 732-736.

Nielsen M. H., Aloni S. and De Yoreo J. J. (2014) In situ TEM imaging of $\mathrm{CaCO}_{3}$ nucleation reveals coexistence of direct and indirect pathways. Science 345, 1158 LP - 1162.

Nielsen M. R., Sand K. K., Rodriguez-Blanco J. D., Bovet N., Generosi J., Dalby K. N. and Stipp S. L. S. (2016) Inhibition of Calcite Growth: Combined Effects of $\mathrm{Mg}^{2+}$ and $\mathrm{SO}_{4}^{2-}$. Cryst. Growth Des. 16, 6199-6207.

Otake T., Lasaga A. C. and Ohmoto H. (2008) Ab initio calculations for equilibrium fractionations in multiple sulfur isotope systems. Chem. Geol. 249, 357-376.

Paris G., Fehrenbacher J. S., Sessions A. L., Spero H. J. and Adkins J. F. (2014) Experimental determination of carbonate-associated sulfate $\delta^{34} \mathrm{~S}$ in planktonic foraminifera shells. Geochemistry, Geophys. Geosystems 15, 1452-1461.

Paris G., Sessions A. L., Subhas A. V. and Adkins J. F. (2013) MC-ICP-MS measurement of $\delta^{34}$ S and $\Delta^{33} \mathrm{~S}$ in small amounts of dissolved sulfate. Chem. Geol. 345, 50-61.

Parkhurst D. and Appelo C. A. J. (2013) PHREEQC (Version 3)-A computer program for speciation, 
batch-reaction, one-dimensional transport, and inverse geochemical calculations. US Geol. Surv. Unites States.

Paytan A., Kastner M., Campbell D. and Thiemens M. H. (2004) Seawater sulfur isotope fluctuations in the Cretaceous. Science 304, 1663-5.

Perrin J., Rivard C., Vielzeuf D., Laporte D., Fonquernie C., Ricolleau A., Cotte M. and Floquet N. (2017) The coordination of sulfur in synthetic and biogenic Mg calcites: The red coral case. Geochim. Cosmochim. Acta 197, 226-244.

Pin S., Huthwelker T., Brown M. A. and Vogel F. (2013) Combined Sulfur K-Edge XANES-EXAFS Study of the Effect of Protonation on the Sulfate Tetrahedron in Solids and Solutions. J. Phys. Chem. A 117, 8368-8376.

Pingitore N. E., Meitzner G. and Love K. M. (1995) Identification of sulfate in natural carbonates by xray absorption spectroscopy. Geochim. Cosmochim. Acta 59, 2477-2483.

Politi Y., Levi-Kalisman Y., Raz S., Wilt F., Addadi L., Weiner S. and Sagi I. (2006) Structural Characterization of the Transient Amorphous Calcium Carbonate Precursor Phase in Sea Urchin Embryos. Adv. Funct. Mater. 16, 1289-1298.

Present T. M., Paris G., Burke A., Fischer W. W. and Adkins J. F. (2015) Large Carbonate Associated Sulfate isotopic variability between brachiopods, micrite, and other sedimentary components in Late Ordovician strata. Earth Planet. Sci. Lett. 432, 187-198.

Raab M. and Spiro B. (1991) Sulfur isotopic variations during seawater evaporation with fractional crystallization. Chem. Geol. Isot. Geosci. Sect. 86, 323-333.

Raz S., Hamilton P. C., Wilt F. H., Weiner S. and Addadi L. (2003) The Transient Phase of Amorphous Calcium Carbonate in Sea Urchin Larval Spicules: The Involvement of Proteins and Magnesium Ions in Its Formation and Stabilization. Adv. Funct. Mater. 13, 480-486.

Reeder R. J., Lamble G. M., Lee J.-F. and Staudt W. J. (1994) Mechanism of $\mathrm{SeO}_{4}{ }^{2-}$ substitution in calcite: An XAFS study. Geochim. Cosmochim. Acta 58, 5639-5646.

Rennie V. C. F., Paris G., Sessions A. L., Abramovich S., Turchyn A. V. and Adkins J. F. (2018) Cenozoic record of $\delta^{34} \mathrm{~S}$ in foraminiferal calcite implies an early Eocene shift to deep-ocean sulfide burial. Nat. Geosci. 11, 761-765.

Rennie V. C. F. and Turchyn A. V. (2014) The preservation of and in carbonate-associated sulfate during marine diagenesis: A 25 Myr test case using marine sediments. Earth Planet. Sci. Lett. 395, 13-23.

Ruiz-Agudo E., Kowacz M., Putnis C. V. and Putnis A. (2010) The role of background electrolytes on the kinetics and mechanism of calcite dissolution. Geochim. Cosmochim. Acta 74, 1256-1267.

Ruiz-Agudo E., Putnis C. V, Jiménez-López C. and Rodriguez-Navarro C. (2009) An atomic force microscopy study of calcite dissolution in saline solutions: The role of magnesium ions. Geochim. Cosmochim. Acta 73, 3201-3217.

Ruzi M. (2016) Voigt line shape fit. MATLAB Cent. File Exch.

Schrag D. P., Higgins J. A., Macdonald F. A. and Johnston D. T. (2013) Authigenic carbonate and the history of the global carbon cycle. Science 339, 540-3.

Staudt W. J., Reeder R. J. and Schoonen M. A. A. (1994) Surface structural controls on compositional zoning of $\mathrm{SO}_{4}{ }^{2-}$ and $\mathrm{SeO}_{4}{ }^{2-}$ in synthetic calcite single crystals. Geochim. Cosmochim. Acta 58, 2087-2098.

Staudt W. J. and Schoonen M. A. A. (1995) Sulfate Incorporation into Sedimentary Carbonates. Geochemical Transform. Sediment. Sulfur 612, 332-345.

Stumm W. and Morgan J. J. (1996) Aquatic chemistry : chemical equilibria and rates in natural waters., Wiley.

Sumner D. Y. and Grotzinger J. P. (2000) Late Archean Aragonite Precipitation: Petrography, Facies Associations, and Environmental Significance.

Sun W., Jayaraman S., Chen W., Persson K. A. and Ceder G. (2015) Nucleation of metastable aragonite $\mathrm{CaCO}_{3}$ in seawater. Proc. Natl. Acad. Sci. U. S. A. 112, 3199-204.

Sun X. and Turchyn A. V. (2014) Significant contribution of authigenic carbonate to marine carbon 
burial. Nat. Geosci. 7, 201-204.

Takano B. (1985) Geochemical implications of sulfate in sedimentary carbonates. Chem. Geol. 49, 393-403.

Takano B., Asano Y. and Watanuki K. (1980) Characterization of sulfate ion in travertine. Contrib. to Mineral. Petrol. 72, 197-203.

Tambutté S., Holcomb M., Ferrier-Pagès C., Reynaud S., Tambutté É., Zoccola D. and Allemand D. (2011) Coral biomineralization: From the gene to the environment. J. Exp. Mar. Bio. Ecol. 408, $58-78$.

Tamenori Y., Yoshimura T., Luan N. T., Hasegawa H., Suzuki A., Kawahata H. and Iwasaki N. (2014) Identification of the chemical form of sulfur compounds in the Japanese pink coral (Corallium elatius) skeleton using $\mu$-XRF/XAS speciation mapping. J. Struct. Biol. 186, 214-23.

Tang J., Köhler S. J. and Dietzel M. (2008) $\mathrm{Sr}^{2+} / \mathrm{Ca}^{2+}$ and ${ }^{44} \mathrm{Ca} /{ }^{40} \mathrm{Ca}$ fractionation during inorganic calcite formation: I. Sr incorporation. Geochim. Cosmochim. Acta 72, 3718-3732.

Tarutani T., Clayton R. N. and Mayeda T. K. (1969) The effect of polymorphism and magnesium substitution on oxygen isotope fractionation between calcium carbonate and water. Geochim. Cosmochim. Acta 33, 987-996.

Thode H. ., Monster J. and Dunford H. . (1961) Sulphur isotope geochemistry. Geochim. Cosmochim. Acta 25, 159-174.

Thode H. G. and Monster J. (1965) Sulfur-isotope geochemistry of petroleum, evaporites, and ancient seas. In Fluids in Subsurface Environments AAPG Special Volumes. pp. 367-377.

Thode H. G., Shima M., Rees C. E. and Krishnamurty K. V. (1965) Carbon-13 Isotope Effects in Systems Containing Carbon Dioxide, Bicarbonate, Carbonate, and Metal Ions. Can. J. Chem. 43, $582-595$.

Trong Nguyen L., Rahman M. A., Maki T., Tamenori Y., Yoshimura T., Suzuki A., Iwasaki N. and Hasegawa H. (2014) Distribution of trace element in Japanese red coral Paracorallium japonicum by $\mu$-XRF and sulfur speciation by XANES: Linkage between trace element distribution and growth ring formation. Geochim. Cosmochim. Acta 127, 1-9.

Trower E. J., Cantine M. D., Gomes M. L., Grotzinger J. P., Knoll A. H., Lamb M. P., Lingappa U., O’Reilly S. S., Present T. M., Stein N., Strauss J. V. and Fischer W. W. (2018) Active Ooid Growth Driven By Sediment Transport in a High-Energy Shoal, Little Ambergris Cay, Turks and Caicos Islands. J. Sediment. Res. 88, 1132-1151.

Vavouraki A. I., Putnis C. V., Putnis A. and Koutsoukos P. G. (2008) An Atomic Force Microscopy study of the growth of calcite in the presence of sodium sulfate. Chem. Geol. 253, 243-251.

Vielzeuf D., Garrabou J., Gagnon A., Ricolleau A., Adkins J., Günther D., Hametner K., Devidal J.-L., Reusser E., Perrin J. and Floquet N. (2013) Distribution of sulphur and magnesium in the red coral. Chem. Geol. 355, 13-27.

Walker J. M., Marzec B. and Nudelman F. (2017) Solid-State Transformation of Amorphous Calcium Carbonate to Aragonite Captured by CryoTEM. Angew. Chemie Int. Ed. 56, 11740-11743.

Walter L. M., Bischof S. A., Patterson W. P., Lyons T. W., O’Nions R. K., Gruszczynski M., Sellwood B. W. and Coleman M. L. (1993) Dissolution and recrystallization in modern shelf carbonates: evidence from pore water and solid phase chemistry. Philos. Trans. R. Soc. London. Ser. A Phys. Eng. Sci. 344, 27-36.

Wang W., Qin T., Zhou C., Huang S., Wu Z. and Huang F. (2017) Concentration effect on equilibrium fractionation of $\mathrm{Mg}-\mathrm{Ca}$ isotopes in carbonate minerals: Insights from first-principles calculations. Geochim. Cosmochim. Acta 208, 185-197.

Watkins J. M., Nielsen L. C., Ryerson F. J. and DePaolo D. J. (2013) The influence of kinetics on the oxygen isotope composition of calcium carbonate. Earth Planet. Sci. Lett. 375, 349-360.

Webb S. M. (2005) SIXPack a Graphical User Interface for XAS Analysis Using IFEFFIT. Phys. Scr. 2005, 1011.

Wefer G. and Berger W. H. (1991) Isotope paleontology: growth and composition of extant calcareous species. Mar. Geol. 100, 207-248.

Wotte T., Shields-Zhou G. a. and Strauss H. (2012) Carbonate-associated sulfate: Experimental 
comparisons of common extraction methods and recommendations toward a standard analytical protocol. Chem. Geol. 326-327, 132-144.

De Yoreo J. J., Zepeda-Ruiz L. A., Friddle R. W., Qiu S. R., Wasylenki L. E., Chernov A. A., Gilmer G. H. and Dove P. M. (2009) Rethinking classical crystal growth models through molecular scale insights: Consequences of kink-limited kinetics. Cryst. Growth Des. 9, 5135-5144.

Yoshimura T., Tamenori Y., Suzuki A., Nakashima R., Iwasaki N., Hasegawa H. and Kawahata H. (2013) Element profile and chemical environment of sulfur in a giant clam shell: Insights from $\mu$ XRF and X-ray absorption near-edge structure. Chem. Geol. 352, 170-175.

Zeebe R. E. and Wolf-Gladrow D. A. (2001) $\mathrm{CO}_{2}$ in seawater: equilibrium, kinetics, isotopes. ed. D. Halpern, Elsevier. 


\section{Appendix I}

\subsection{Constant addition}

The constant addition experiments consisted of two main steps: I. reaching a steady state, and II. precipitation at a stable rate and headspace $\mathrm{pCO}_{2}$ (Figure A1). In step I, $50 \mathrm{~mL}$ each of the $\mathrm{Ca}^{2+}$ and DIC solutions was added. In step II, $200 \mathrm{~mL}$ of each of these solutions was added, for a total accumulation of $500 \mathrm{~mL}$ of solution in steps I and II. The conditions of the constant addition experiments are in Table A1. During solution injection, the solutions were held under a constant flow of compressed air to reduce accumulation in the headspace of $\mathrm{CO}_{2}$ released during $\mathrm{CaCO}_{3}$ precipitation. The compressed air cylinders contained between 370 and $630 \mathrm{ppm}$ $\mathrm{CO}_{2}$, and the air was pre-moistened via a dual gas dispersion tube (GDT) system with deionized water $(18.2 \mathrm{M} \Omega \mathrm{cm})$ to avoid loss of water vapor from the reaction vessel. In both steps I and II, two solutions were used: i) a $\mathrm{Ca}^{2+}$ stock solution with $0.2 \mathrm{~mol} / \mathrm{kg} \mathrm{CaCl}_{2} \times 2 \mathrm{H}_{2} \mathrm{O}(99 \% \mathrm{ACS}$, Sigma Aldrich), $1 \mathrm{mmol} / \mathrm{kg} \mathrm{Na}_{2} \mathrm{SO}_{4}(99.9955 \%$, Alfa Aesar) and $0.169 \mathrm{~mol} / \mathrm{kg} \mathrm{NaCl}$ (ACS, J.T.Baker), and ii), a DIC stock solution to which $0.1 \mathrm{~mol} / \mathrm{kg} \mathrm{NaHCO}_{3}$ (99.7, ACS, Sigma Aldrich) was added along with $1 \mathrm{mmol} / \mathrm{kg} \mathrm{Na}_{2} \mathrm{SO}_{4}$ and $0.683 \mathrm{~mol} / \mathrm{kg} \mathrm{NaCl}$. The $\mathrm{NaCl}$ was added to achieve an ionic strength of $\sim 0.7$ in the stock solutions. According to calculation, the DIC stock solution would have to degas $65 \%$ of the DIC to reach equilibrium with the $\mathrm{pCO}_{2}$ of the compressed air, leaving 63-67 mmol/kg DIC at a pH value of 9.3-9.4 (depending on cylinder $\mathrm{pCO}_{2}$ ). To expedite degassing, $\mathrm{N}_{2}$ was bubbled via a GDT into the DIC stock solution until the target $\mathrm{pH}$ was reached, which took 2-3 days. Lyophilized carbonic anhydrase (CA) powder was added to the stock solutions to catalyze chemical equilibrium in the carbonate system. To prevent biological contamination, reaction vessels and tubing were sterilized prior to the experiments, and all solutions and gases were passed through $0.2-\mu \mathrm{m}$ filters.

Step I started upon solution injection and air flow into a $250-\mathrm{mL}$ bottle, stirred with a magnetic stir bar, at room temperature. $\mathrm{pH}$ was measured periodically. Precipitation commenced upon mixing of the two stock solutions, and when $\mathrm{pH}$ values stabilized and a mixed solution volume of more than $100 \mathrm{~mL}$ was accumulated, the mixed solution was quickly filtered. Step II started when $100 \mathrm{~mL}$ of filtrate was poured into the main $500-\mathrm{mL}$ double-jacketed temperaturecontrolled glass reactor, which contained 100 or $200 \mathrm{mg}$ of calcite nucleation seeds. In step II, solution injection and airflow rates remained unchanged from step I, but an overhead Teflon stirring rod at 400 RPM replaced the magnetic stir bar, the jacketed reactor replaced the 250$\mathrm{mL}$ bottle, and a temperature of $25.0 \pm 0.1^{\circ} \mathrm{C}$ was maintained. The precipitation rates $(J)$ during the experiments were $10^{-7.5}, 10^{-6.8}, 10^{-6.2}, 10^{-5.3}$ and $10^{-4.3} \mathrm{~mol} / \mathrm{m}^{2} / \mathrm{s}$ and will be expressed hereafter as the logarithm of $J$ for simplification.

The remaining $200 \mathrm{~mL}$ of both DIC and $\mathrm{Ca}^{2+}$ solutions were added dropwise via 1/8" PTFE tubing into the mixed solution at a rate of 5 to $5000 \mu \mathrm{L} / \mathrm{min}$ using an Atlas Syringe Pump (Syrris), in dual dose mode or in continuous mode (for $\log (J)=-4.3$ experiments only). Addition of $200 \mathrm{~mL}$ of the DIC and $\mathrm{Ca}^{2+}$ solutions resulted in precipitation of $\sim 900 \mathrm{mg}$ of calcite. The moistened air was introduced into either the headspace or the solution via a GDT at rates of 23 to 1,000 standard cubic centimeters per minute (SCCM), controlled by a mass flow controller (Alicat Scientific), and forming $\sim 1 \mathrm{~mm}$ bubbles when the GDT was submerged. Variations of up to $0.15 \mathrm{pH}$ units were measured in all experiments, and are considered acceptable for the purposes of these experiments. Larger and short-lived $\mathrm{pH}$ changes occurred at the onset of step II, in the fastest precipitating experiments, CCK and CCL, where variation of $0.4 \mathrm{pH}$ units over 10 minutes and $0.75 \mathrm{pH}$ units over 100 minutes, respectively, were observed. However, these changes were short enough relative to the duration of the experiments, that the $\mathrm{pH}$ standard deviation throughout the experiment duration did not exceed 0.2 units $(1 \sigma)$. 
Upon completion of step II, solids were filtered out of the solution through a $0.2-\mu \mathrm{m}$ nylon filter, washed with deionized water, and left overnight in a vacuum oven at $60^{\circ} \mathrm{C}$ and $700 \mathrm{mmHg}$ to dry. The mass of the solids precipitated was evaluated gravimetrically by the difference in filter mass with and without the precipitates.

\section{$6.2 \mathrm{CO}_{2}$ degassing}

The $\mathrm{CO}_{2}$ degassing experiments consisted of three main steps: I. acidification (to dissolve the calcite reagent), II. undersaturated diffusive loss of $\mathrm{CO}_{2}$, III. saturated diffusive loss of $\mathrm{CO}_{2}$ and precipitation of $\mathrm{CaCO}_{3}$ (Figure 4). The conditions of the $\mathrm{CO}_{2}$ degassing experiments are in Table A2.

In step I (Figure 4) a calcite reagent (99.997\%, Alfa Aesar) was dissolved in a 2-liter solution of deionized water with $\mathrm{Na}_{2} \mathrm{SO}_{4}\left(99.9955 \%\right.$, Alfa Aesar) and $\mathrm{MgCl}_{2} \times 6 \mathrm{H}_{2} \mathrm{O}$ (ACS grade, Sigma Aldrich). One bottle with pure deionized water was used as a control. Dissolution was achieved by three cycles of evacuation of the contents of the $\mathrm{GB}$, and replacement by cylinder $\mathrm{CO}_{2}$ $(95.7 \%)$ at near-atmospheric pressure. The open solutions in the GB were continuously stirred on a multi-point magnetic stirring plate. Subsequent to atmosphere replacement, a constant $\mathrm{CO}_{2}$ flow was maintained to assure a constant $\mathrm{pCO}_{2}$. Acidification of the solution due to the increased $\mathrm{pCO}_{2}$ led to the dissolution of the $\mathrm{CaCO}_{3}$ solid in the following net reaction:

$$
\mathrm{CO}_{2}(\mathrm{~g})+\mathrm{CaCO}_{3}+\mathrm{H}_{2} \mathrm{O} \rightarrow \mathrm{Ca}^{2+}+2 \mathrm{HCO}_{3}^{-} .
$$

Step I was considered complete when no $\mathrm{CaCO}_{3}$ was visible in the most $\mathrm{CaCO}_{3}$-rich solution and the target $\mathrm{pH}$ was reached and remained stable. This step took $\sim 1$ day, and an extra day was taken to assure full dissolution. In step II (Figure 4) small threads in the GB with a total area of $3.5 \mathrm{~cm}^{2}$ were opened, to allow diffusive exchange with the ambient atmosphere (with 400-700 ppm $\mathrm{CO}_{2}$ ). As $\mathrm{pCO}_{2}$ decreased, the $\mathrm{pH}$ increased, until the concentration of $\mathrm{CO}_{3}{ }^{2-}$ was high enough to reach calcite or aragonite saturation at $\mathrm{pH}_{\text {sat. }}$ Step III started when a further decrease in $\mathrm{pCO}_{2}$ increased $\mathrm{pH}$ (to above $\mathrm{pH}_{\text {sat }}$ ) and the degree of saturation increased enough to lead to nucleation. Precipitates then formed both in solution and on the 2-liter glass bottle walls. When the $\mathrm{pH}$ of the deionized water in the control bottle and in the other solutions remained static for a day or so (i.e., $\mathrm{GB} \mathrm{CO}_{2}$ reached equilibrium with the atmosphere), the experiment was terminated and the GB was opened. Upon completion of step III, solids were filtered out of solution through a $0.2-\mu \mathrm{m}$ nylon filter, after the bottles were sonicated to remove solids from the bottle walls to maximize yield. The filtrate was washed with deionized water and then with ethanol, and left overnight in a $60^{\circ} \mathrm{C}$ oven. The mass of the solids precipitated was evaluated gravimetrically by the difference in filter mass with and without precipitates, except for cases in which the filter became clogged and was replaced by one or more additional filters (see dashes in column ' $\mathrm{m}_{\mathrm{tot}}$ ' of Table A2).

The two main variables in this experimental set were the concentrations of $\mathrm{Na}_{2} \mathrm{SO}_{4}$ and the $\mathrm{CaCO}_{3}$ mineralogy. Some aragonite precipitates alongside calcite in solutions with $\mathrm{Mg}^{2+} / \mathrm{Ca}^{2+}$ greater than 2 (e.g., Bots et al., 2011). To ensure the precipitation of a pure aragonite phase and to mimic the $\mathrm{Mg}^{2+} / \mathrm{Ca}^{2+}$ of the modern ocean (5.2), we chose a $\mathrm{Mg}^{2+} / \mathrm{Ca}^{2+}$ of 5 for the experiments. The $a \mathrm{Ca}^{2+} / a \mathrm{CO}_{3}{ }^{2-}$ ratio, which was controlled by the initial mass of dissolved $\mathrm{CaCO}_{3}$ reagent, was $\sim 950$ in all of the calcite-forming solutions and $\sim 470$ in all of the aragoniteforming solutions. Activity ratios refer to the fully dissolved $\mathrm{CaCO}_{3}$ at the maximal $\mathrm{pCO}_{2}$ reached, as modeled by PHREEQC. The concentrations of $\mathrm{Na}_{2} \mathrm{SO}_{4}$ in the calcite-forming solutions were $0.03,0.1,0.3,1,3$ and $8 \mathrm{mM}$, with the upper sulfate concentration chosen as the expected threshold that still led to calcite (rather than aragonite) precipitation. The concentrations of $\mathrm{Na}_{2} \mathrm{SO}_{4}$ in the aragonite-forming solutions were $0.1,0.3,1,3,10$ and $30 \mathrm{mM}$. 
The progress of the experiments was monitored by measuring $\mathrm{pH}$ directly in the precipitating solution with the highest initial amount of $\mathrm{CaCO}_{3}$, and in the control bottle with deionized water to monitor $\mathrm{pCO}_{2}$ indirectly, because a $\mathrm{pCO}_{2}$ range of 4 orders of magnitude is difficult to accurately measure directly by one method. The duration of the diffusive loss steps (II+III) was designed to be $1-2$ weeks, resulting in a $\log (J)$ of about $-5.9 \mathrm{~mol} / \mathrm{m}^{2} / \mathrm{s}$ on average. As the $\mathrm{pCO}_{2}$ within the GB decays exponentially, and due to non-linearity in the dissolved inorganic carbon system, $J, a \mathrm{Ca}^{2+}, a \mathrm{CO}_{3}{ }^{2-}$ and other chemical parameters changed throughout the experiment duration, and were retrieved from the measured quantities ( $\mathrm{pH}$ in the precipitating solution and $\mathrm{pCO}_{2}$ calculated from the $\mathrm{pH}$ measured in the deionized water) by geochemical modeling (Section 6.4).

\section{$6.3 \mathrm{pH}$ measurements}

A combination of 2 types of $\mathrm{pH}$ electrode and 2 types of $\mathrm{pH}$ meter were used in the 3 experimental methods. In all but the $\mathrm{CO}_{2}$ degassing experiments, where a Syrris $\mathrm{pH}$ probe was used for the deionized water measurment, an InLab® 413SG electrode (Mettler-Toledo) was used. A combination of the SevenGo2 meter (Mettler-Toledo) and the built-in pH meter in an Atlas Syringe Pump (Syrris) was used both experiments. Repeated calibration and measurement with each electrode gave practical accuracy and precision of $0.02 \mathrm{pH}$ units for the InLab® 413SG, and an accuracy of 0.1 and a precision of $0.02 \mathrm{pH}$ units for the Syrris $\mathrm{pH}$ electrode. The choice of $\mathrm{pH}$ meter had no appreciable effect on accuracy or precision. The calibration was done either against disposable buffer sachets (Mettler-Toledo) at $\mathrm{pH} 4.00,7.00$ and 10.01, or against buffer solutions (Fluka) at $\mathrm{pH}$ 4.0, 7.0 and 9.0. The Atlas Syringe Pump failed on rare occasions, leading to loss of some logged $\mathrm{pH}$ data.

\subsection{Calculation of precipitation rates and geochemical parameters}

Precipitation rates were calculated as the moles precipitated per surface area available per second $\left(\mathrm{mole} / \mathrm{m}^{2} / \mathrm{s}\right)$. In the constant addition experiments, the precipitation rate is determined by the surface area of nucleation seeds added, the rate of delivery of the stock solutions and the response of the solution chemistry. We calculate an average precipitation rate using the measured mass of seeds ( $m_{\text {seed }}$ converted to moles using the molar mass $\left.M_{w}\right)$, the measured seed material specific surface area $(S S A)$, the gravimetrically measured mass of total solid $\left(m_{t o t}\right.$ converted to moles using the molar mass) and the experiment duration $(t)$ is:

$$
J_{\text {Cons. Add. }}=\frac{\left(m_{\text {tot }}-m_{\text {seed }}\right)}{t \times M_{w} \times m_{\text {seed }} \times S S A},
$$

where the SSA of the 100-200 mg of nucleation seeds was measured on a NOVA 2000e BET surface area analyzer (Quantachrome) using $\mathrm{N}_{2}$ gas. The calcite samples were first placed under vacuum and heated to $60^{\circ} \mathrm{C}$ and yielded a $S S A$ of $0.60 \pm 0.01 \mathrm{~m}^{2} / \mathrm{g}(\mathrm{n}=8)$. Processes such as nucleation of new particles, a change in the morphology of the crystals or roughening of the crystal surface could increase the surface area and decrease the per-area precipitation rate. Calculations accounting for such a change in the surface area are expected to yield lower rates than those in which the surface area is held constant (as in this study), and so the $J$ values we report for the constant addition experiments should be treated as upper limits on the precipitation rates.

Parameters of the $\mathrm{CO}_{2}$ degassing experimental system, including the $\mathrm{pH}$, ion concentrations and precipitation rates, change over the course of an experiment, as $\mathrm{pCO}_{2}$ decreases. To account for these changes, and allow for calculation of mass-weighted average precipitation rates and other parameters (e.g., $a \mathrm{SO}_{4}{ }^{2-} / a \mathrm{CO}_{3}{ }^{2-}$ ), we calculated the ion concentrations through time, using the $\mathrm{pH}$ measurements as constraints. In order to describe the state of the carbonate system, one needs at least 2 parameters out of $6\left(\mathrm{pCO}_{2}, \mathrm{CO}_{2}(\mathrm{aq}), \mathrm{HCO}_{3}{ }^{-}, \mathrm{CO}_{3}{ }^{2-}, \mathrm{pH}, \mathrm{A}_{\mathrm{T}}\right)$; (Stumm and Morgan, 1996). In the case of deionized water under a $\mathrm{CO}_{2}$ atmosphere, $\mathrm{A}_{\mathrm{T}}=0$, and it is possible to calculate $\mathrm{pCO}_{2}(\mathrm{t})$ in the $\mathrm{GB}$ from $\mathrm{pH}(\mathrm{t})$ measurements, under an assumption of chemical 
equilibrium. This value of $\mathrm{pCO}_{2}(\mathrm{t})$, which is common to all solutions open to the GB atmosphere, along with the $\mathrm{pH}(\mathrm{t})$ measured in the solutions, allows a complete description of the state of the carbonate system (i.e., DIC speciation).

Thermodynamic calculations were carried out using the PHREEQC interactive V3.3.3 software (Parkhurst and Appelo, 2013), with the default database. The pH measurements in deionized water and in two of the 24 precipitating solutions (8KCL2, 30KAR1) were used to calculate the time-dependent $\mathrm{pCO}_{2}$ in the GB. The $\mathrm{pCO}_{2}$ time series was used as input to PHREEQC calculations of time-dependent $\mathrm{pH}$ values, ion activities, $\mathrm{CaCO}_{3}$ saturation, and precipitation rates (moles/s) in the 22 solutions for which we did not have $\mathrm{pH}$ measurements. This approach assumes equilibrium between the dissolved inorganic carbon in the solutions and the $\mathrm{CO}_{2}$ in the GB atmosphere, which is a reasonable approximation of reality, given the slow rate of decrease in $\mathrm{pCO}_{2}$ and the long duration of the $\mathrm{CO}_{2}$ degassing experiments.

To calculate per-area precipitation rates, and allow comparison between the results of the constant addition and $\mathrm{CO}_{2}$ degassing experiments, we approximated the $\mathrm{SSA}$ of $\mathrm{CaCO}_{3}$ precipitated in the $\mathrm{CO}_{2}$ degassing experiments as constant at a value of $0.27 \mathrm{~m}^{2} / \mathrm{g}$, following observations of stabilization of $S S A$ at $0.27 \pm 0.05 \mathrm{~m}^{2} / \mathrm{g}$ in long (> 30 hours) nucleation and precipitation experiments (Tang et al., 2008). The mass-weighted average precipitation rate is then:

$$
J_{C O_{2} \text { Degas. }}=\sum_{i=0}^{n}\left(\frac{\Delta m_{i}}{m_{\text {tot }}} \times \frac{\Delta m_{i}}{\Delta t_{i} \times M_{w} \times S S A \times \sum_{j=0}^{i} \Delta m_{j}}\right),
$$

where $m_{t o t}$ (moles) is the total amount of $\mathrm{CaCO}_{3}$ precipitated, $M_{w}(\mathrm{~g} / \mathrm{mole})$ is the molar weight of $\mathrm{CaCO}_{3}$, and $\Delta m_{i}$ (moles) and $\Delta t_{i}$ (seconds) are the mass of $\mathrm{CaCO}_{3}$ precipitated in time interval $i$, and the duration of time interval $i$, respectively.

In the constant addition experiments $a \mathrm{SO}_{4}{ }^{2-} / a \mathrm{CO}_{3}{ }^{2-}$ was constant, and retrieved from PHREEQC simulations of the experimental solutions. In the $\mathrm{CO}_{2}$ degassing experiments $a \mathrm{SO}_{4}{ }^{2-}$ $/ a \mathrm{CO}_{3}{ }^{2-}$ varied over the experiment, and was calculated as a mass-weighted average, similar to the precipitation rate:

$$
a \mathrm{SO}_{4}^{2-} / a \mathrm{CO}_{3}^{2-} \mathrm{CO}_{2} \text { Degas. }=\sum_{i=0}^{n}\left(\frac{\Delta m_{i}}{m_{\text {tot }}} \times a \mathrm{SO}_{4}^{2-} / a \mathrm{CO}_{3}^{2-}{ }_{i}\right) .
$$

The precipitation rates and $a \mathrm{SO}_{4}{ }^{2-} / a \mathrm{CO}_{3}{ }^{2-}$ in the $\mathrm{CO}_{2}$ degassing experiments are given in Table $\mathrm{A} 2$, including a conservative estimate of uncertainty in their values. This estimate accounts for uncertainty in the $\mathrm{pH}$ measurements and small disagreements between the $\mathrm{pCO}_{2}$ calculated from $\mathrm{pH}$ measurements in the precipitating solutions (8KCL2, 30KAR1) and the deionized water. 
Table A1 - Experimental conditions for the constant addition experiments.

\begin{tabular}{|c|c|c|c|c|c|c|c|c|c|c|}
\hline \multirow[t]{2}{*}{ Name } & \multicolumn{3}{|c|}{ Solution } & \multicolumn{2}{|c|}{ Air } & \multicolumn{3}{|c|}{$\mathrm{CaCO}_{3}$} & \multirow{2}{*}{$\begin{array}{c}\text { Time } \\
\\
\text { (hours) }\end{array}$} & \multirow{2}{*}{$\begin{array}{c}\log (J) \\
\left(\mathrm{mole} / \mathrm{m}^{2} / \mathrm{s}\right)\end{array}$} \\
\hline & $\begin{array}{c}\text { Flow } \\
(\mu \mathrm{L} / \mathrm{min})\end{array}$ & $\mathrm{pH}$ & $\frac{a \mathrm{SO}_{4}^{2-}}{a \mathrm{CO}_{3}^{2-}}$ & $\begin{array}{c}\text { Flow } \\
\text { (SCCM) }\end{array}$ & $\begin{array}{l}\mathrm{pCO}_{2} \\
(\mathrm{ppmv})\end{array}$ & $\begin{array}{l}\mathrm{m}_{\text {seed }} \\
(\mathrm{mg})\end{array}$ & $\begin{array}{l}\mathrm{m}_{\mathrm{tot}} \\
(\mathrm{mg})\end{array}$ & $\begin{array}{c}\text { cal|arg|vat } \\
(\%)\end{array}$ & & \\
\hline СCHA & 4.7 & $7.30 \pm 0.02$ & $525_{-26}^{+27}$ & $23^{\mathrm{d}}$ & 607.1 & 200 & 903 & $99|0| 1$ & 709 & $-7.53 \pm 0.01$ \\
\hline ССНB & 4.7 & $7.30 \pm 0.16$ & $523_{-156}^{+225}$ & $23^{\mathrm{d}}$ & 607.1 & 201 & 922 & $100|0| 0$ & 709 & $-7.53 \pm 0.01$ \\
\hline CCIA & 12.1 & $7.30 \pm 0.04$ & $529_{-43}^{+47}$ & $61^{\mathrm{d}}$ & 607.1 & 100 & - & $100|0| 0$ & 276 & $-6.80 \pm 0.01$ \\
\hline CCIB & 12.1 & $7.33 \pm 0.05$ & $481_{-47}^{+53}$ & $61^{\mathrm{d}}$ & 628.8 & 103 & 951 & $100|0| 0$ & 279 & $-6.82 \pm 0.01$ \\
\hline CCIC & 12.1 & $7.33 \pm 0.08$ & $483_{-74}^{+88}$ & $61^{\mathrm{d}}$ & 628.8 & 102 & 963 & $99|0| 1$ & 283 & $-6.81 \pm 0.01$ \\
\hline CCJA & 48.6 & $7.20 \pm 0.09$ & $660_{-114}^{+139}$ & $243^{\mathrm{d}}$ & 607.1 & 101 & 910 & $100|0| 0$ & 68.6 & $-6.22 \pm 0.01$ \\
\hline CCJB & 48.6 & $7.20 \pm 0.10$ & $646_{-133}^{+169}$ & $243^{\mathrm{d}}$ & 628.8 & 101 & 864 & $99|0| 0$ & 68.6 & $-6.24 \pm 0.01$ \\
\hline CCJC & 48.6 & $7.24 \pm 0.08$ & $584_{-100}^{+121}$ & $243^{d}$ & 628.8 & 101 & 897 & $100|0| 0$ & 68.6 & $-6.22 \pm 0.01$ \\
\hline CCKC & 425 & $7.54 \pm 0.07$ & $389_{-52}^{+61}$ & $500^{\mathrm{s}}$ & 371.5 & 101 & 886 & $99|0| 1$ & 7.85 & $-5.29 \pm 0.01$ \\
\hline CCKD & 425 & $7.40 \pm 0.06$ & $535_{-64}^{+73}$ & $500^{\mathrm{s}}$ & 371.5 & 100 & 825 & $99|0| 0$ & 7.87 & $-5.32 \pm 0.01$ \\
\hline CCKE & 425 & $7.58 \pm 0.05$ & $362_{-38}^{+42}$ & $500^{\mathrm{s}}$ & 371.5 & 100 & 845 & $99|0| 0$ & 7.85 & $-5.31 \pm 0.01$ \\
\hline CCLB & 4878 & $7.10 \pm 0.10$ & $1033_{-213}^{+269}$ & $1000^{\mathrm{s}}$ & 371.5 & 101 & 865 & $52|0| 48$ & 0.70 & $-4.25 \pm 0.01$ \\
\hline CCLC & 4878 & $7.22 \pm 0.19$ & $802_{-274}^{+424}$ & $1000^{\mathrm{s}}$ & 371.5 & 101 & 810 & $69|0| 31$ & 0.70 & $-4.28 \pm 0.01$ \\
\hline CCLD & 4878 & $6.97 \pm 0.06$ & $1073_{-145}^{+168}$ & $1000^{\mathrm{s}}$ & 628.8 & 100 & 756 & $65|0| 35$ & 0.68 & $-4.29 \pm 0.01$ \\
\hline
\end{tabular}

$\mathrm{Na}_{2} \mathrm{SO}_{4}$ concentration in all experiment was $1 \mathrm{mM}$.

The abbreviations cal, arg, and vat refers to percentage of calcite, aragonite and vaterite in a sample.

Superscript $\mathrm{d}$ and $\mathrm{s}$ indicate whether the gas dispersion tube was dry or submerged in solution, respectively. $a \mathrm{SO}_{4}{ }^{2-} / a \mathrm{CO}_{3}{ }^{2-}$ was calculated based on the $\mathrm{pH}$ range. 
Table A2 - Experimental conditions for the $\mathrm{CO}_{2}$ degassing experiments.

\begin{tabular}{|c|c|c|c|c|c|c|c|}
\hline Name & & Solution & & & $\mathrm{CaCO}$ & & $\log (J)$ \\
\hline & $\begin{array}{c}\mathrm{Na}_{2} \mathrm{SO}_{4} \\
(\mathrm{mM})\end{array}$ & $\mathrm{pH}$ & $\frac{a \mathrm{SO}_{4}^{2-}}{a \mathrm{CO}_{3}^{2-}}$ & $\begin{array}{c}\mathrm{m}_{\text {initial }} \\
(\mathrm{mg} / 2 \mathrm{~L})\end{array}$ & $\begin{array}{l}\mathrm{m}_{\mathrm{tot}} \\
(\mathrm{mg})\end{array}$ & $\begin{array}{c}\text { cal|arg|vat } \\
(\%)\end{array}$ & $\left(\mathrm{mole} / \mathrm{m}^{2} / \mathrm{s}\right)$ \\
\hline 30CL1 & 0.03 & $7.35_{-0.05}^{+0.05}$ & $5 \pm 2$ & 498 & 283 & $100|0| 0$ & $-5.89_{-0.21}^{+0.14}$ \\
\hline 30CL2 & 0.03 & $7.35_{-0.05}^{+0.05}$ & $5 \pm 2$ & 501 & 260 & $100|0| 0$ & $-5.89_{-0.21}^{+0.14}$ \\
\hline $100 C L 1$ & 0.1 & $7.34_{-0.05}^{+0.05}$ & $17 \pm 7$ & 505 & 249 & $100|0| 0$ & $-5.89_{-0.21}^{+0.14}$ \\
\hline $100 C L 2$ & 0.1 & $7.34_{-0.05}^{+0.05}$ & $17 \pm 7$ & 506 & 239 & $100|0| 0$ & $-5.89_{-0.21}^{+0.14}$ \\
\hline 300CL1 & 0.3 & $7.34_{-0.05}^{+0.05}$ & $51 \pm 21$ & 522 & 268 & $100|0| 0$ & $-5.91_{-0.21}^{+0.14}$ \\
\hline 300CL2 & 0.3 & $7.34_{-0.05}^{+0.05}$ & $51 \pm 21$ & 520 & 281 & $100|0| 0$ & $-5.91_{-0.21}^{+0.14}$ \\
\hline 1KCL1 & 1 & $7.32_{-0.05}^{+0.05}$ & $159 \pm 67$ & 566 & 307 & $100|0| 0$ & $-5.93_{-0.21}^{+0.14}$ \\
\hline 1KCL2 & 1 & $7.32_{-0.05}^{+0.05}$ & $159 \pm 67$ & 565 & 336 & $100|0| 0$ & $-5.93_{-0.21}^{+0.14}$ \\
\hline 3KCL1 & 3 & $7.28_{-0.05}^{+0.05}$ & $422 \pm 176$ & 680 & 398 & $100|0| 0$ & $-6.04_{-0.22}^{+0.14}$ \\
\hline 3KCL2 & 3 & $7.28_{-0.05}^{+0.05}$ & $422 \pm 176$ & 681 & 404 & $100|0| 0$ & $-6.04_{-0.22}^{+0.14}$ \\
\hline 8KCL1 & 8 & $7.22_{-0.05}^{+0.05}$ & $923 \pm 386$ & 893 & 590 & $47|52| 0$ & $-6.17_{-0.22}^{+0.15}$ \\
\hline 8KCL2 & 8 & $7.22_{-0.05}^{+0.05}$ & $923 \pm 386$ & 895 & - & $100|0| 0$ & $-6.17_{-0.22}^{+0.15}$ \\
\hline 100AR1 & 0.1 & $7.47_{-0.12}^{+0.02}$ & $7 \pm 2$ & 652 & 436 & $0|100| 0$ & $-5.97_{-0.1}^{+0.08}$ \\
\hline 100AR2 & 0.1 & $7.47_{-0.12}^{+0.02}$ & $7 \pm 2$ & 650 & 427 & $0|100| 0$ & $-5.97_{-0.1}^{+0.08}$ \\
\hline 300AR1 & 0.3 & $7.47_{-0.12}^{+0.02}$ & $22 \pm 6$ & 655 & 447 & $0|100| 0$ & $-5.97_{-0.1}^{+0.08}$ \\
\hline 300AR2 & 0.3 & $7.47_{-0.12}^{+0.02}$ & $22 \pm 6$ & 655 & 439 & $0|100| 0$ & $-5.97_{-0.1}^{+0.08}$ \\
\hline 1KAR1 & 1 & $7.47_{-0.12}^{+0.02}$ & $73 \pm 20$ & 670 & 451 & $0|100| 0$ & $-5.96_{-0.1}^{+0.08}$ \\
\hline 1KAR2 & 1 & $7.47_{-0.12}^{+0.02}$ & $73 \pm 20$ & 670 & 459 & $0|100| 0$ & $-5.96_{-0.1}^{+0.08}$ \\
\hline 3KAR1 & 3 & $7.45_{-0.11}^{+0.02}$ & $213 \pm 58$ & 713 & 490 & $0|100| 0$ & $-5.96_{-0.1}^{+0.08}$ \\
\hline 3KAR2 & 3 & $7.45_{-0.11}^{+0.02}$ & $213 \pm 58$ & 713 & 484 & $0|100| 0$ & $-5.96_{-0.1}^{+0.08}$ \\
\hline 10KAR1 & 10 & $7.41_{-0.11}^{+0.02}$ & $669 \pm 182$ & 846 & 598 & $0|99| 1$ & $-5.96_{-0.1}^{+0.08}$ \\
\hline 10KAR2 & 10 & $7.41_{-0.11}^{+0.02}$ & $669 \pm 182$ & 845 & 582 & $0|99| 1$ & $-5.96_{-0.1}^{+0.08}$ \\
\hline 30KAR1 & 30 & $7.35_{-0.11}^{+0.02}$ & $1717 \pm 467$ & 1150 & - & $0|100| 0$ & $-5.94_{-0.09}^{+0.08}$ \\
\hline 30KAR2 & 30 & $7.35_{-0.11}^{+0.02}$ & $1717 \pm 467$ & 1150 & - & $0|99| 1$ & $-5.94_{-0.09}^{+0.08}$ \\
\hline
\end{tabular}

$a \mathrm{SO}_{4}{ }^{2-} / a \mathrm{CO}_{3}{ }^{2-}, \mathrm{pH}$ and $\log (J)$ were calculated as a mass-weighted average (Section 6.4).

The abbreviations cal, arg, and vat refers to percentage of calcite, aragonite and vaterite in a sample. Unavailable $\mathrm{m}_{\text {tot }}$ due to use of multiple filters is marked in dashes (see Section 6.2). 


\section{Appendix II}

\subsection{Competition between entrapment and exchange of CAS}

While a complete growth-entrapment model is beyond the scope of this study, a simplified version suffices to explore this possibility. The change in sulfate concentration at the surface of a growing crystal can be described by the following mass balance:

$$
\frac{\mathrm{d}\left[\mathrm{CAS}_{\mathrm{s}}\right]}{d t}=J_{A}-J_{D}-\frac{v}{L}\left[\mathrm{CAS}_{\mathrm{S}}\right]=k_{A}\left[\mathrm{SO}_{4}^{2-}\right]-k_{D}\left[\mathrm{CAS}_{\mathrm{s}}\right]-\frac{v}{L}\left[\mathrm{CAS}_{\mathrm{s}}\right]
$$

where $J_{A}$ and $J_{D}$ are the sulfate attachment and detachment rates, respectively, $\left[\mathrm{CAS}_{\mathrm{S}}\right]$ and $\left[\mathrm{SO}_{4}^{2-}\right]$ are the sulfate concentrations in the solid and solution, respectively, $v$ is the onedimensional growth front velocity, and $L$ is the typical growth step height. $k_{A}$ and $k_{D}$ are rate constants, which incorporate the kinetics of attachment and detachment as well as the kinetics of creation and destruction of appropriate kink sites for sulfate (or carbonate) attachment. The latter are thought to be the limiting factor for calcite growth (De Yoreo et al., 2009). The change in the isotopic composition of CAS is then described by:

$$
\text { 19) } \frac{d}{d t}\left[\mathrm{CAS}_{\mathrm{S}}\right] \mathrm{R}_{\mathrm{CAS}}=k_{A}\left[\mathrm{SO}_{4}^{2-}\right] \mathrm{R}_{\mathrm{SO}_{4}} \alpha_{\mathrm{f}}-k_{D}\left[\mathrm{CAS}_{\mathrm{S}}\right] \mathrm{R}_{\mathrm{CAS}} \alpha_{\mathrm{b}}-\frac{v}{L}\left[\mathrm{CAS}_{\mathrm{S}}\right] \mathrm{R}_{\mathrm{CAS}} \text {, }
$$

where $\mathrm{R}$ is the ratio of ${ }^{34} \mathrm{~S}$ to ${ }^{32} \mathrm{~S}$ and $\alpha_{\mathrm{f}}$ and $\alpha_{\mathrm{b}}$ are the forward and backward kinetic isotopic fractionation factors. At a steady state (ss), the mass balances in equations 18 and 19 are equal to zero, yielding an expression for the isotopic composition of CAS,

$$
\mathrm{R}_{\mathrm{CAS}}^{\mathrm{sS}}=\frac{\left(k_{D}+\frac{v}{L}\right) \mathrm{R}_{\mathrm{SO}_{4}} \alpha_{\mathrm{f}}}{k_{D} \alpha_{\mathrm{b}}+\frac{v}{L}} .
$$

When $k_{D} \gg \frac{v}{L}$, the expression for $\mathrm{R}_{\mathrm{CAS}}^{\mathrm{ss}}$ reduces to $\mathrm{R}_{\mathrm{SO}_{4}} \alpha_{\mathrm{f}} / \alpha_{\mathrm{b}}$, which is the isotopic composition of CAS in isotopic equilibrium with sulfate in solution. When $k_{D} \ll \frac{v}{L}$, the expression for $\mathrm{R}_{\text {CAS }}^{\text {ss }}$ reduces to $\mathrm{R}_{\mathrm{SO}_{4}} \alpha_{\mathrm{f}}$, which is the isotopic composition of CAS irreversibly incorporated into the carbonate and fractionated from the sulfate in solution by the forward kinetic isotope fractionation. Thus, increasing precipitation rate, expressed here by the growth front velocity, $v$, shifts the isotopic fractionation from $\alpha_{\mathrm{eq}}$ to $\alpha_{\mathrm{f}}$ (Equations 3, 20). The results of the constant addition experiments, in which the CAS-SO ${ }_{4}{ }^{2-}$ isotope fractionation decreased with an increase in the precipitation rate of $\sim 2$ orders of magnitude (at a constant $a \mathrm{SO}_{4}{ }^{2-} / a \mathrm{CO}_{3}{ }^{2-}$ ), and suggests that for sulfate incorporation into calcite, $\alpha_{\mathrm{eq}}>\alpha_{\mathrm{f}}$.

The fluxes of sulfate attachment and detachment ( $J_{A}$ and $J_{D}$, respectively) onto a growth step are proportional to the sulfate concentration in the solution and solid, respectively (Equation 18). We assume that the associated rate constants, $k_{A}$ and $k_{D}$, are independent of the aqueous sulfate concentration, supported by a similar independence of the rate constants for $\mathrm{Mg}^{2+}$ attachment and detachment on the aqueous $\mathrm{Mg}^{2+}$ concentration (Davis et al., 2000). With constant $k_{A}$ and $k_{D}$, an increase in $\left[\mathrm{SO}_{4}^{2-}\right]$, and a consequent increase in $\left[\mathrm{CAS}_{\mathrm{s}}\right]$, leads to higher rates of both attachment and detachment, or a high sulfate exchange rate between the solution and mineral surface relative to the precipitation rate. However, a larger size of the surface CAS pool at higher $\left[\mathrm{SO}_{4}^{2-}\right]$ means that exchange timescales $\left(\left[\mathrm{CAS}_{\mathrm{S}}\right] / J_{D}\right)$ do not change with increasing $a \mathrm{SO}_{4}{ }^{2-} / a \mathrm{CO}_{3}{ }^{2-}$. On the other hand, the precipitation rate $(v)$, has been shown to decrease with increasing $a \mathrm{SO}_{4}{ }^{2-}$ (Busenberg and Plummer, 1985). Therefore, with increasing $\left[\mathrm{SO}_{4}^{2-}\right]$ we expect increasingly rapid sulfate exchange relative to $\mathrm{CaCO}_{3}$ precipitation, and a shift towards $\alpha_{\text {eq }}$, which in our case is larger than $\alpha_{\mathrm{f}}$, as discussed above. In other words, exchange-entrapment dynamics lead to the expectation of increasing $\mathrm{CAS}_{-} \mathrm{SO}_{4}{ }^{2-}$ isotope fractionation with increasing $a \mathrm{SO}_{4}{ }^{2-} / a \mathrm{CO}_{3}{ }^{2-}$, which is opposite to the experimental results (Figure 5a).

The competition between sulfate exchange and entrapment may be further explained by the mechanism of calcite growth, which is thought to be limited by the creation of new kink sites 
(De Yoreo et al., 2009). When a new kink forms, attachment of solute molecules $\left(\mathrm{Ca}^{2+}, \mathrm{CO}_{3}{ }^{2-}\right.$, $\mathrm{HCO}_{3}{ }^{-}$) onto the kink is rapid and the new layer or step advances quickly from the original site of kink formation. Impurities bind to kinks, blocking further growth and generating a hiatus until the next kink is created. Increasing concentrations of the "contaminant" in the solution increase the density of blocked kinks, and result in slow mineral growth (De Yoreo et al., 2009). The decrease in bulk precipitation rate with increasing $a \mathrm{SO}_{4}{ }^{2-}$, as demonstrated experimentally by $\mathrm{B} \& \mathrm{P}$, has been observed also in studies of nano-scale surface processes at variable $a \mathrm{SO}_{4}{ }^{2-}$ (Vavouraki et al., 2008; Nielsen et al., 2016). Consequently, the time available for the attached sulfate ions to exchange and equilibrate with sulfate ions in solution before the sulfate is entrapped increases. In other words, high $a \mathrm{SO}_{4}{ }^{2-} / a \mathrm{CO}_{3}{ }^{2-}$ should promote isotope fractionations closer to $\alpha_{\text {eq }}$, which in our case is larger than $\alpha_{\mathrm{f}}$. This is inconsistent with the decrease in CAS$\mathrm{SO}_{4}{ }^{2-}$ isotope fractionation with increasing $a \mathrm{SO}_{4}{ }^{2-} / a \mathrm{CO}_{3}{ }^{2-}$ measured in our experiments.

\section{Appendix III}

*Includes only figure A3. 


\section{Figure Captions}

Figure 1: Speciation of DIS as a function of $\mathrm{pH}$. The results are for a solution containing 10 mM DIS and $10 \mathrm{mM}$ each of $\mathrm{Ca}^{2+}, \mathrm{Mg}^{2+}, \mathrm{Na}^{+}$, and $\mathrm{K}^{+}$as chloride salts. Equal concentrations were chosen to show the affinity of sulfate towards the different cations. $\mathrm{Na}^{+}$and $\mathrm{K}^{+}$ion-pair concentrations were negligible. The low fraction of $\mathrm{Mg}^{2+}$ and $\mathrm{Ca}^{2+}$ ion pairs at high $\mathrm{pH}$ is due to increasing proportions of metal-hydroxide ion pairs.

Figure 2: Compilation of CAS concentrations and $\mathrm{CAS}_{-} \mathrm{SO}_{4}{ }^{2-} \mathrm{S}$ isotope fractionations ${ }^{\mathrm{b}}$ measured in modern calcifying organisms (Burdett et al., 1989; Kampschulte et al., 2001; Lyons et al., 2004; Paris et al., 2014; Present et al., 2015; Rennie et al., 2018). DFT calculations are based on CAS $\beta$ values (reduced partition function ratios) at $25^{\circ} \mathrm{C}$, calculated in calcite and aragonite by Balan et al. (2014), and $\beta$ values for $\mathrm{SO}_{4}{ }^{2-}$ (aq) calculated by Otake et al., (2008) and Eldridge et al., (2016). $\beta$ values from Eldridge et al., (2016) yield the larger isotope fractionation.

Figure 3: Example of a fit to a S K-edge spectrum. The detrended XANES data (blue dots) is fit (black line) as a sum of one step-function ( $\mathrm{Sfn})$ and four Voight line shapes $\left(\mathrm{V}_{1 \ldots .}\right.$, gray lines).

Figure 4: CAS concentrations of all calcite (blue) and aragonite (yellow) samples versus (a) $a \mathrm{SO}_{4}{ }^{2-} / a \mathrm{CO}_{3}{ }^{2-}$ and (b) $\log (J)$. The [CAS] in calcite from the two experimental methods are in agreement for corresponding values of $\log (J)$ and $a \mathrm{SO}_{4}{ }^{2-} / a \mathrm{CO}_{3}{ }^{2-}$. The dependence of [CAS] in calcite on precipitation rate is much weaker than on $a \mathrm{SO}_{4}{ }^{2-} / a \mathrm{CO}_{3}{ }^{2-}$.

Figure 5: $1000 \ln \alpha_{\mathrm{CAS}^{-} \mathrm{Na}_{2} \mathrm{SO}_{4}}$ in the calcite (blue) and aragonite (yellow) samples versus (a) $\mathrm{aSO}_{4}{ }^{2-} / \mathrm{aCO}_{3}{ }^{2-}$ and (b) $\log (J)$. The vertical error bars represent error on the measurements, which is the larger of the root mean square error and 1 standard deviation of external replicates.

Figure 6: Representative XANES spectra and fit results. Left: Representative spectra of calcite (3KCL1 in blue) and aragonite (30KAR1 in yellow, shifted upwards) and the difference in energy of the sulfate pre-edge peak (inset). A 5-point moving average was applied to smooth the spectra. Right: $\mathrm{E}_{\mathrm{V} 1}, \mathrm{I}_{\mathrm{V} 1}$ and $\mathrm{FWHM}_{\mathrm{V} 1}$ against [CAS] in panels b-d, respectively. The two aragonite samples with highest [CAS] mentioned in the text are denoted by circles with no outline.

Figure 7: Schematic illustration of 2 possible scenarios to explain the $\mathrm{S}$ isotope results from calcite precipitation at various precipitation rates and constant $a \mathrm{SO}_{4}{ }^{2-} / a \mathrm{CO}_{3}{ }^{2-}$. The kinetic forward and equilibrium $S$ isotope fractionation factors are represented by $\alpha_{\mathrm{f}}$ and $\alpha_{\mathrm{eq}}$, respectively, where superscripts $(\mathrm{s} 1, \mathrm{~s} 2)$ indicate the specific scenario (see text).

Figure 8: CAS-SO ${ }_{4}^{2-} \mathrm{S}$ isotope fractionation vs. CAS concentration in computational, abiotic experimental and modern carbonate samples. See Figure 2 for computational and modern clacifier data sources. The gray area indicates the CAS concentrations expected over the range of Phanerozoic $a \mathrm{SO}_{4}{ }^{2-} / a \mathrm{CO}_{3}{ }^{2-}$, and the yellow area indicates the CAS-SO ${ }_{4}^{2-}$ isotope fractionation range in natural modern aragonite ooids. The range of $\mathrm{S}$ isotope fractionation from variation in precipitation rate over $\sim 2.5$ orders of magnitude (Figure 5) is shown for reference.

Figure 9: Experimental (Exp.) and simulated (Sim.) CAS- $\mathrm{SO}_{4}{ }^{2-} \mathrm{S}$ isotope fractionations for the case of a large (20.4\%o) isotope fractionation between $\mathrm{SO}_{4}{ }^{2-}$ and $\mathrm{CaSO}_{4}{ }^{0}$ and $a \mathrm{SO}_{4}{ }^{2-} / a \mathrm{CO}_{3}{ }^{2-}-$

${ }^{\mathrm{b}} \alpha_{\mathrm{CAS}_{-} \mathrm{SO}_{4}^{2-}}=\left(1000+\delta^{34} \mathrm{~S}_{\mathrm{CAS}}\right) /\left(1000+\delta^{34} \mathrm{~S}_{\mathrm{SO}_{4}^{2-}}\right)$ 
dependent DIS speciation. Simulated and measured S isotope fractionations are in agreement, but this scenario seems improbable (see text).

Figure A1: Schematic illustration of the components and steps in the constant addition method. Lines represent tubing, where the thick gray line is for airflow. Solid lines indicate flow in step I and broken lines in step II.

Figure A2: Schematic illustration of the steps in the $\mathrm{CO}_{2}$ degassing method (top), the evolution of $\mathrm{pCO}_{2}$ in the glove box (bottom, blue) and $\mathrm{pH}$ in an experiment bottle (bottom, black). See text for details of steps I-III.

Figure A3: Normalized S K-edge X-ray absorption near-edge spectra (XANES). The spectra are shown by blue and yellow dots, for calcite and aragonite, respectively, together with a 5point moving average, which was applied to smooth the spectra (black lines). Samples with poor fits to the spectra $(\mathrm{r} 2<0.9)$ are marked with a star. 


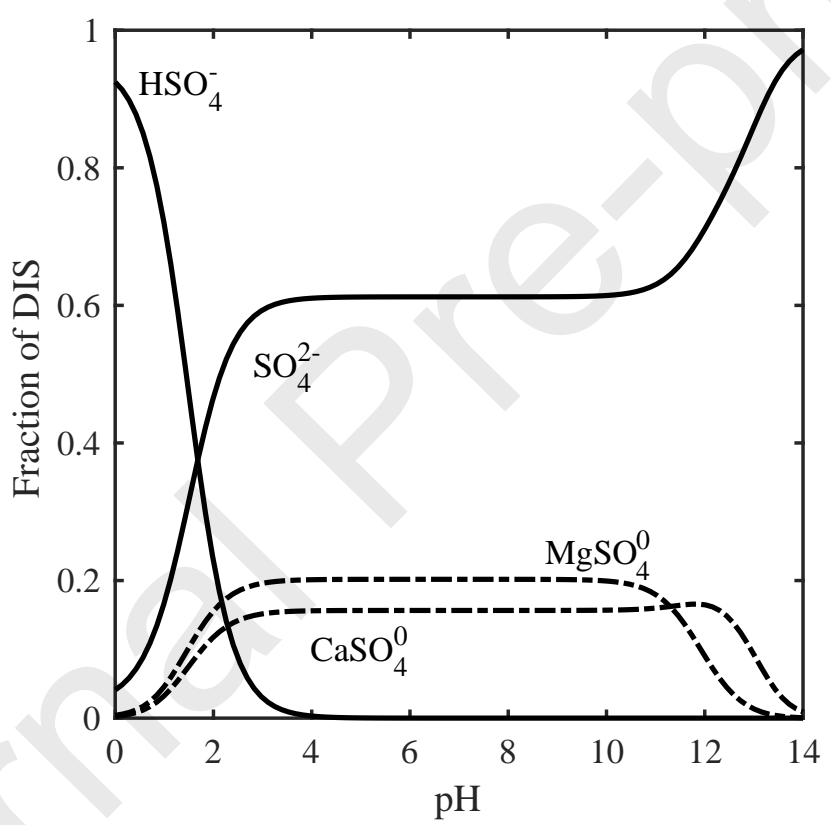




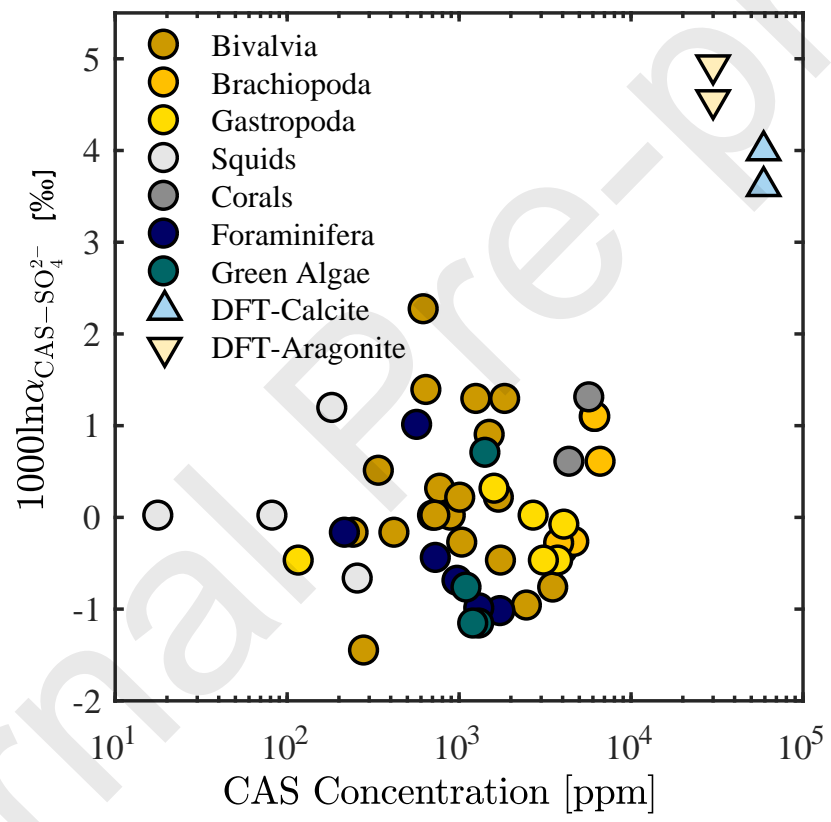




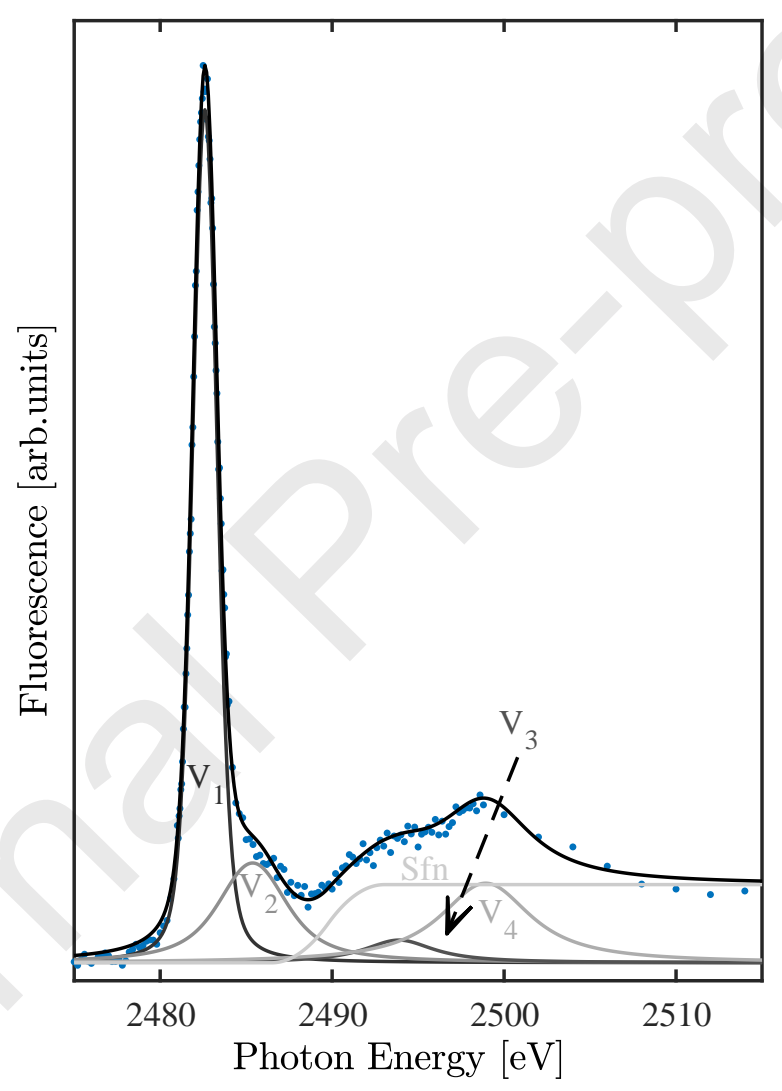




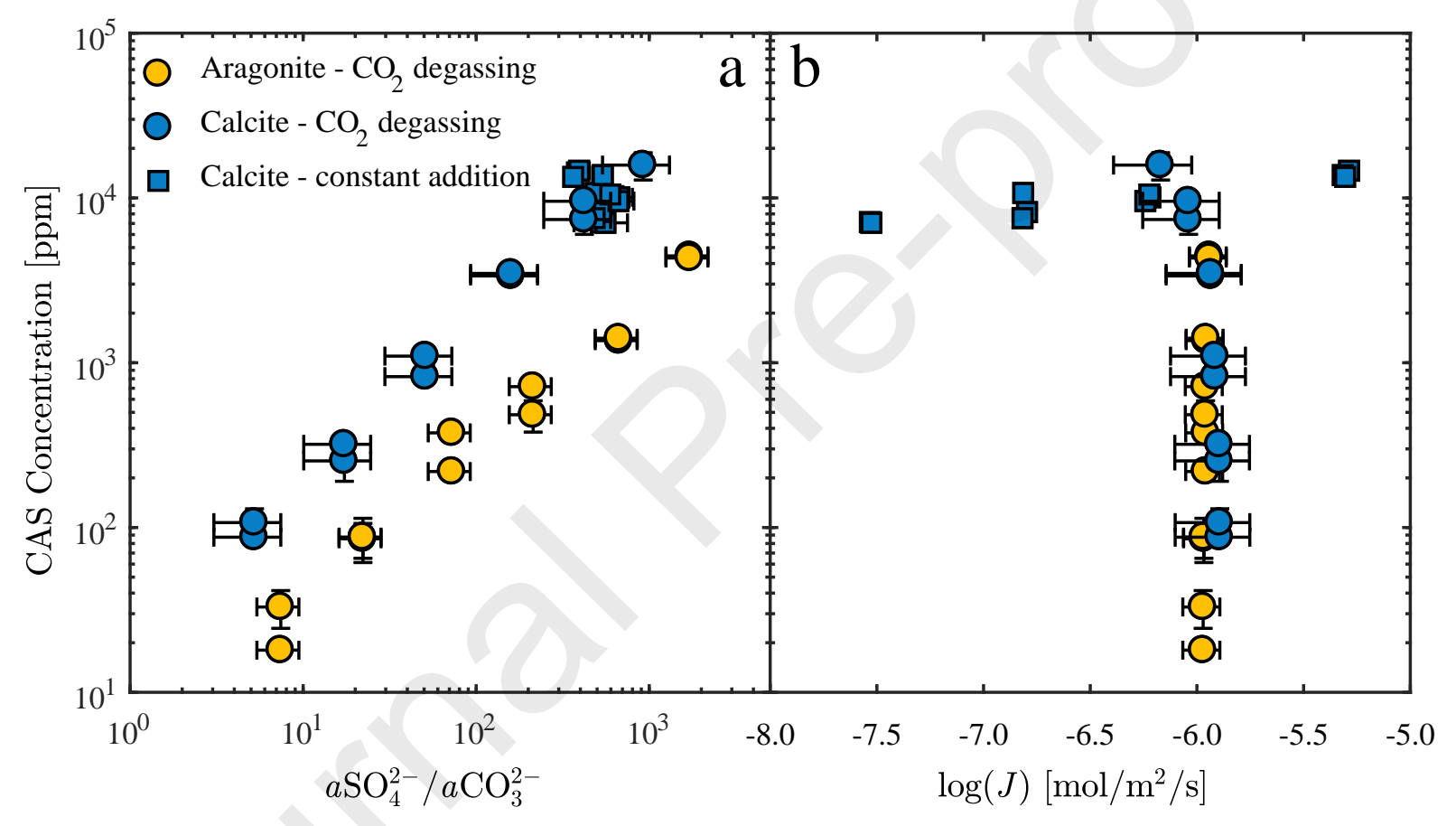




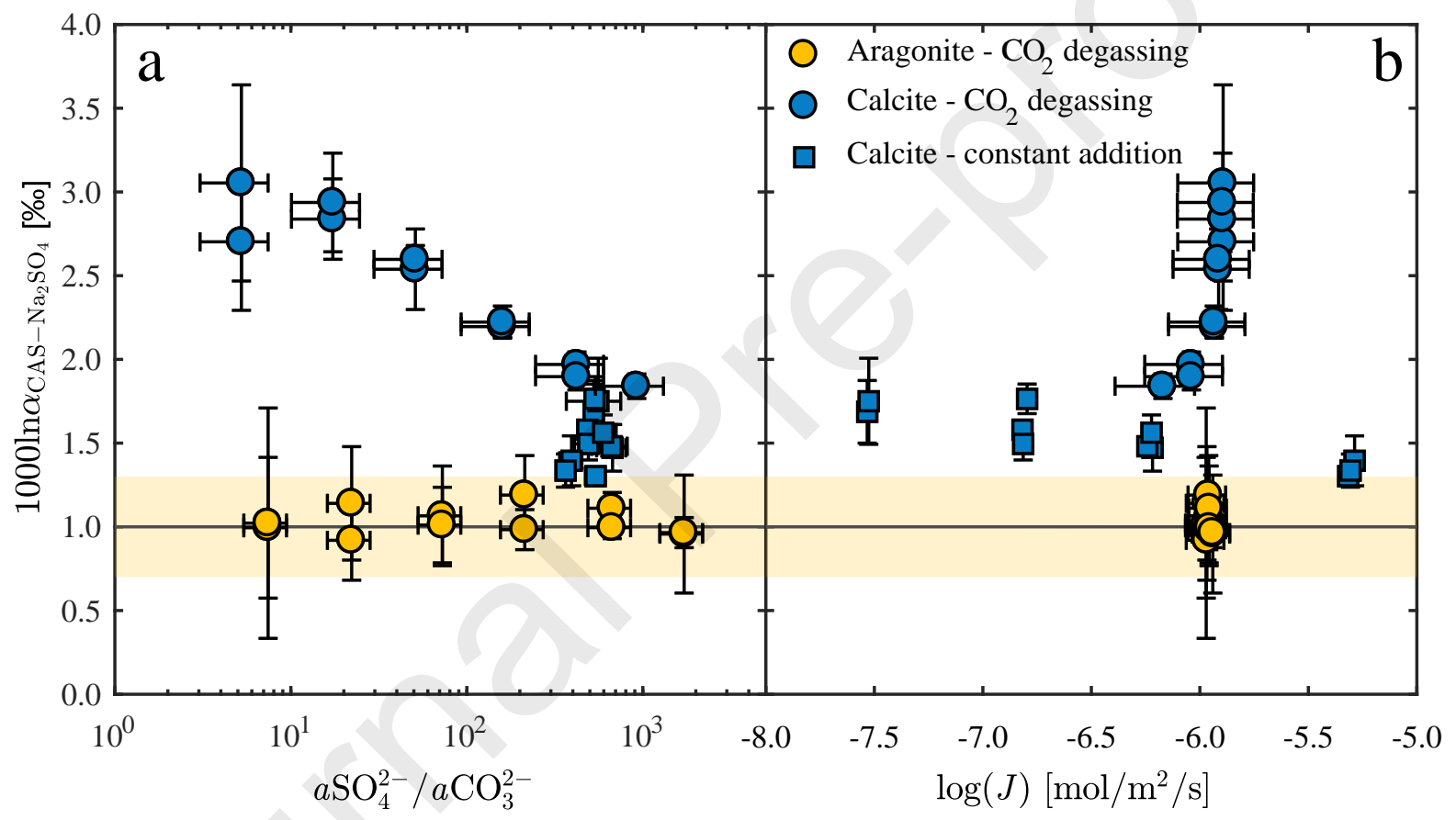



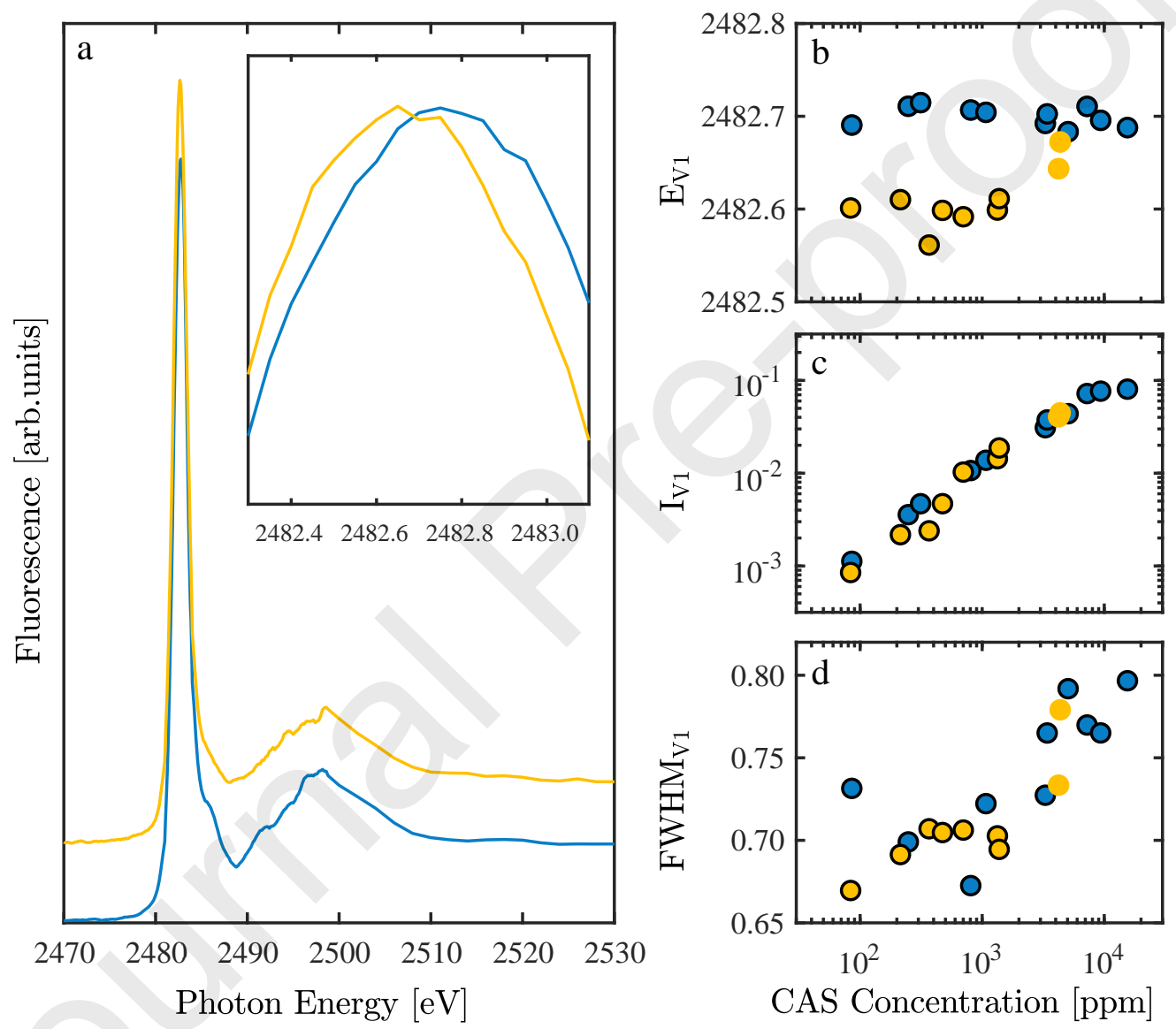


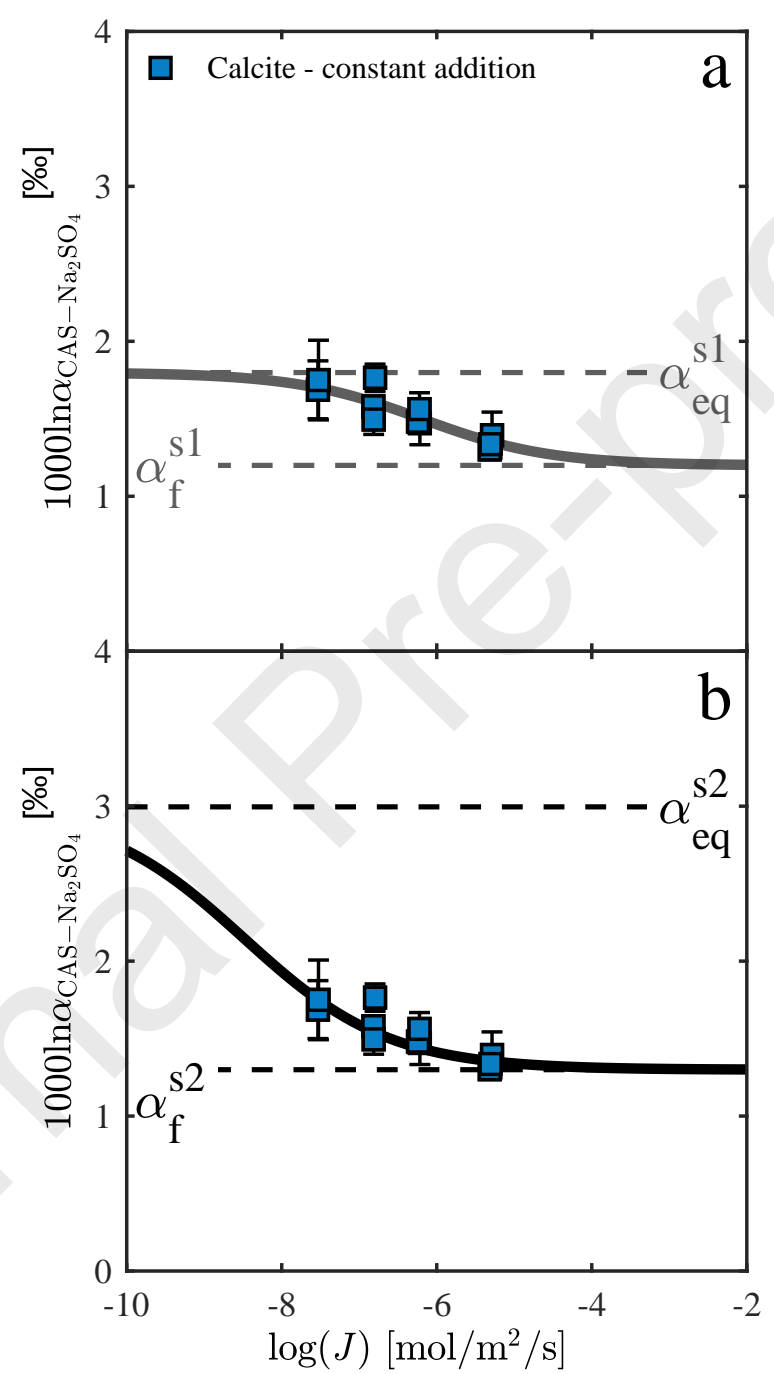




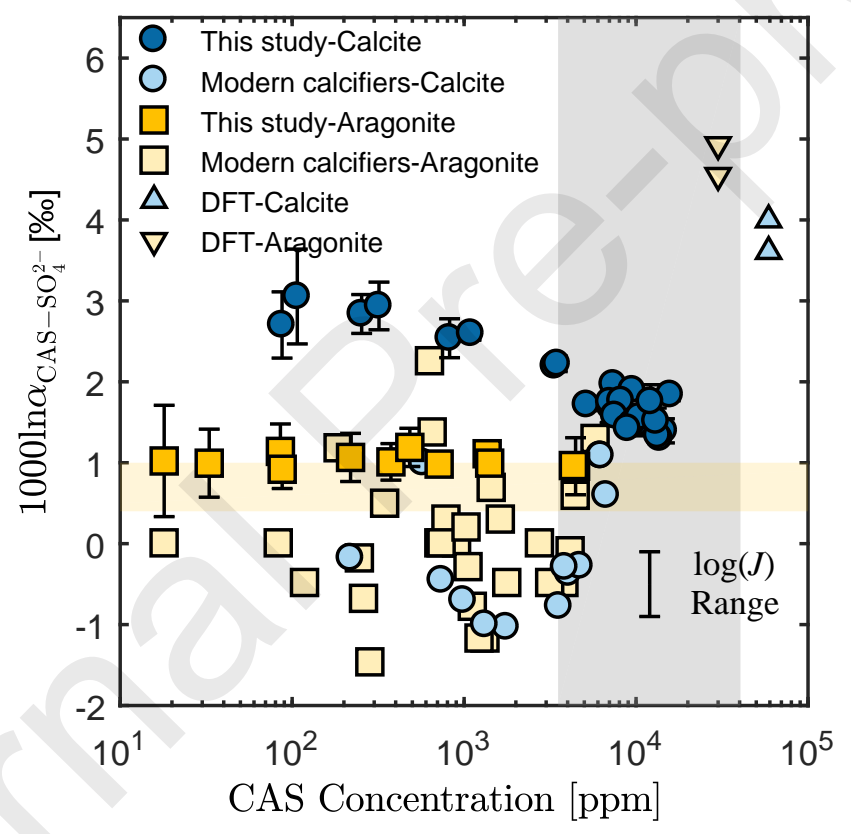




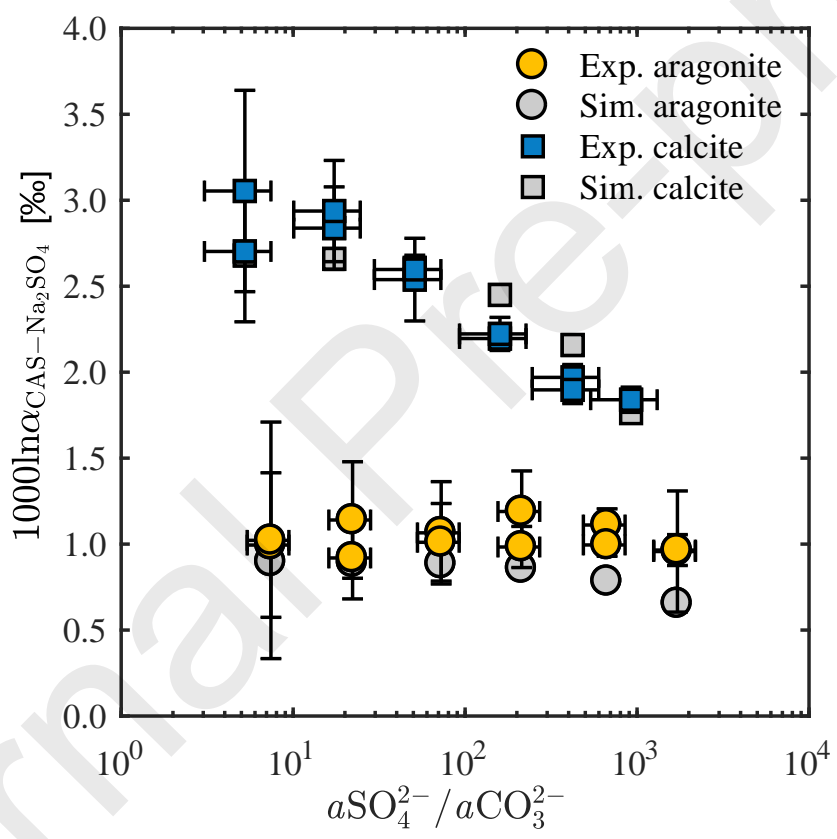




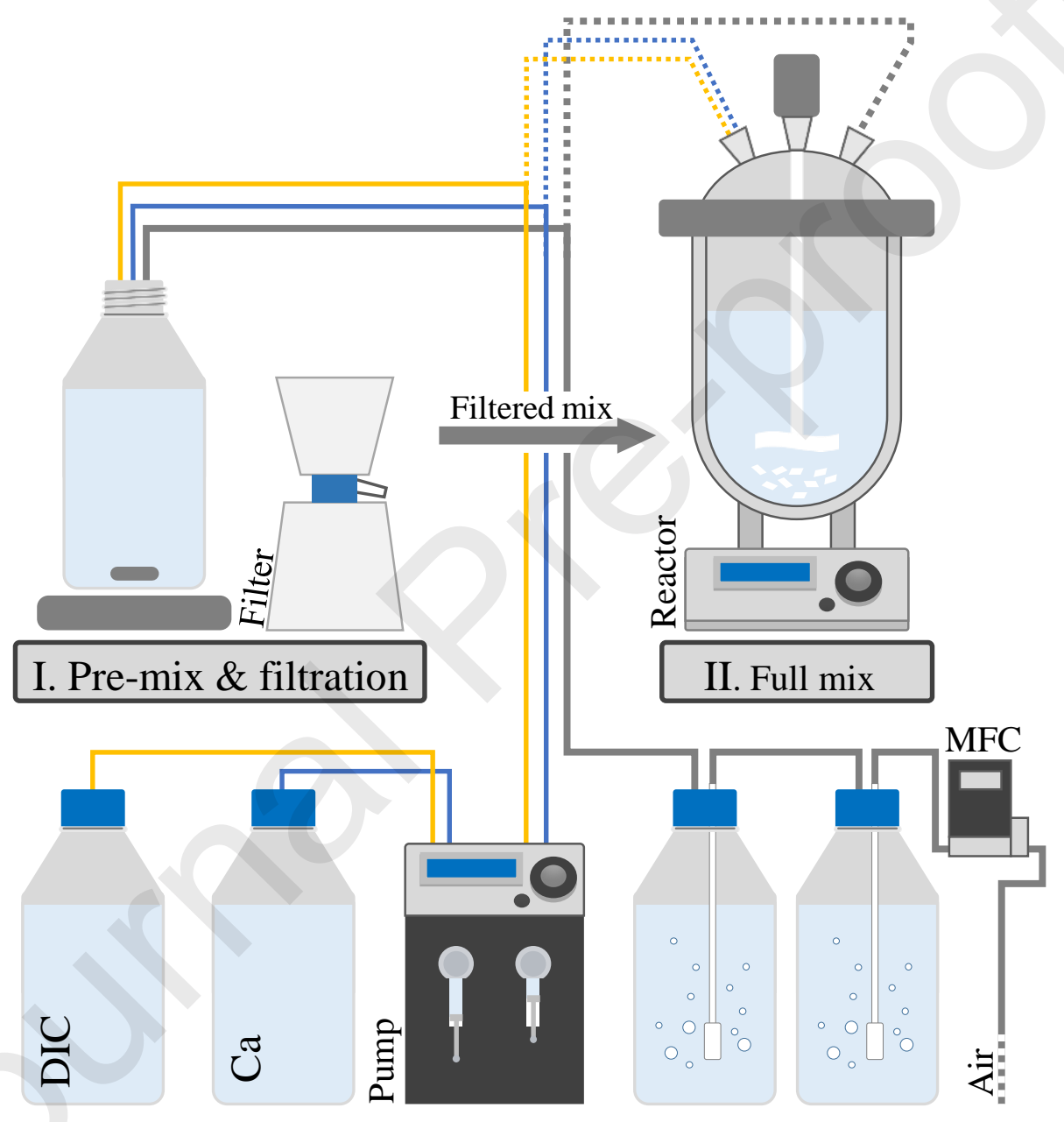



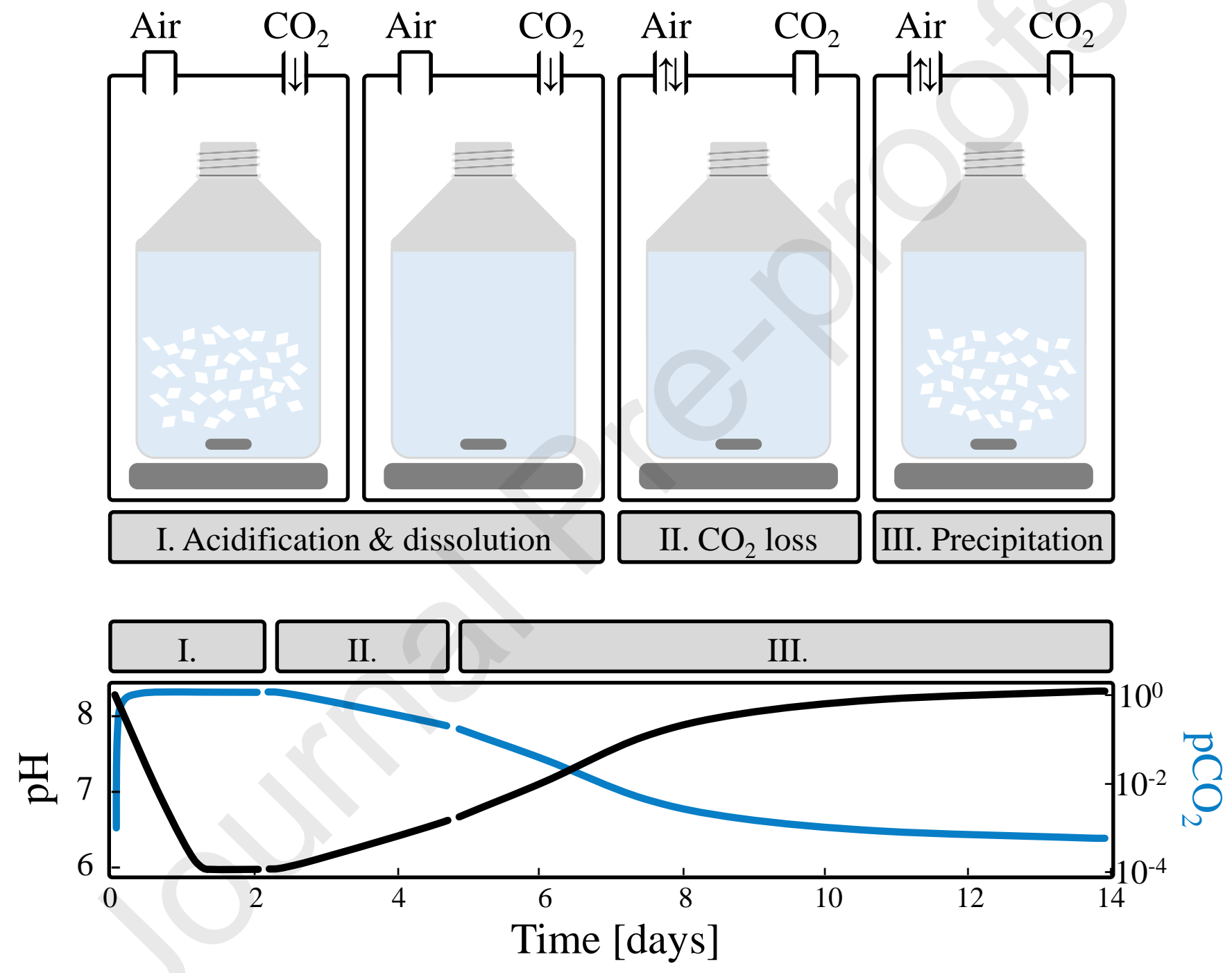

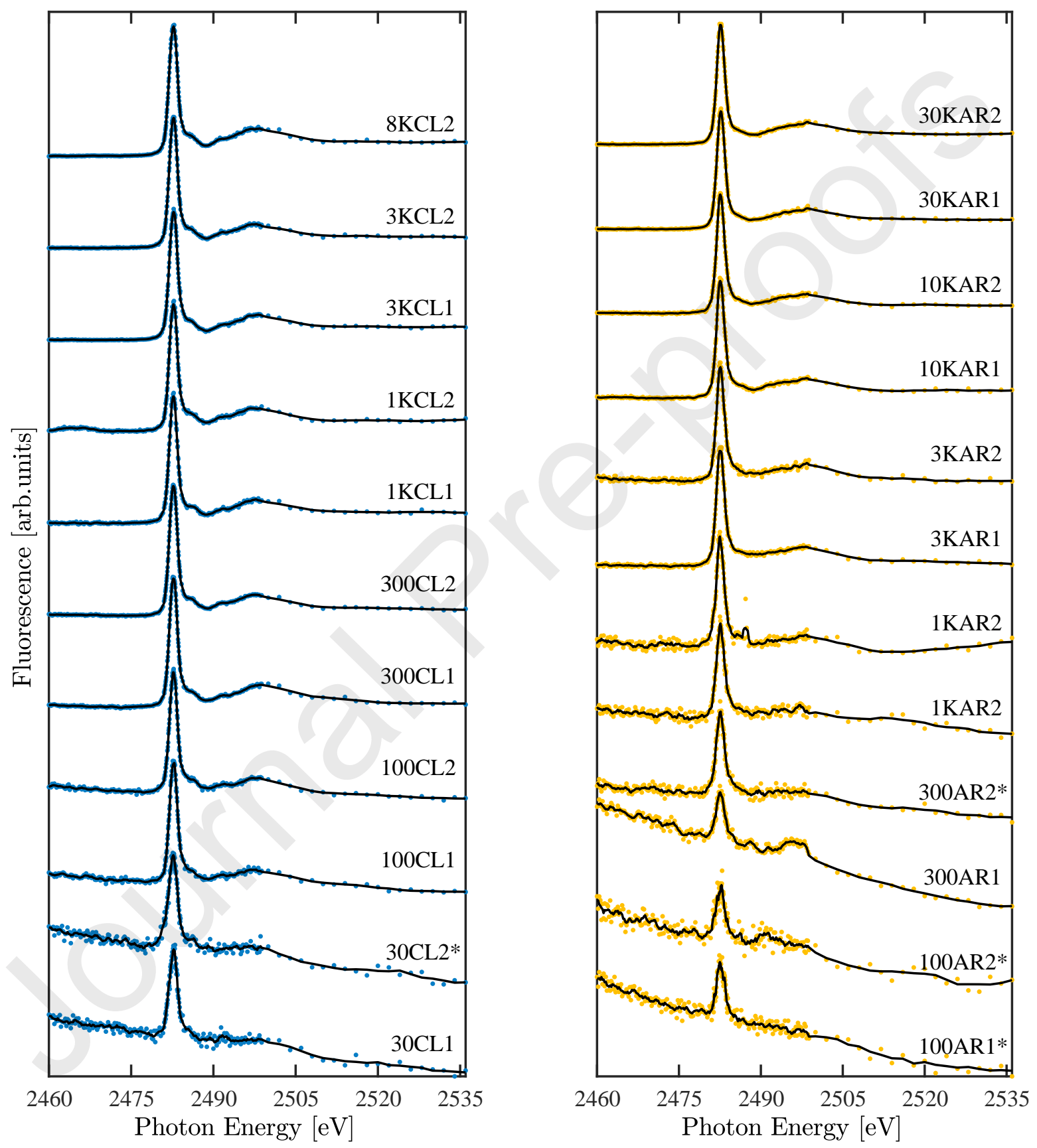


\section{Declaration of interests}

$\bigotimes$ The authors declare that they have no known competing financial interests or personal relationships that could have appeared to influence the work reported in this paper.

$\square$ The authors declare the following financial interests/personal relationships which may be considered as potential competing interests:

None 